Partitioned Waveform Inversion Applied to Eurasia and Northern Africa

H. bedle, E. Matzel, M. Flanagan

August 29, 2006 
This document was prepared as an account of work sponsored by an agency of the United States Government. Neither the United States Government nor the University of California nor any of their employees, makes any warranty, express or implied, or assumes any legal liability or responsibility for the accuracy, completeness, or usefulness of any information, apparatus, product, or process disclosed, or represents that its use would not infringe privately owned rights. Reference herein to any specific commercial product, process, or service by trade name, trademark, manufacturer, or otherwise, does not necessarily constitute or imply its endorsement, recommendation, or favoring by the United States Government or the University of California. The views and opinions of authors expressed herein do not necessarily state or reflect those of the United States Government or the University of California, and shall not be used for advertising or product endorsement purposes.

This work was performed under the auspices of the U.S. Department of Energy by University of California, Lawrence Livermore National Laboratory under Contract W-7405-Eng-48. 


\section{Partitioned Waveform Inversion Applied to Eurasia and Northern Africa}

Heather Bedle, Eric Matzel, and Megan Flanagan

This work was supported by DE-PS52-04NA25154 (BAA04-40)

July 2006

\section{INTRODUCTION}

This report summarizes the data analysis achieved during Heather Bedle's eleven-week Technical Scholar internship at Lawrence Livermore National Labs during the early summer 2006. The work completed during this internship resulted in constraints on the crustal and upper mantle $S$-velocity structure in Northern Africa, the Mediterranean, the Middle East, and Europe, through the fitting of regional waveform data. This data extends current raypath coverage and will be included in a joint inversion along with data from surface wave group velocity measurements, $S$ and $P$ teleseismic arrival time data, and receiver function data to create an improved velocity model of the upper mantle in this region.

The tectonic structure of the North African/ Mediterranean/ Europe/ Middle Eastern study region is extremely heterogeneous. This region consists of, among others, stable cratons and platforms such as the West Africa Craton, and Baltica in Northern Europe; oceanic subduction zones throughout the Mediterranean Sea where the African and Eurasian plate collide; regions of continental collision as the Arabian Plate moves northward into the Turkish Plate; and rifting in the Red Sea, separating the Arabian and Nubian shields). With such diverse tectonic structures, many of the waveforms were difficult to fit. This is not unexpected as the waveforms are fit using an averaged structure. In many cases the raypaths encounter several tectonic features, complicating the waveform, and making it hard for the software to converge on a $1 \mathrm{D}$ average structure. Overall, the quality of the waveform data was average, with roughly $30 \%$ of the waveforms being discarded due to excessive noise that interfered with the frequency ranges of interest.

An inversion for the 3D $S$-velocity structure of this region was also performed following the methodology of Partitioned Waveform Inversion (Nolet, 1990; Van der Lee and Nolet, 1997). The addition of the newly fit waveforms drastically extends the range of the model. The model now extends as far east in Africa to cover Chad and Niger, and reaches south to cover Zambia. The model is also stretched eastward to cover the eastern half of India, and northward to cover the southern portion of Scandinavia.

\section{METHODOLOGY}

The method of Partitioned Waveform Inversion (PWI) (Nolet, 1990; Van der Lee and Nolet, 1997) is applied to the regional waveforms throughout the study region. PWI is essentially a two-step process: 1) deriving linear constraints of the average velocity structure along each station-event path by the nonlinear fitting of the regional $S$ - and surface waves of each waveform, and then, 2) performing a damped linear inversion for the three-dimensional $S$-velocity structure.

In this investigation, the constraints from the waveforms fit this summer were divided into several subgroups based on either the geographic region covered or on a specific seismic array. These subgroups are: 1) NEurope; 2) ETSE; 3) IOC; 4) NEA; 5) RedSea. The crustal thickness and velocity constraints from these 1D waveform fits are combined with other crustal and upper - mantle constraints previously fit by Eric Matzel and Federica Marone (Marone et al., 2003, and Marone et al., 2004) for the 3D inversion.

\section{DATA ANALYSIS Waveform Fitting}

Below, the five datasets are discussed and examples are given of bad quality data, waveforms that were difficult to fit to a one-dimensional model, and successful waveform fits and their respective 1D models. 


\section{I) NEurope Dataset}

This dataset originally consisted of $\sim 2700$ waveforms from events which occurred primarily in the Northern Mediterranean region and were recorded in Northern Europe. This region covers the Kola and Karella Precambrian cratonic terrane in northern Scandinavia. Further south the raypaths cross the East European platform of Precambrian age, the Variscan Terrane, and the region of the currently deforming Alpine Orogen and Terrane in southern Europe. These terranes combine to create a very heterogeneous crustal and upper mantle structure, with the seismic stations placed in the relatively stable shield regions, recording earthquakes that occur in the complex Mediterranean region. From the original dataset, roughly 750 waveforms, or, $28 \%$ of the data, were fit. Approximately 1200 waveforms were discarded due to noise or bad signal. A map showing the raypaths of the waveforms that were fit is shown in Figure 1.

Several problems were encountered while fitting this dataset. First, these data were processed using the moment tensor solutions' halfduration, instead of its rise time. It was also found, that on occasion two moment tensor solutions were pulled from the database and inserted into the file 'momenttensor'. When this occurred, the inversion would abort. In all these cases where more than one moment tensor was found for the event, the Harvard CMT solution was chosen to fit the waveforms.

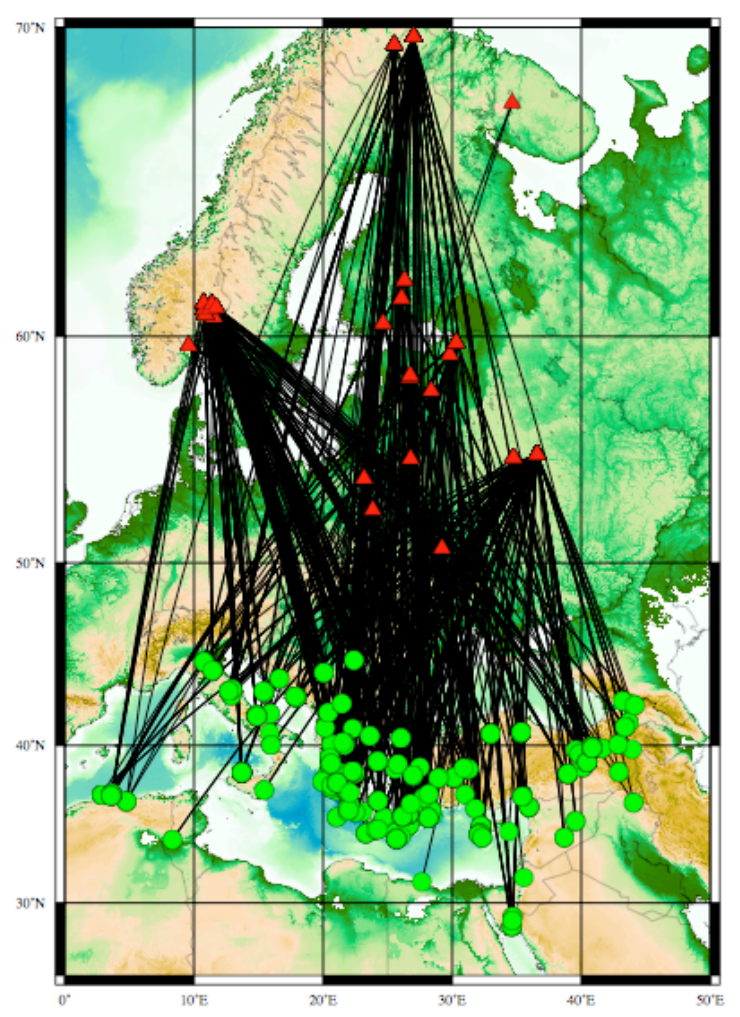

Figure 1: Raymap of paths fit from the NEurope dataset

\section{Example Waveforms Rejected data}

A little more than a third of the waveforms were rejected due to noise, or bad waveforms. Examples of waveforms that were discarded due to noise are shown in Figure 2 and 3. Some of the early data (mostly recorded by station OBN in Obninsk, Russia) was not of the best quality. Problems also arose with data from the NORSAR array, which often had long, complicated paths that caused the waveforms to be too noisy, or the signal too weak to allow a good fit. 


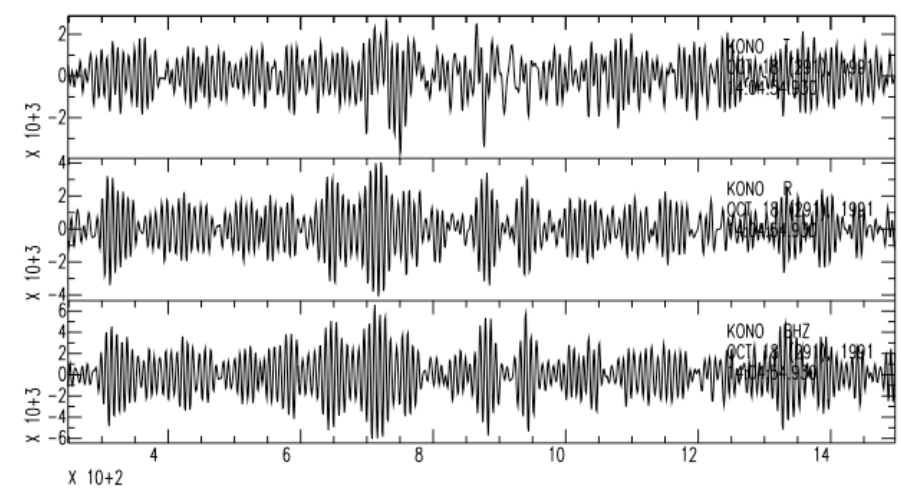

Figure 2: Event 1595 (Eastern Mediterranean Sea) recorded by station KONO in Kongsberg, Norway.

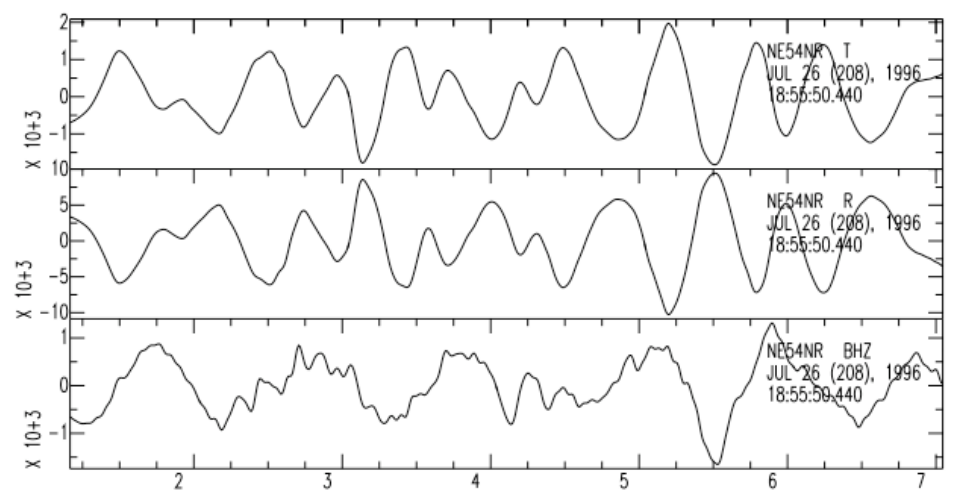

Figure 3: Event 5379 (Greece- Albania border) recorded by station NE54NR, in Eastern Poland.

\section{Difficult Paths/ Events}

Figures 4, 5, and 6 display waveforms from event - station pairs that had trouble converging to reasonable solutions. These waveforms all show clear body and surface waves, and strong signals, but were not able to converge on an acceptable $1 \mathrm{D} S$-velocity model within the target frequency range.

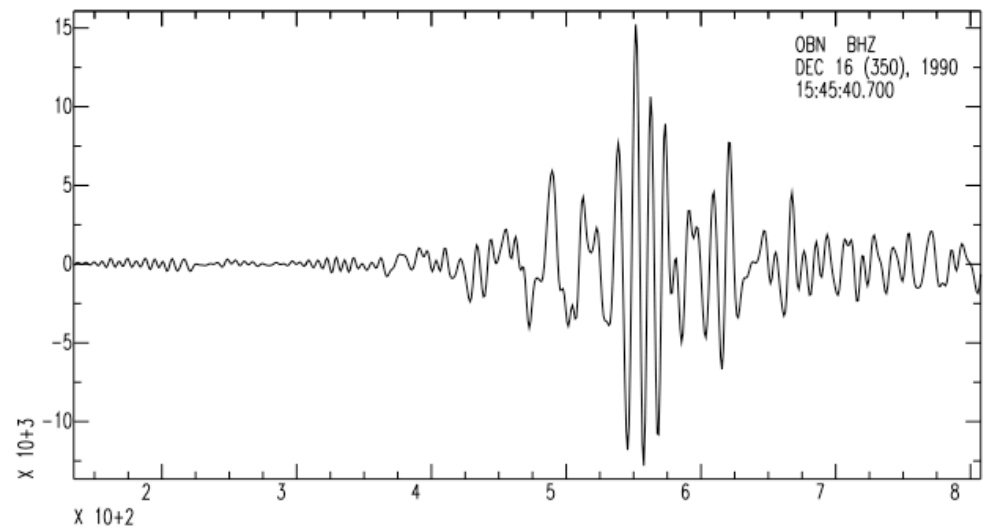

Figure 4: Event 947 (Georgia-Armenia-Turkey border) recorded by OBN.Z in Obninsk, Russia. 


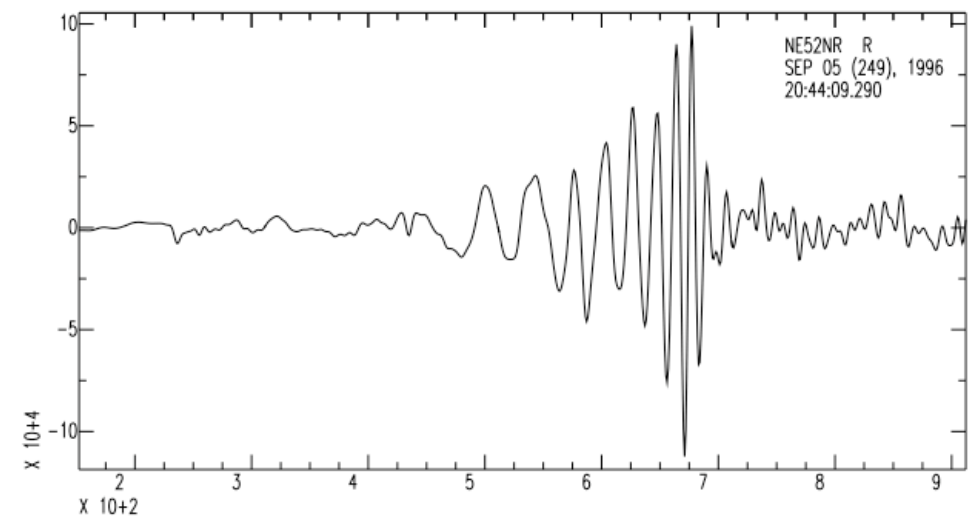

Figure 5: Event 5502 in the Adriatic Sea recorded by NE52NR.R near the Latvia /Russian border.

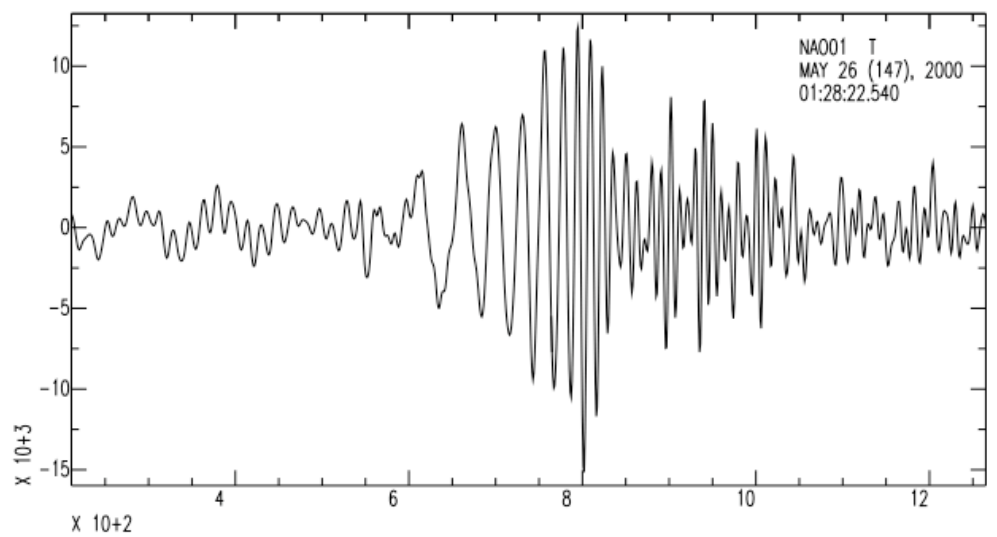

Figure 6: Event 1331099 in Greece recorded by NAO01.T, from the NORSAR array in NORWAY.

\section{Good Waveform Fits}

In general, the data in this set was relatively easy to fit, with $\sim 750$ waveforms adequately fit. Examples of some of the better fits are shown below. These examples were chose to display a variety of geographically different events (and thus paths). A map of the paths for these waveforms is shown in Figure 7. Overall the transverse components were easier to fit than the radial and vertical. Examples of all three components are shown. Figure 7 i shows a 1D model with a slower lithosphere, expected as the raypath originates in the seismically slow Mediterranean and transverse Europe, not sampling much of the older faster shield regions. In Figures $7 \mathrm{~h}$ and $7 \mathrm{j}$, we see the waveform fits result in a slightly faster, thicker lithosphere, as expected for a raypath that crosses through a cratonic and shield region.

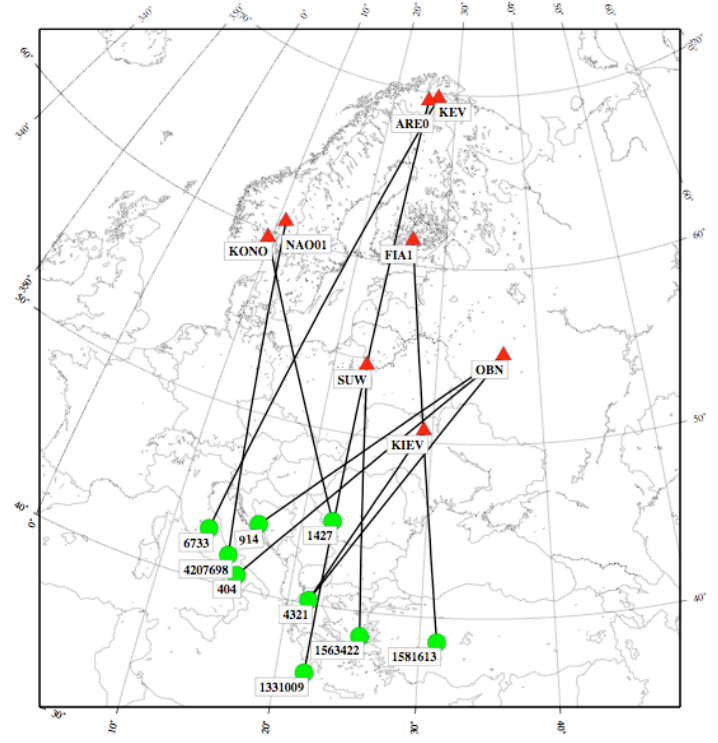

Figure 7: Raymap for the waveforms shown in Figures 7a- 7i. Green circles are events, red triangles are stations. 

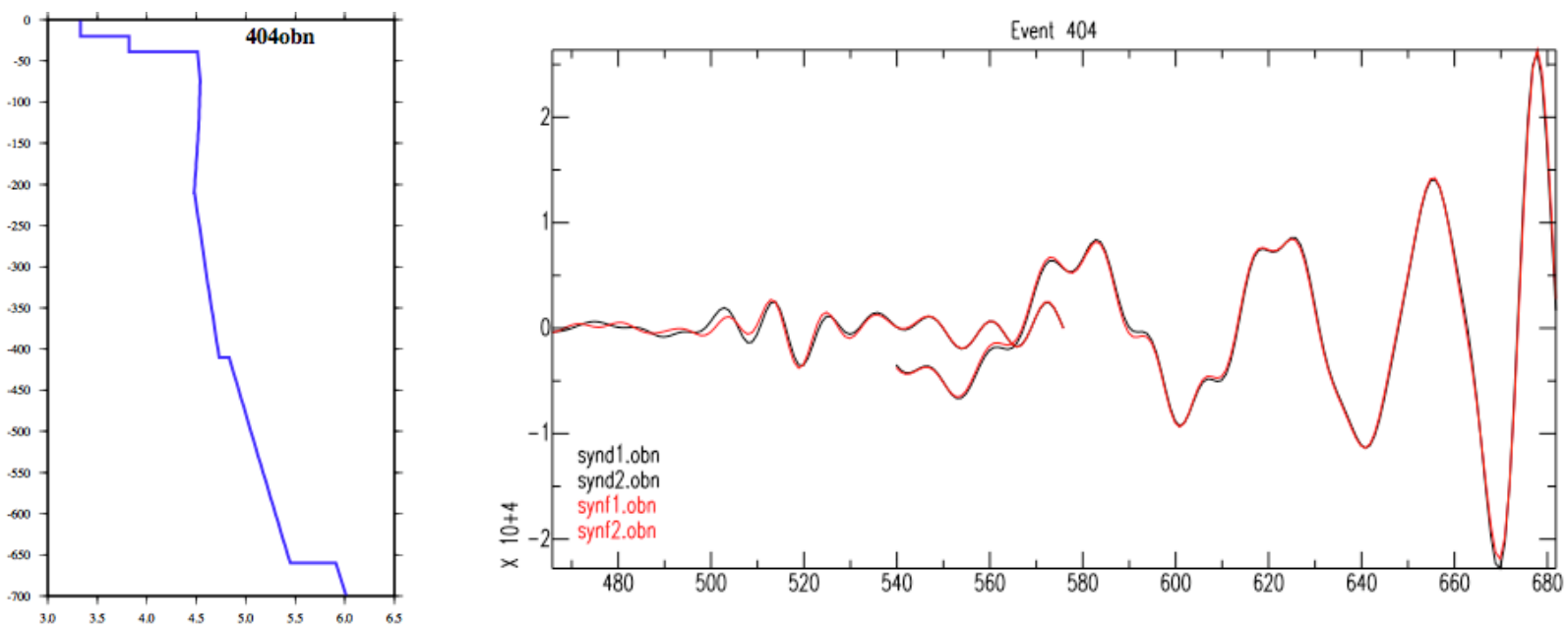

Figure 7a: Event 404 / Station OBN / Transverse component

Final 1D model shown in blue to the left. Windowed and filtered raw data is plotted in black, and the final synthetic seismogram is in red.
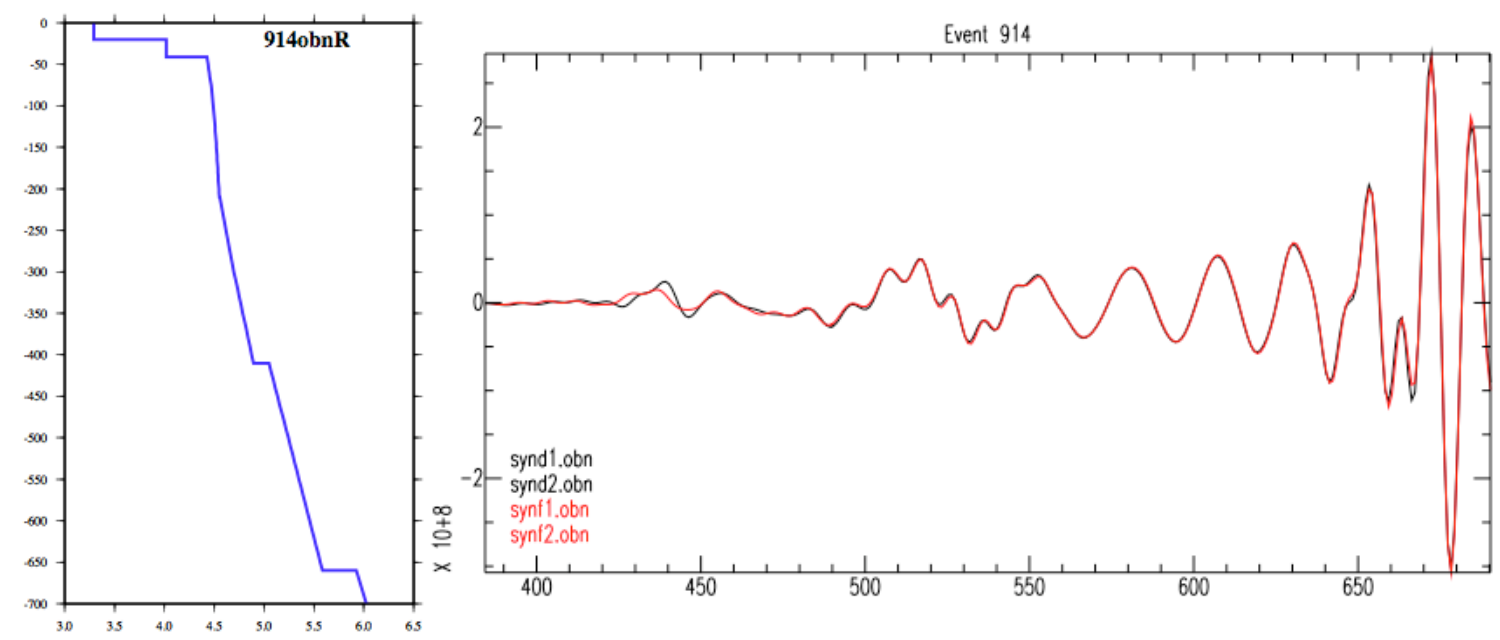

Figure 7b: Event 914 /Station OBN / Radial component
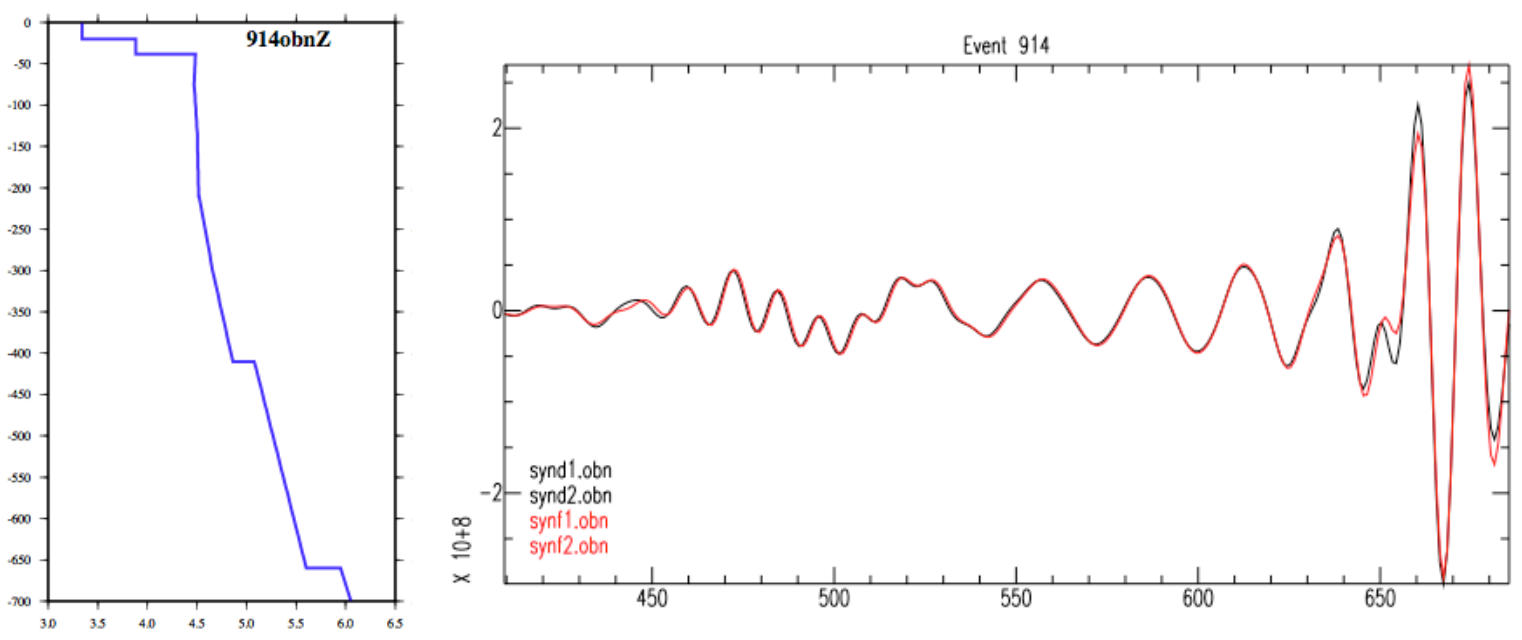

Figure 7c: Event 914 /Station OBN / Vertical component 

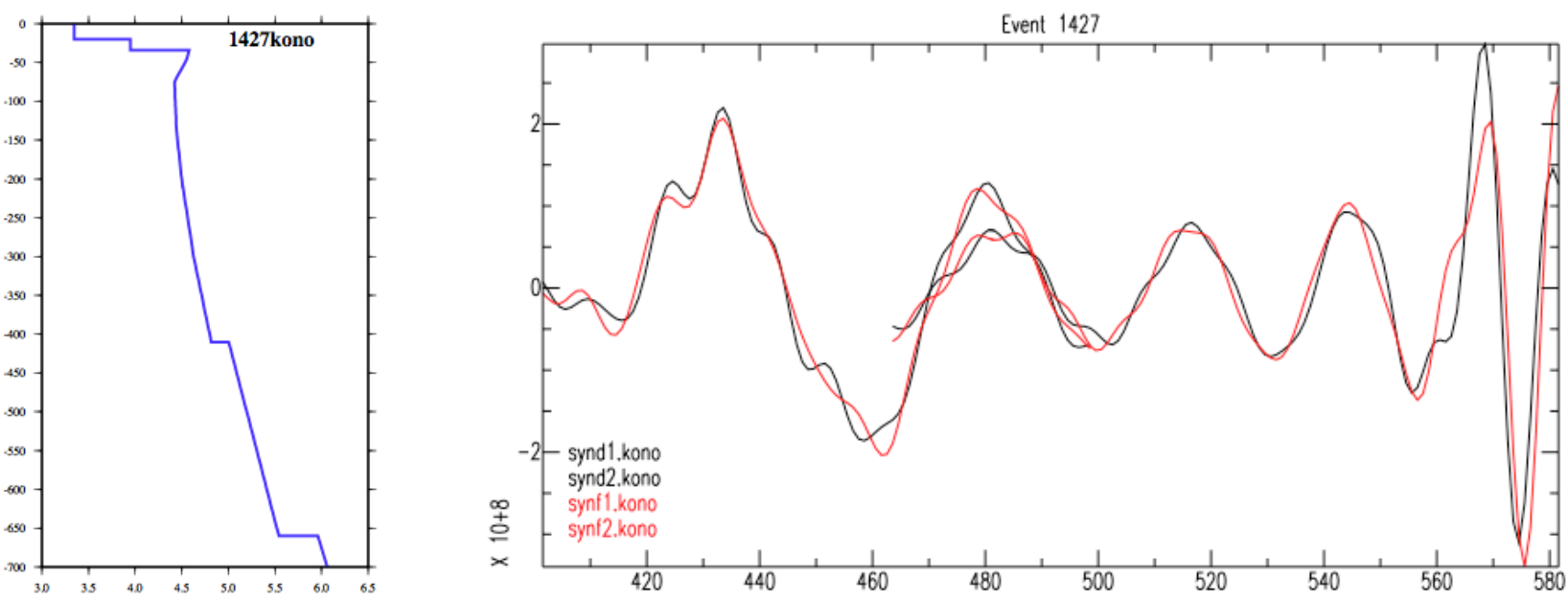

Figure 7d: Event 1427 / Station KONO / Transverse component
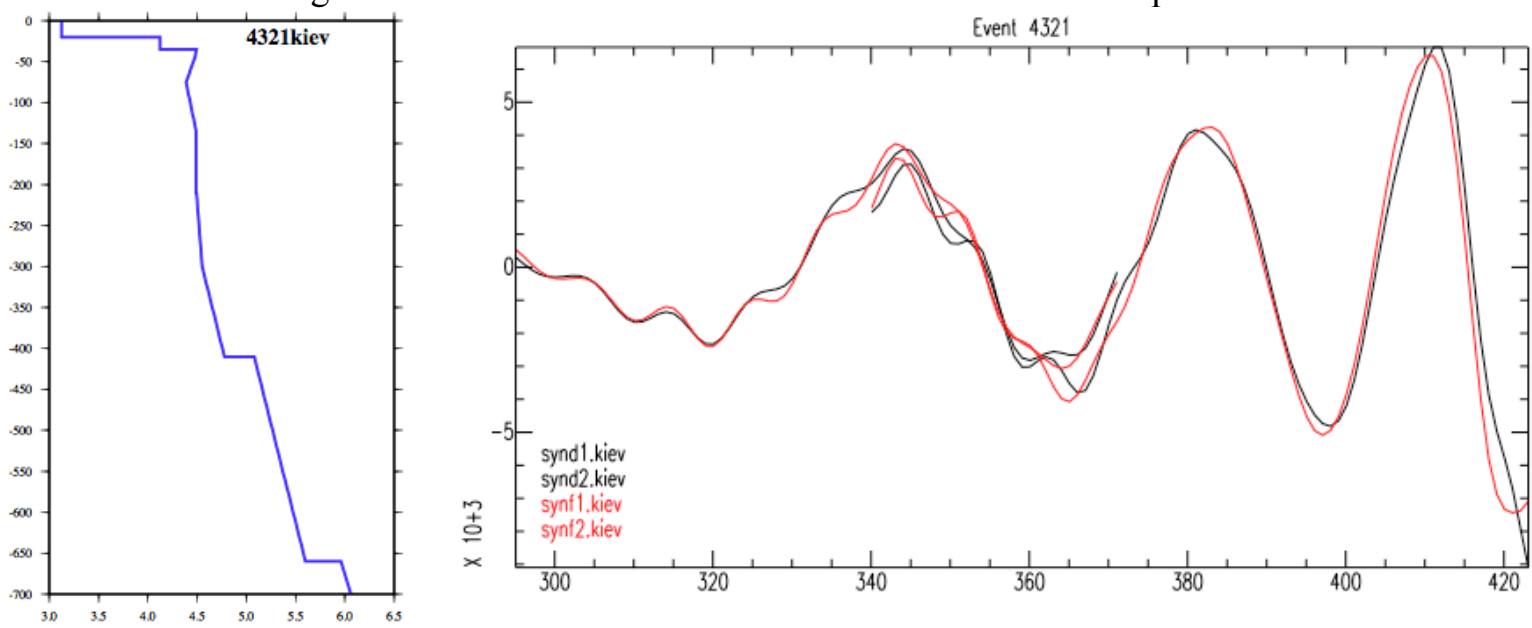

Figure 7e: Event 4321 / Station OBN / Transverse component
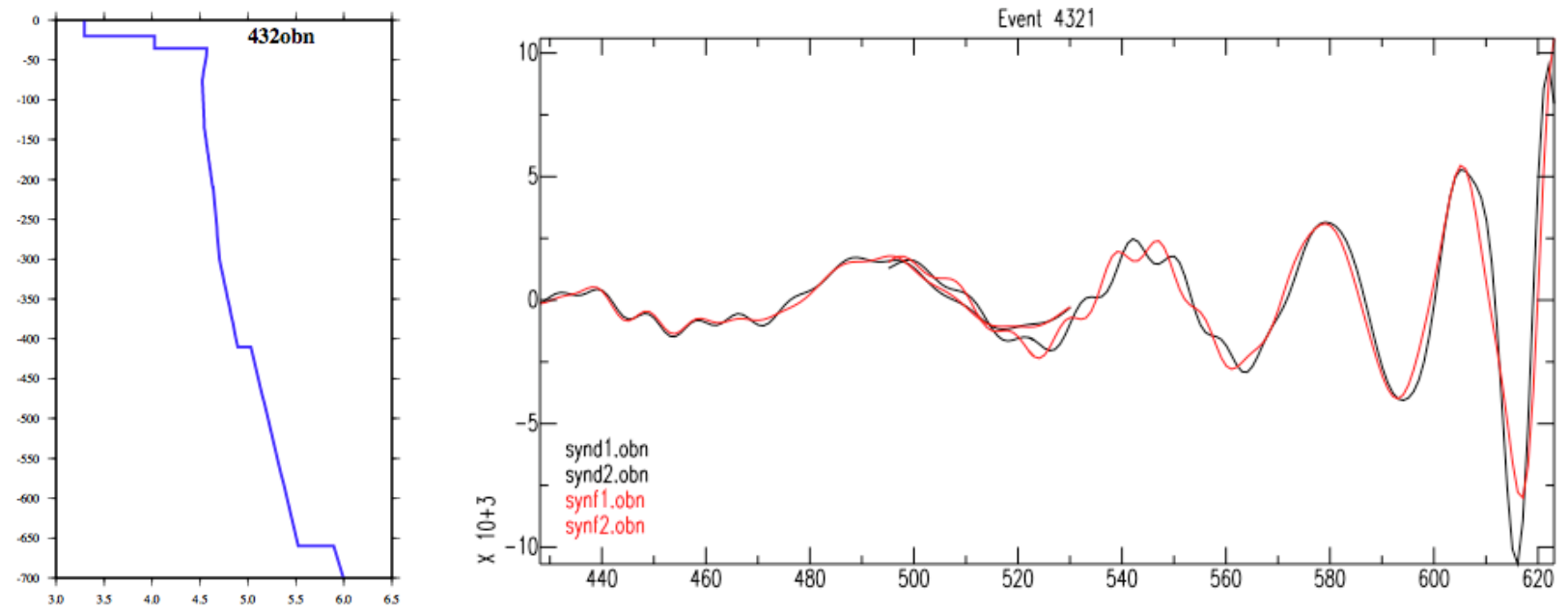

Figure 7f: Event 4321 / Station OBN / Transverse component 

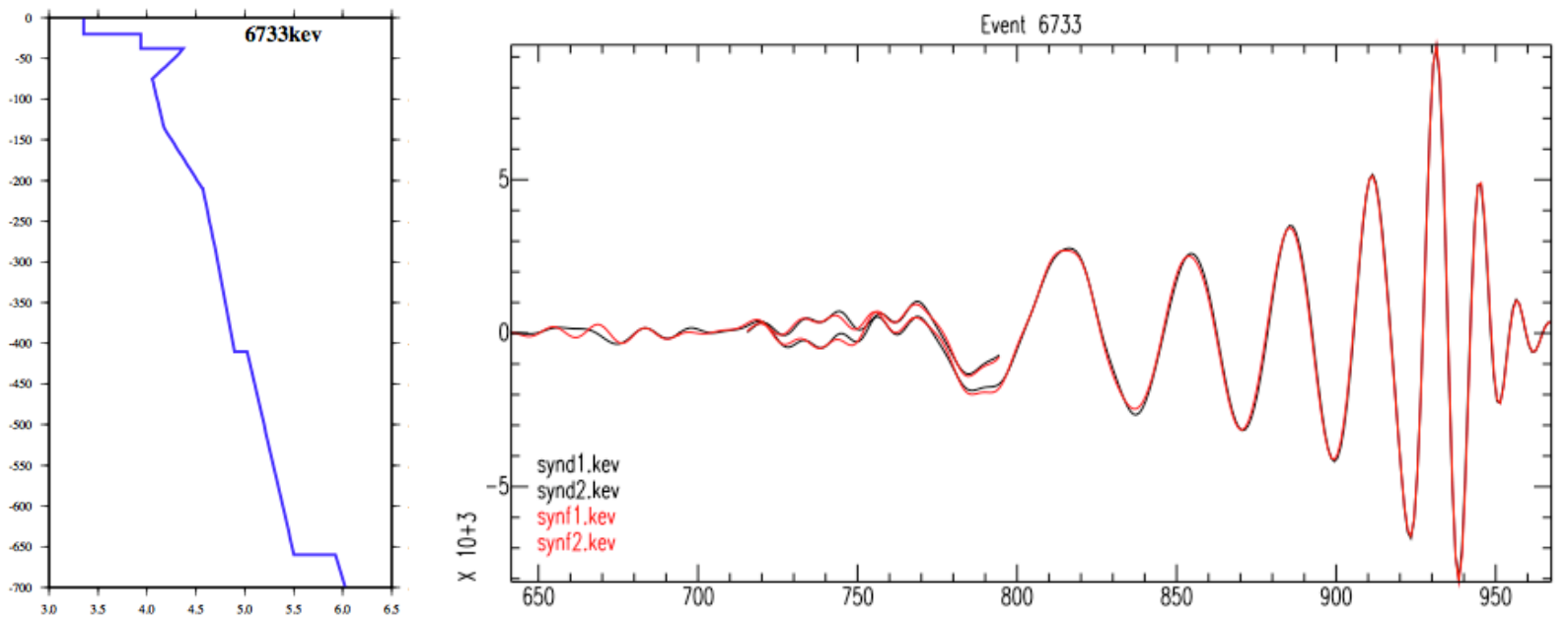

Figure 7g: Event 6733 / Station KEV / Transverse component
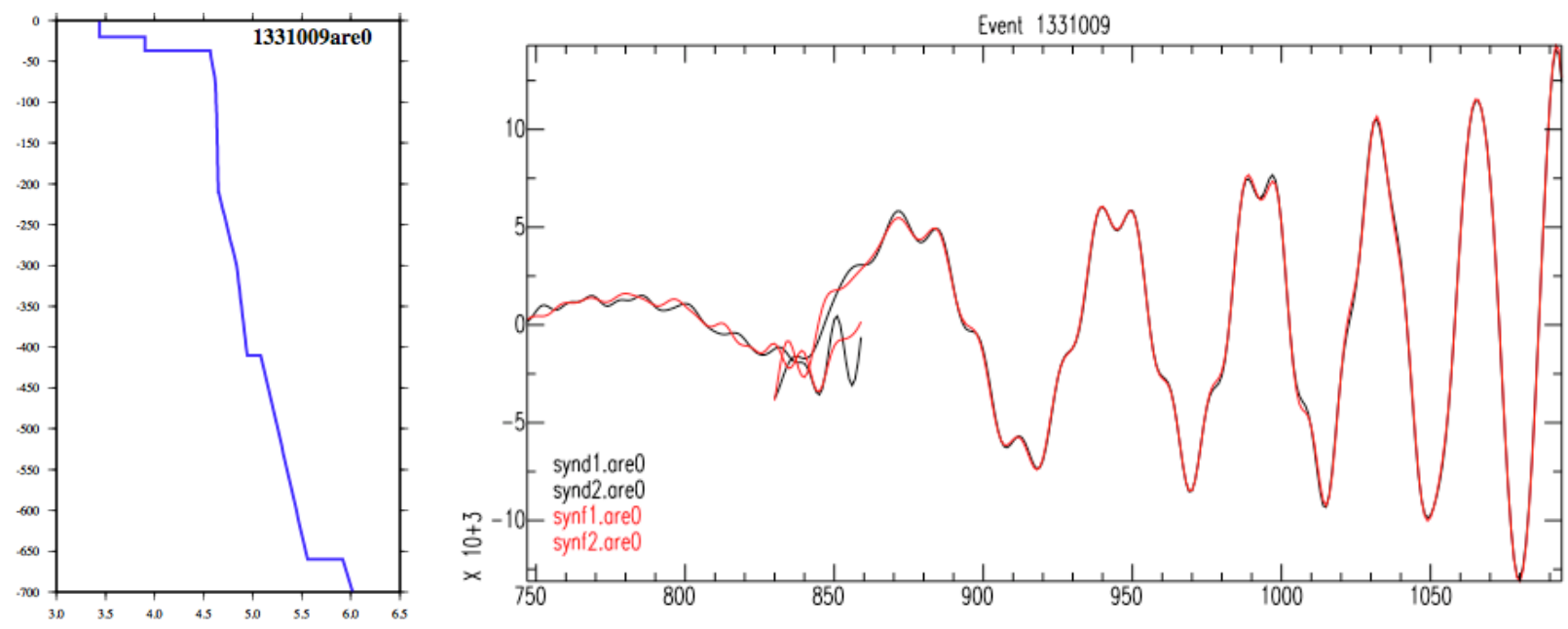

Figure 7h: Event 1331009 / Station AREO / Transverse component
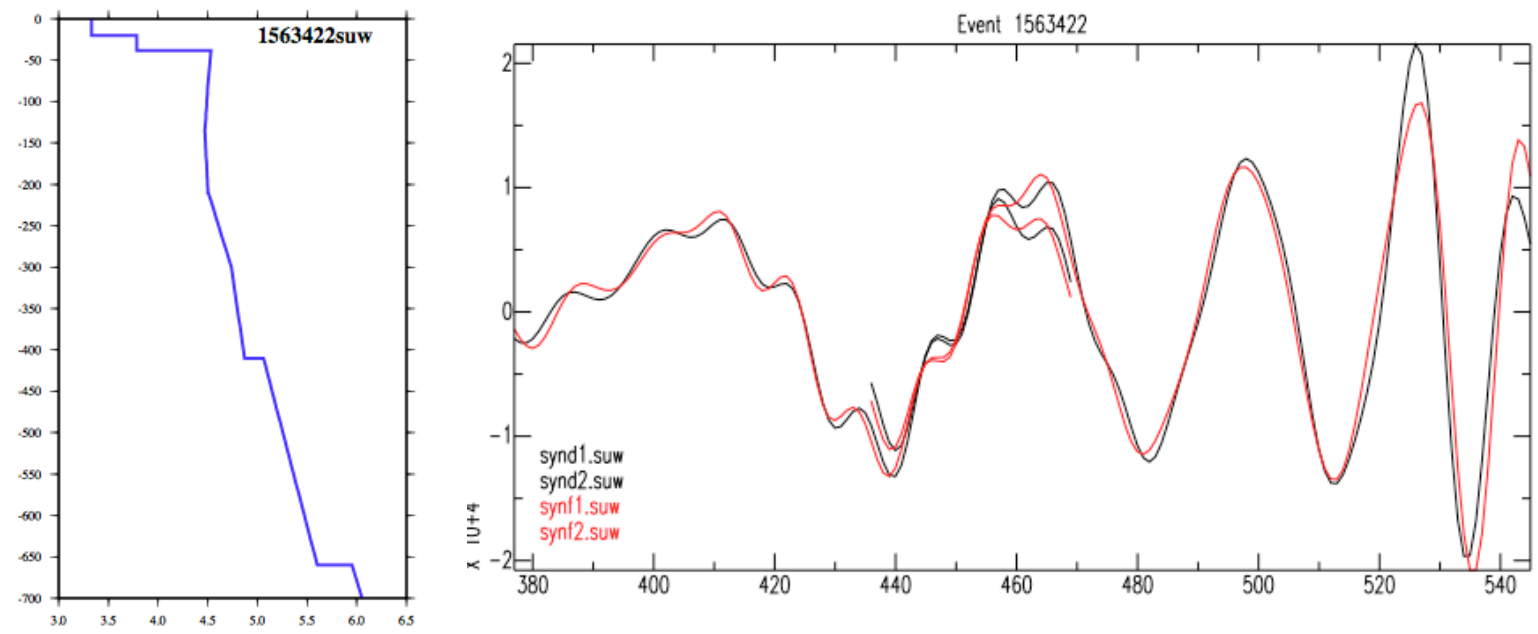

Figure 7i: Event 1563422 / Station SUW / Transverse component 

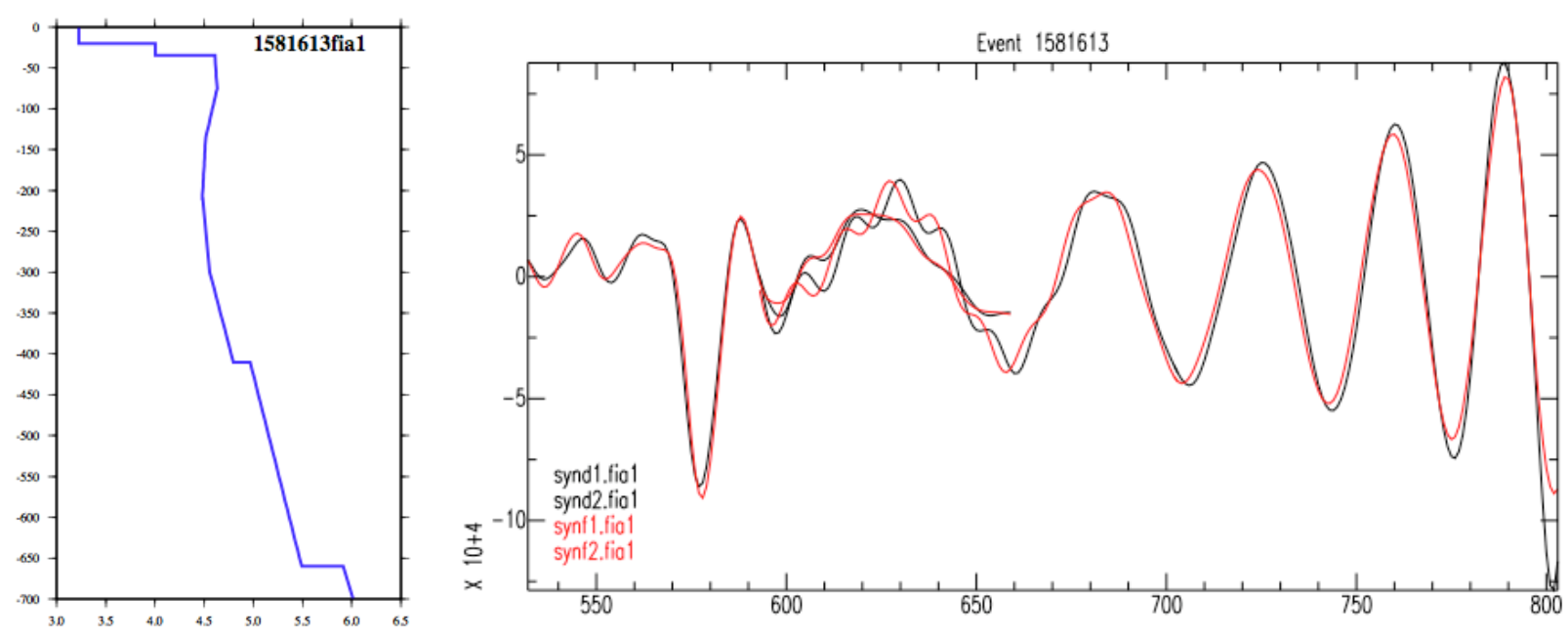

Figure 7j: Event 1581613 / Station FIA1 / Transverse component
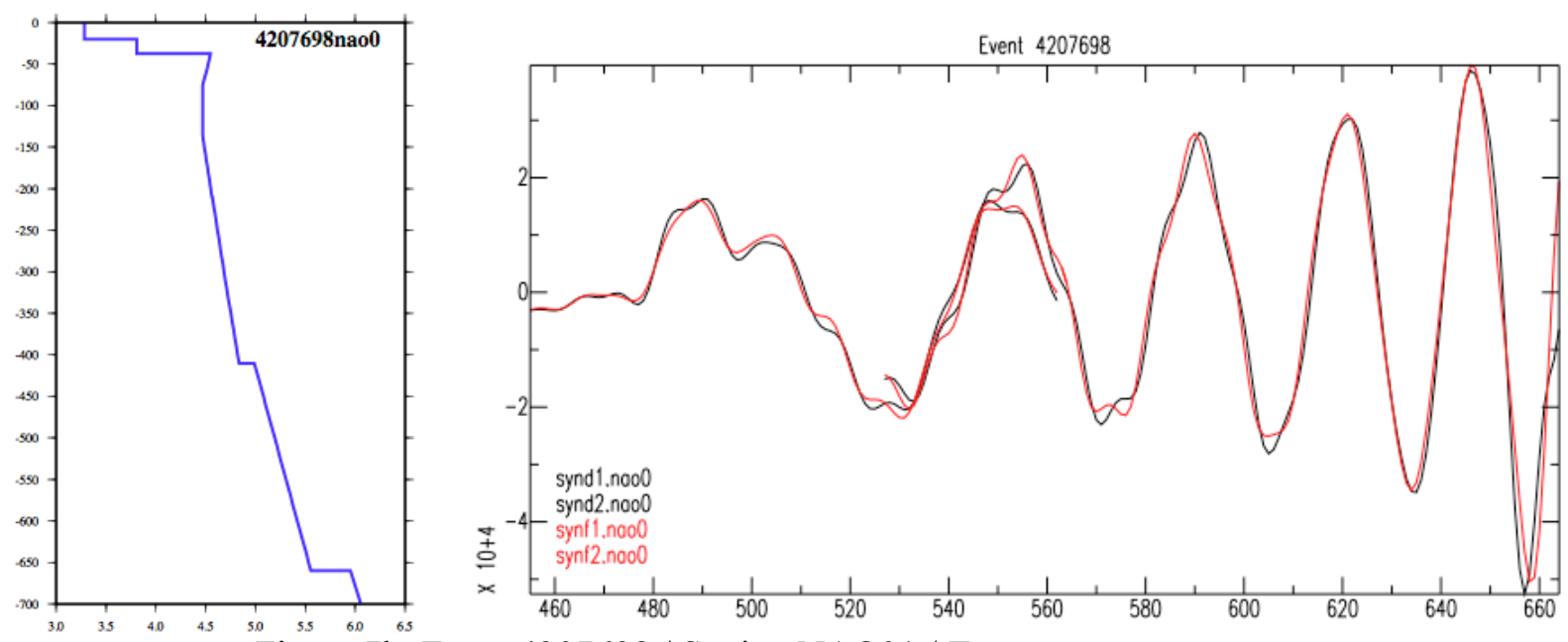

Figure 7k: Event 4207698 / Station NAO01 / Transverse component 


\section{II.) ETSE Dataset}

Instead of focusing on improving coverage over a broad geographic region, this dataset consists of waveforms recorded exclusively from the Eastern Turkey Seismic Experiment (ETSE) PASSCAL project. This deployment consisted of 29 broadband seismic stations, which were deployed from October 1999 through August 2001 (Sandvol et al., 2001). The range of tectonic features covered by this dataset is broad, as events were chosen from a large geographic region, from the Carlsberg Ridge and Gulf of Aden, to Himalayan events and Mediterranean events. The ETSE Array sits on the Turkish Plate, which is being squeezed to the west by the northward moving Arabian Plate.

The data from the ETSE array was, as a whole, difficult to fit, primarily due to bad signal. A majority of stations, especially with later events, had long period noise - up to .02 Hz. Due to the large quantity of data, a significant amount of this dataset was set aside, to be possibly returned to if needed to fill in sparsely covered area. Also, I removed data that had weak signals, due to being in the radiation null of the source. Of the 3046 waveforms, $\sim 50 \%$ were set aside due to poor waveform quality. In many cases the body waves were easy to fit, but problems arose when fitting the surface waves. The transverse components were consistently easier to fit. Figure 8 shows the path coverage of the waveforms successfully fit from this dataset.

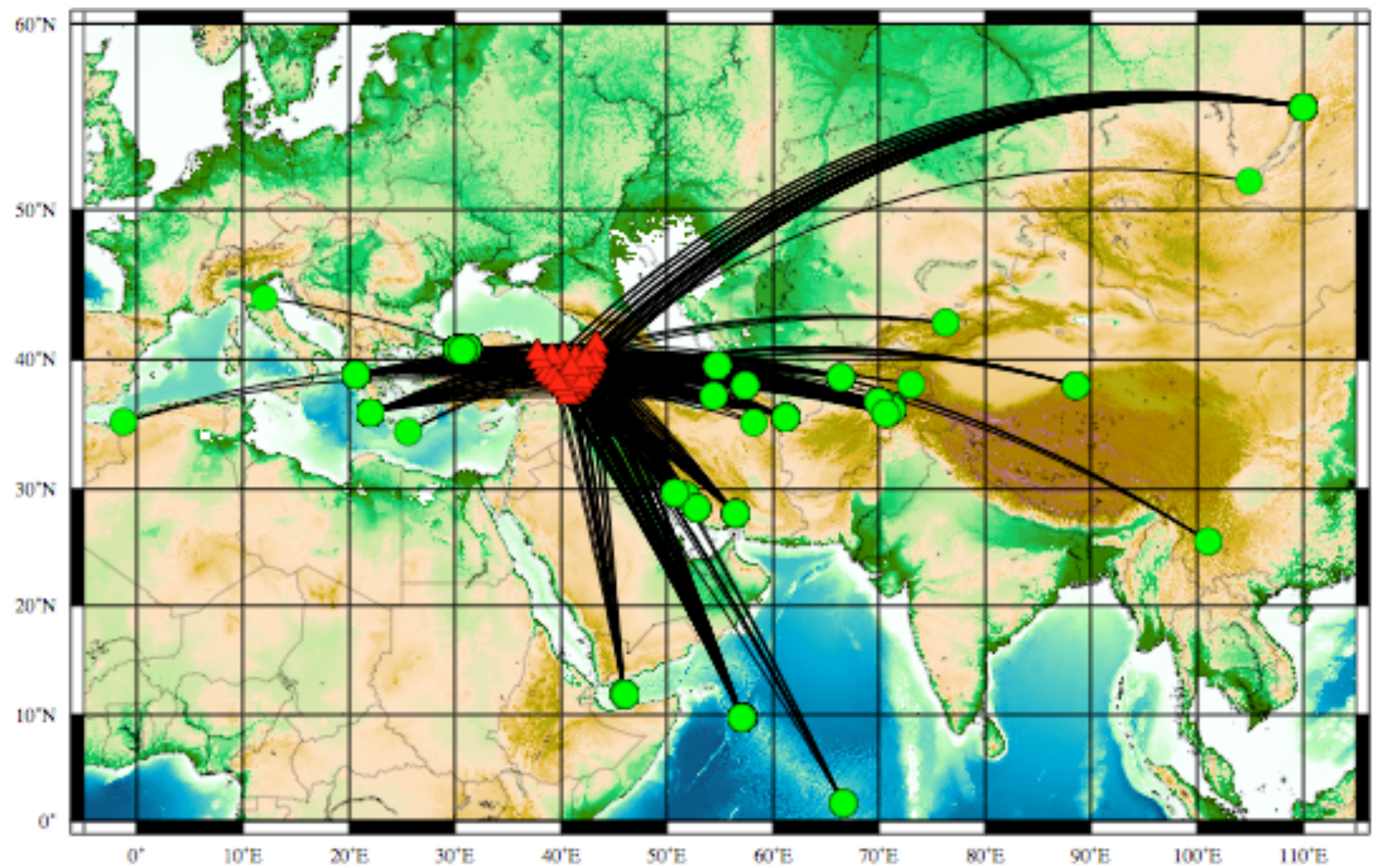

Figure 8: Raymap of ETSE waveforms that were successfully fit. Green circles represent events, red triangles represent the ETSE seismic stations.

The double moment tensor problem encountered while fitting the NEurope dataset arose in about five events in this dataset. In these cases, the Harvard CMT solution was used in the inversions. For this and the following datasets the rise time was used, and not the half duration. 


\section{Example Waveforms}

\section{Rejected Data/ Difficult Paths/ Events}

Paths that were most difficult were from events that occurred in the Morocco region (e.g., 1383201). These paths crossed the Mediterranean Sea - a tectonically complicated region. Several weaker events (magnitudes of $<5.5$ ), which occurred to the north, in Russia had long wavepaths (gcarc $>50^{\circ}$ ) and the signal was difficult to fit with confidence, so many of these waveforms were rejected. Some events, such as 1324179, possessed a good signal (Figure 9), but the inversion could not converge to a solution. This particular event occurred in the Yunnan Province of China, with an event station distance is $>50^{\circ}$ and crossed the Himalayas, which may have complicated and scattered the seismic arrivals. As previously mentioned, many events in this dataset had very noisy waveforms, among these is 1326787, which occurred near Crete (Figure 10), and 1383049, which occurred in north-central Iran near the southern Caspian Sea.

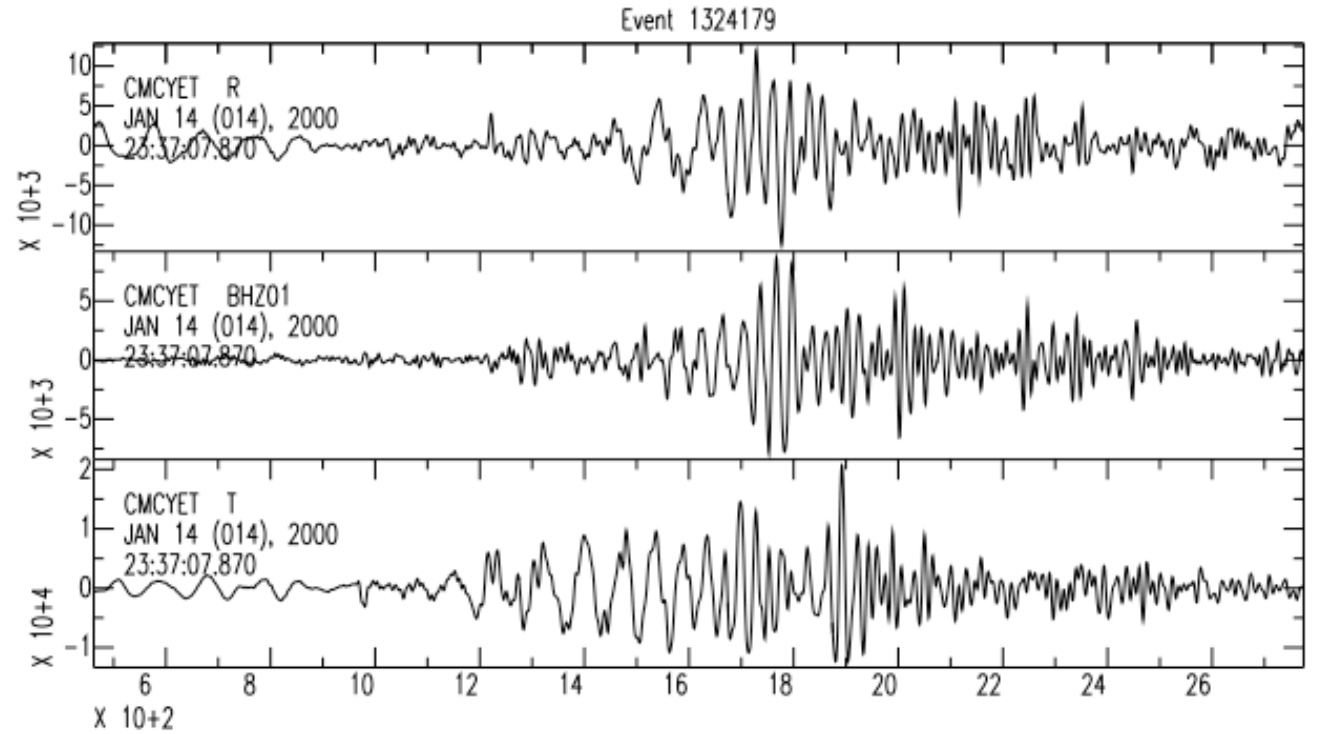

Figure 9: Example of waveforms that I had trouble fitting.

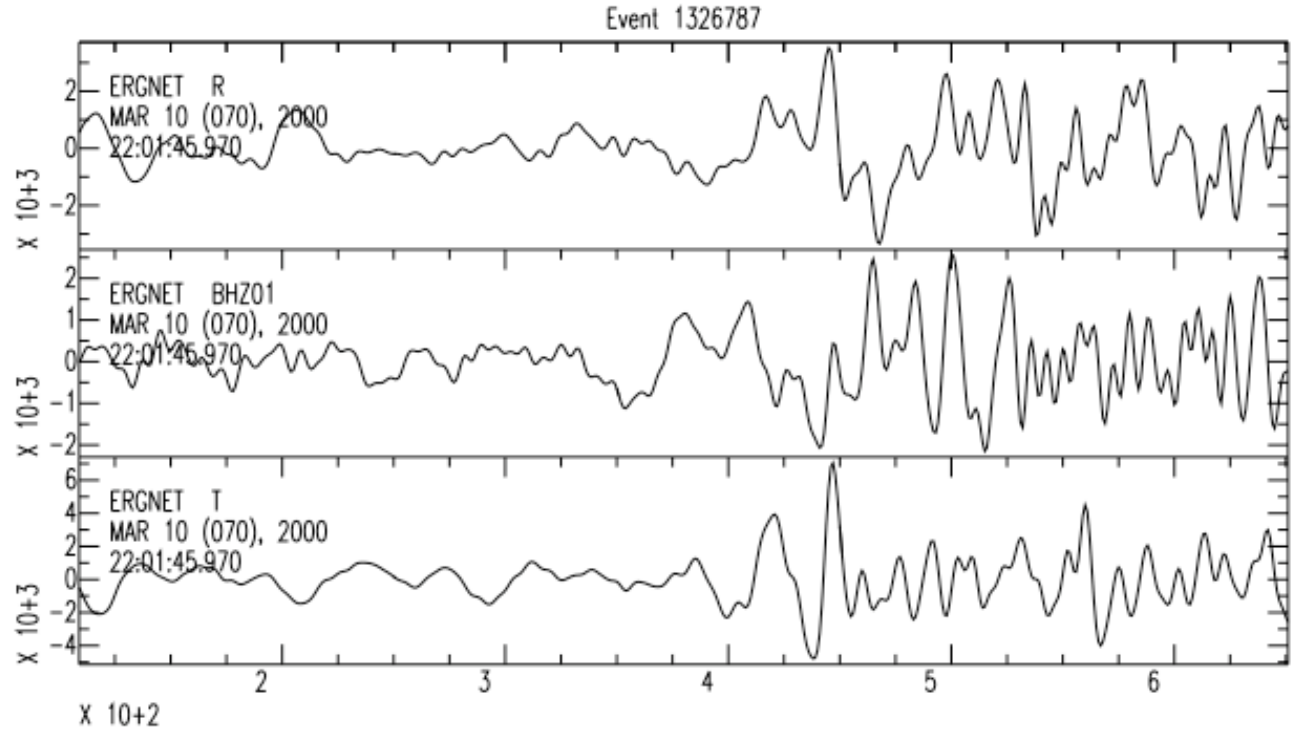

Figure 10: Example of noisy waveform data 


\section{Good Waveform Fits}

In general, the data in this set were difficult to fit, nonetheless, 460 waveforms were adequately fit. Examples of some of the better fits are shown below. These examples were chose to display a variety of geographically different events (and thus paths). A map of the paths for these waveforms is shown in Figure 11. For future reference, asterisked events had a relatively high amount of good fits, when compared to other events from this dataset.

A previous study by Al-Lazki et al. (2003) using the ETSE data found low Pn velocities, which the authors attribute to the possible absence of a mantle lid beneath this region, allowing the asthenosphere to come into direct contact with the base of the crust. We see some evidence in the 1D velocity models for this, as many of the 1D models do not show a fast lithosphere beneath the crust. The exception to this is Figures $11 \mathrm{~b}$ and $11 \mathrm{~h}$, which occur respectively in western and eastern Afghanistan. Interestingly, with waveform fitting sometimes good fits are obtained with unusual 1D models. Several examples are shown here of good waveform fits, but with excessively slow velocities between the 410 and $660 \mathrm{~km}$ discontinuity, and fast velocities below the 660 (Figure 11f), or vise versa (Figure 11i).

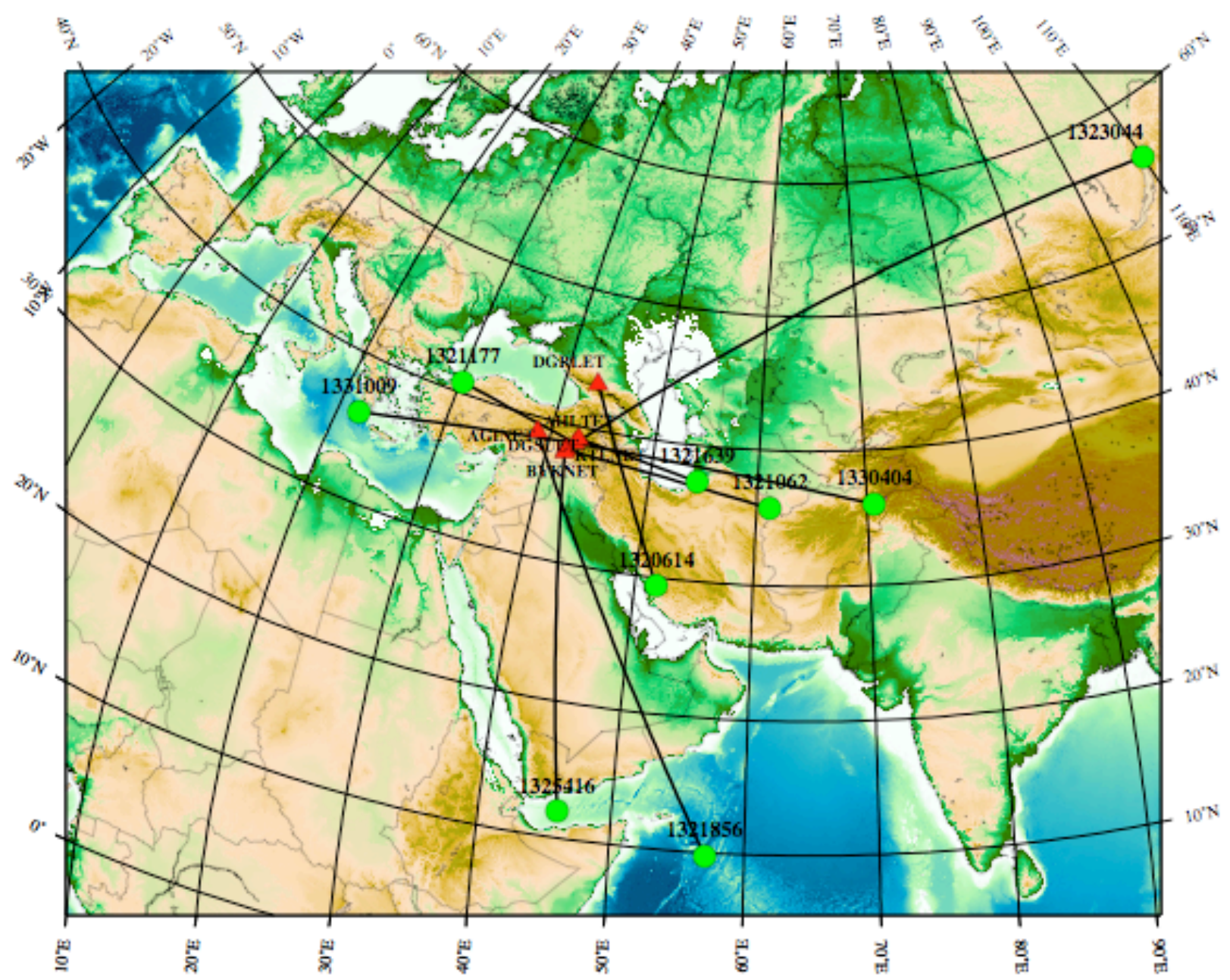

Figure 11: Raymap for the waveforms shown in Figures 11a-11k. 

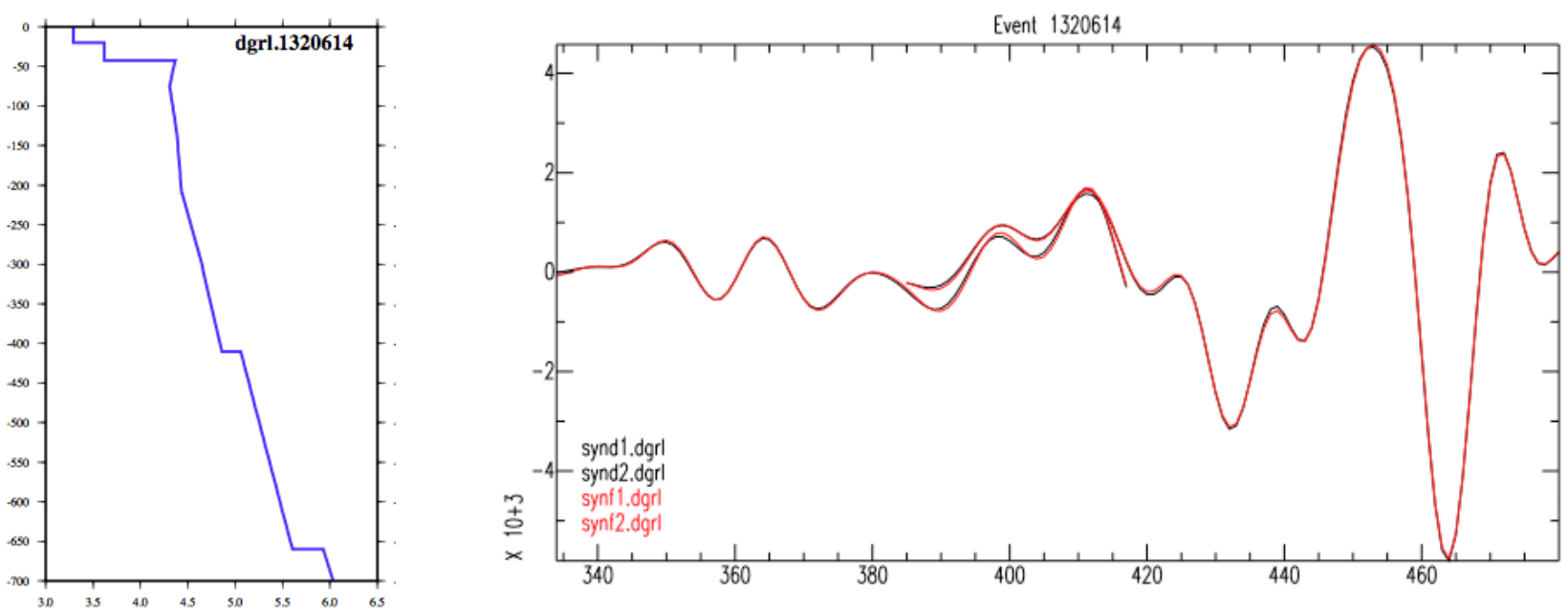

Figure 11a: Event 1320614 / Station DGRLET / Transverse component
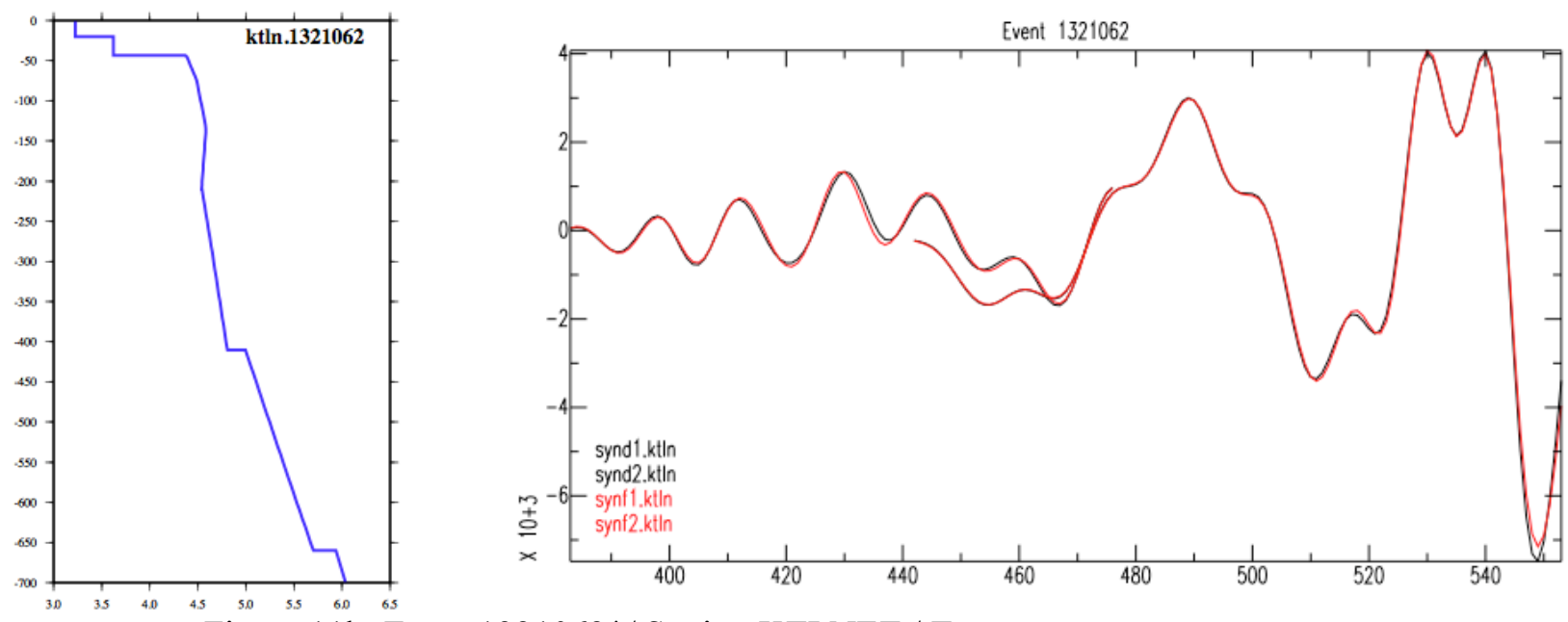

Figure 11b: Event $1321062 * /$ Station KTLNET / Transverse component
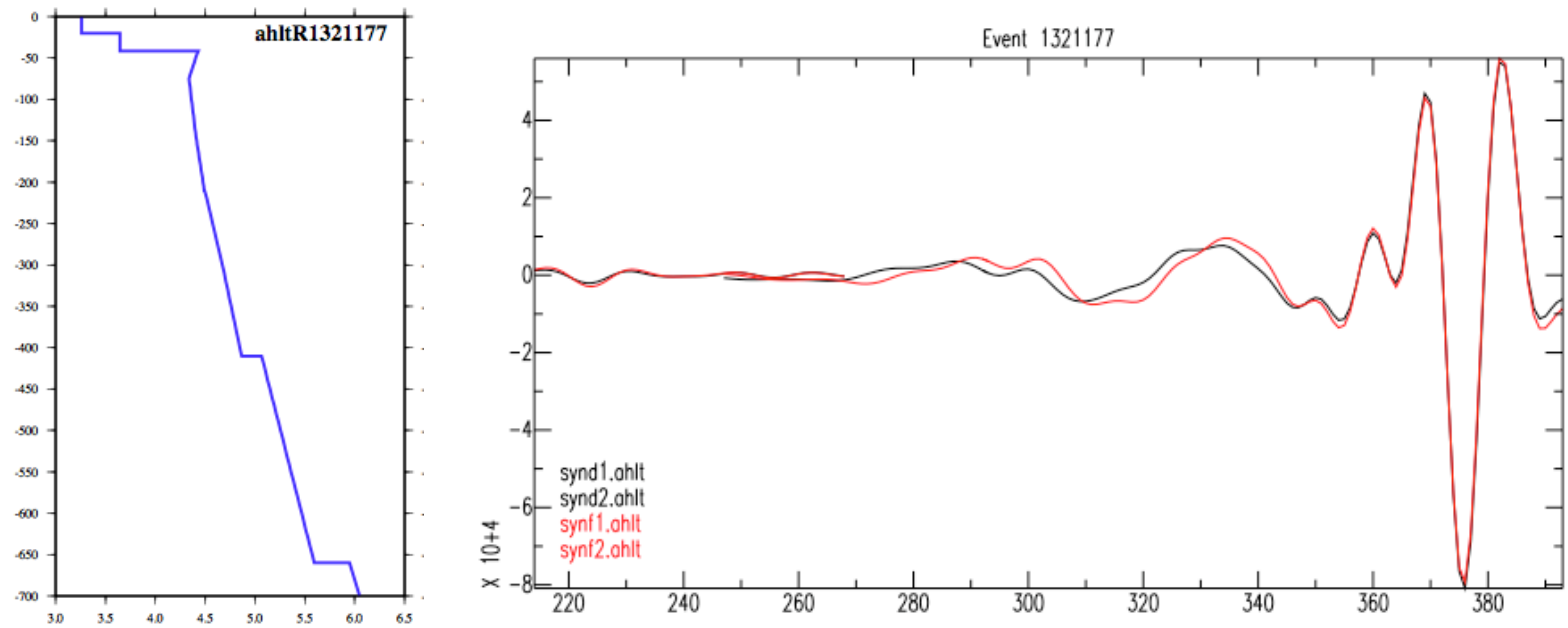

Figure 11c: Event 1321177 / Station AHLTET / Radial component 

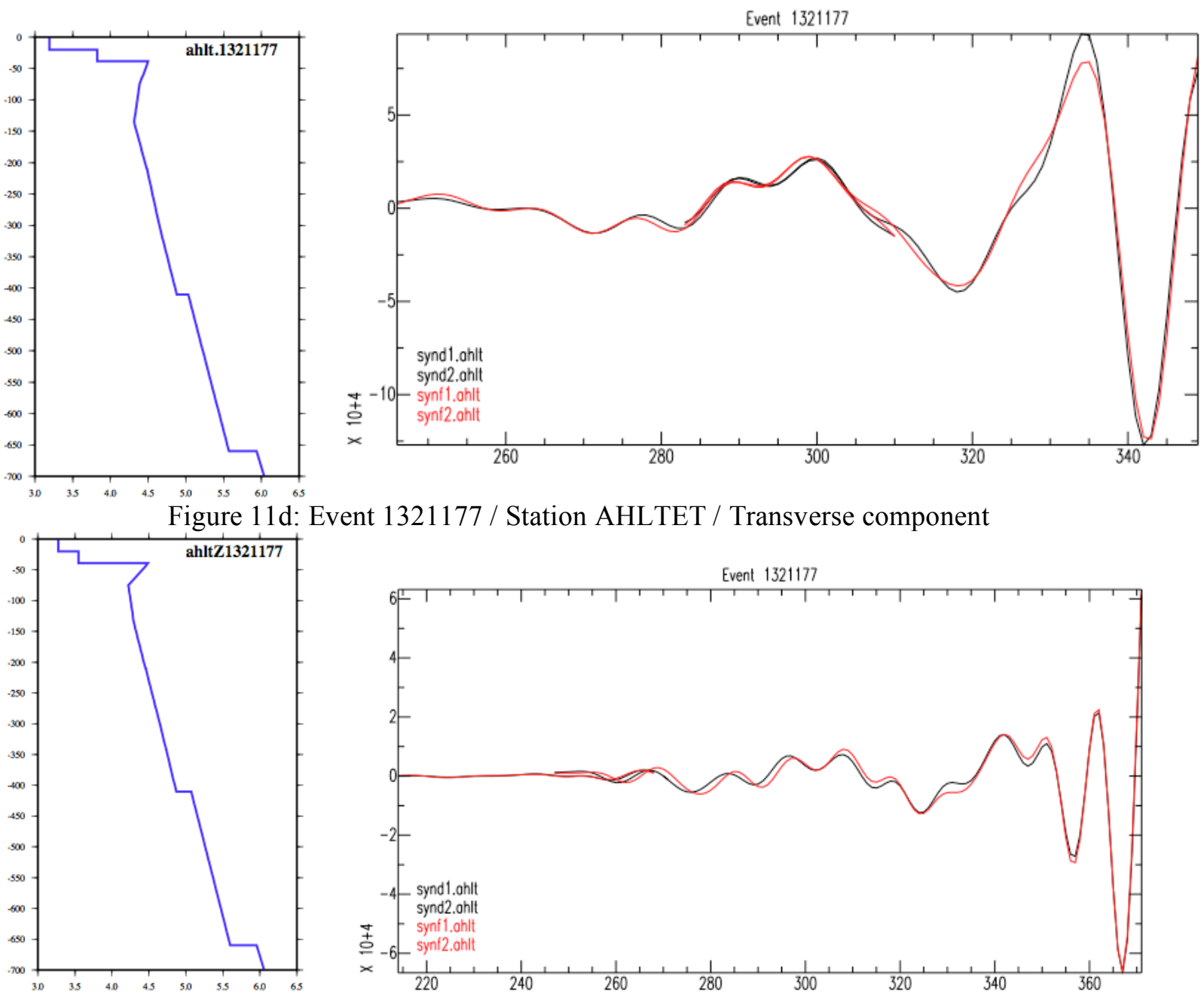

Figure 11e: Event 1321177 / Station AHLTET / Vertical component
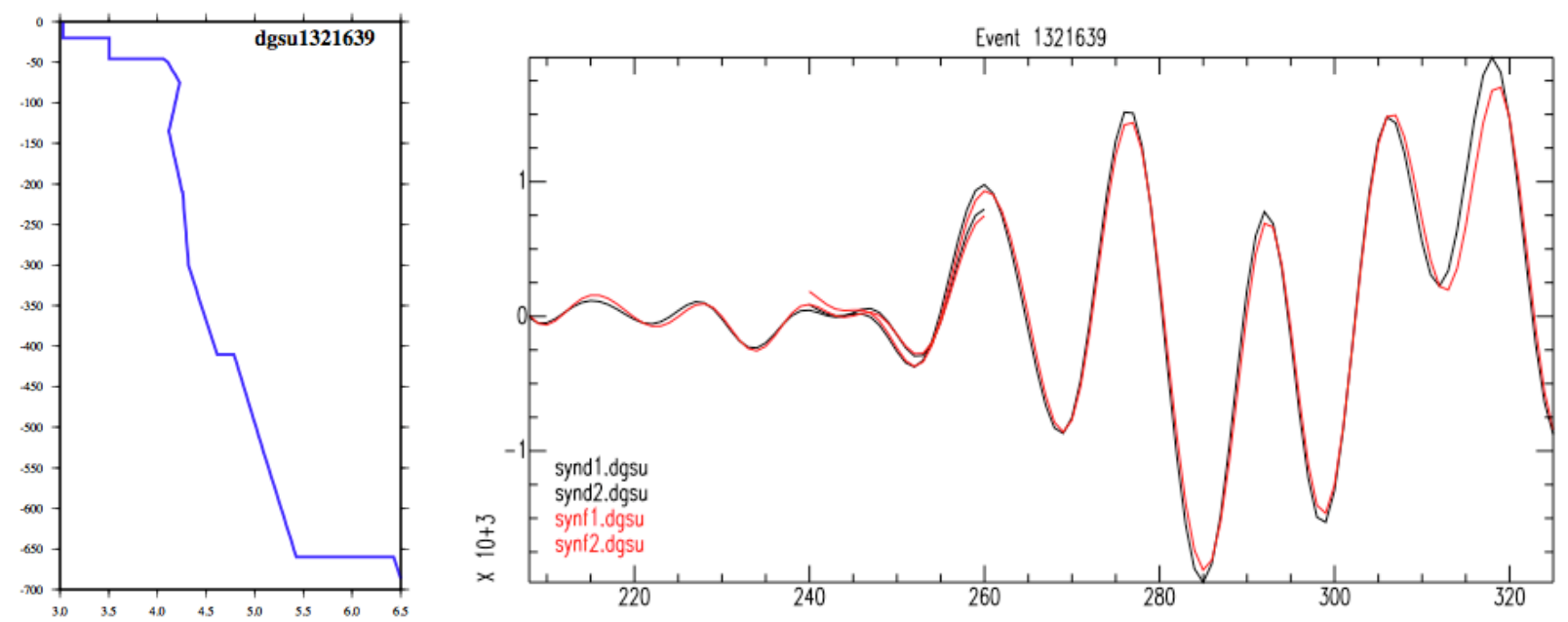

Figure 11f: Event 1321639 / Station DGSUET / Vertical component 

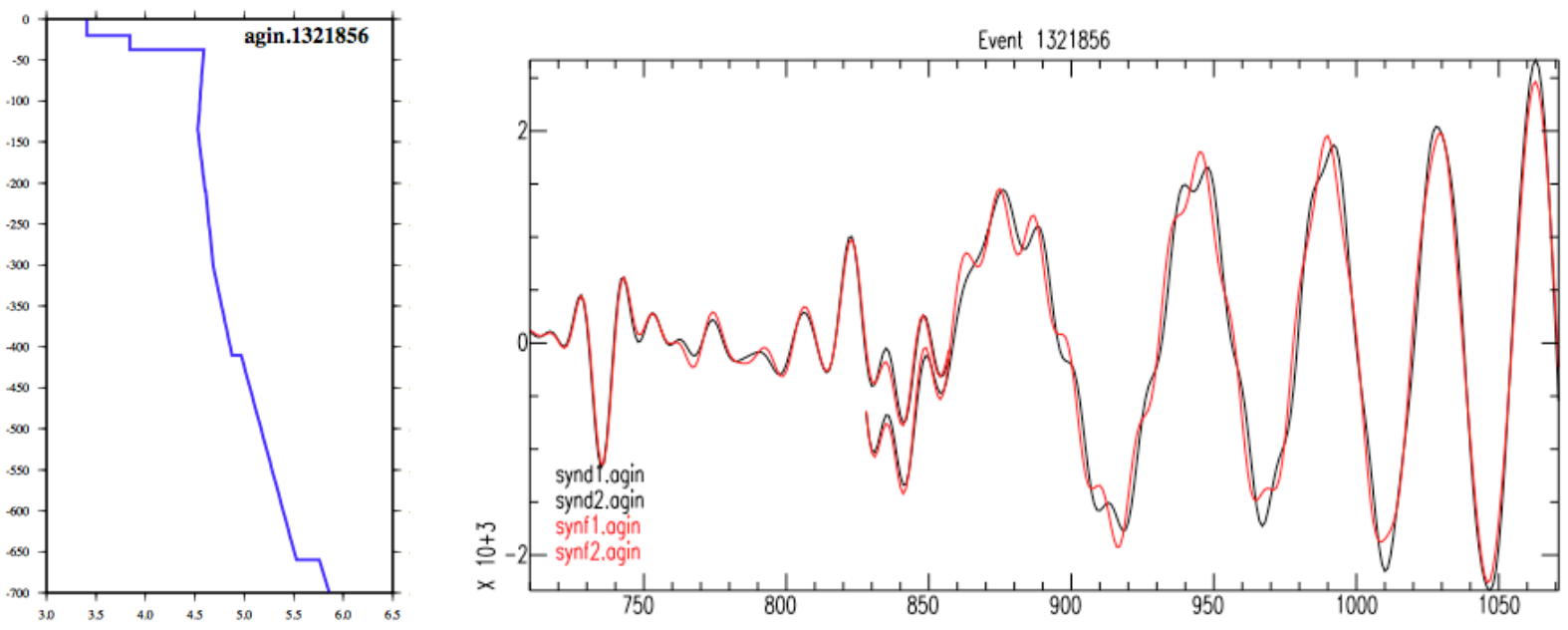

Figure 11g: Event 1321856 / Station AGINET / Transverse component
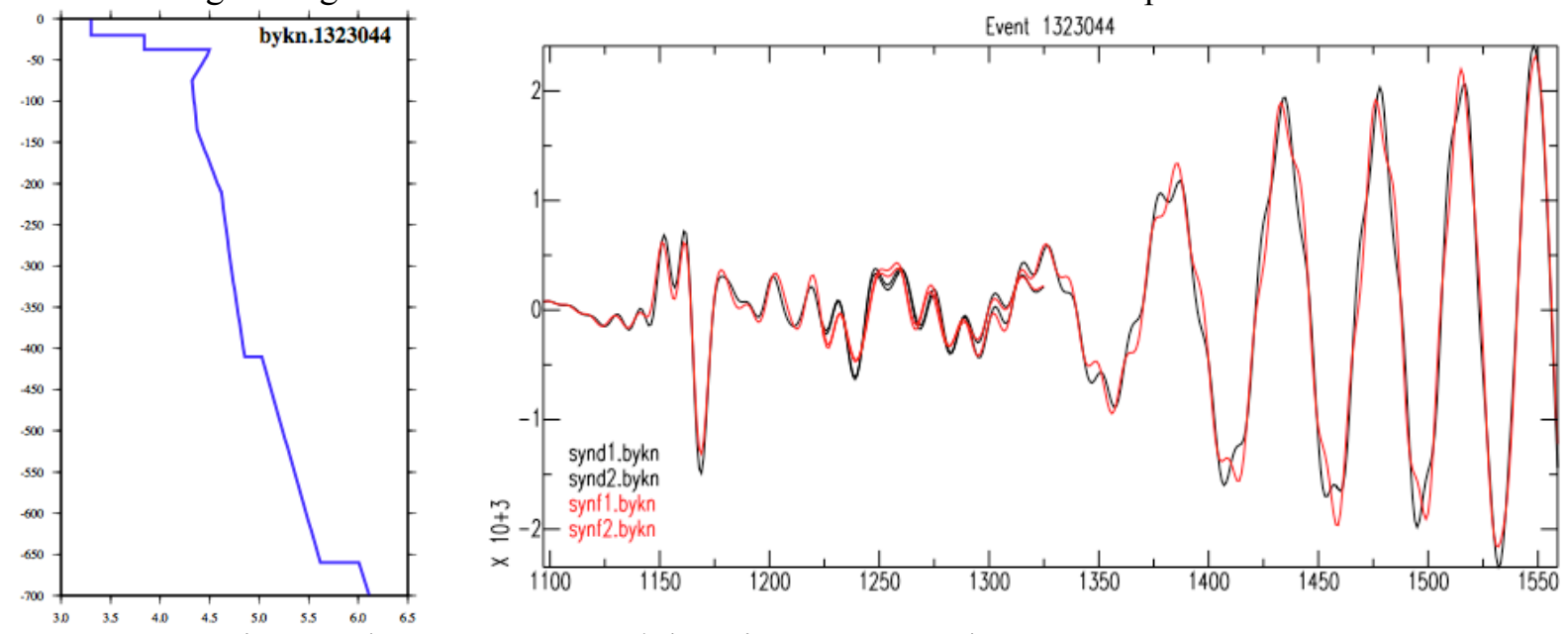

Figure 11h: Event 1323044* / Station BYKNET / Transverse component
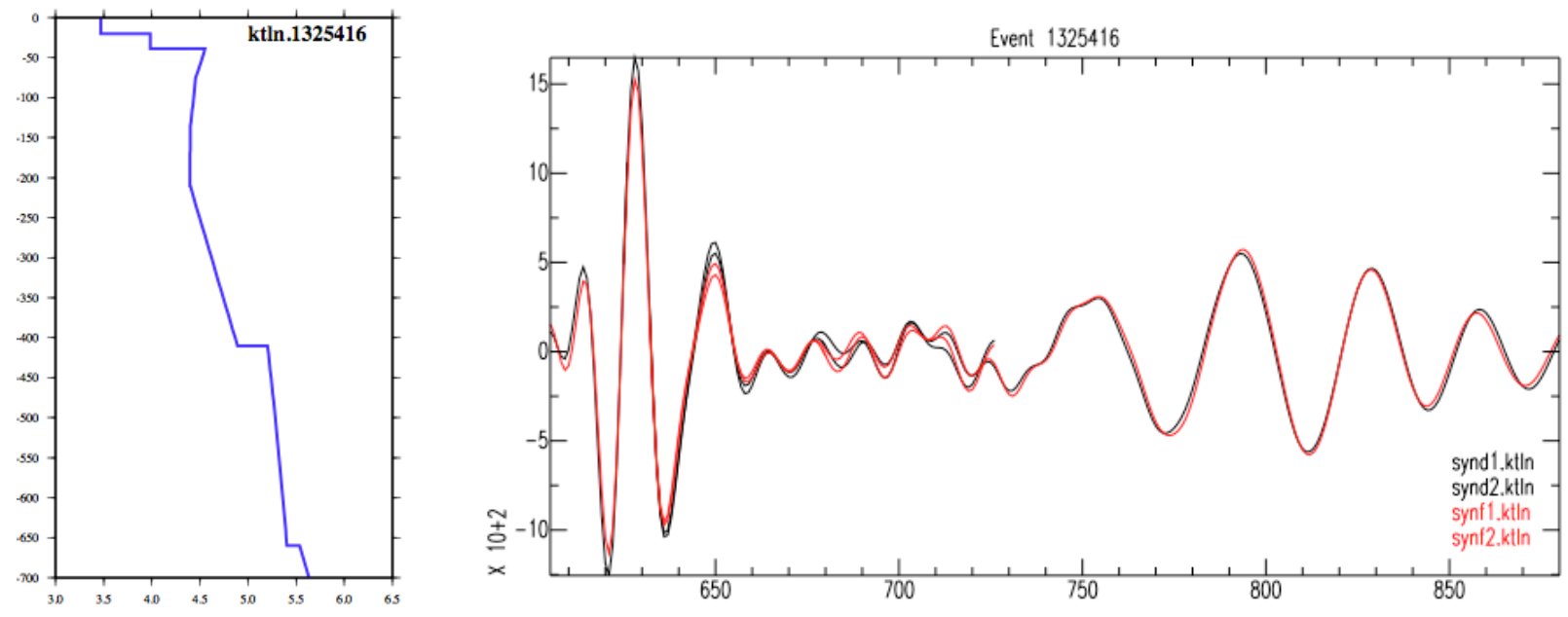

Figure 11i: Event 1325416 / Station KTLNET / Radial component This path is an example of a fit where low period noise $(<0.02 \mathrm{~Hz})$ was filtered out. 

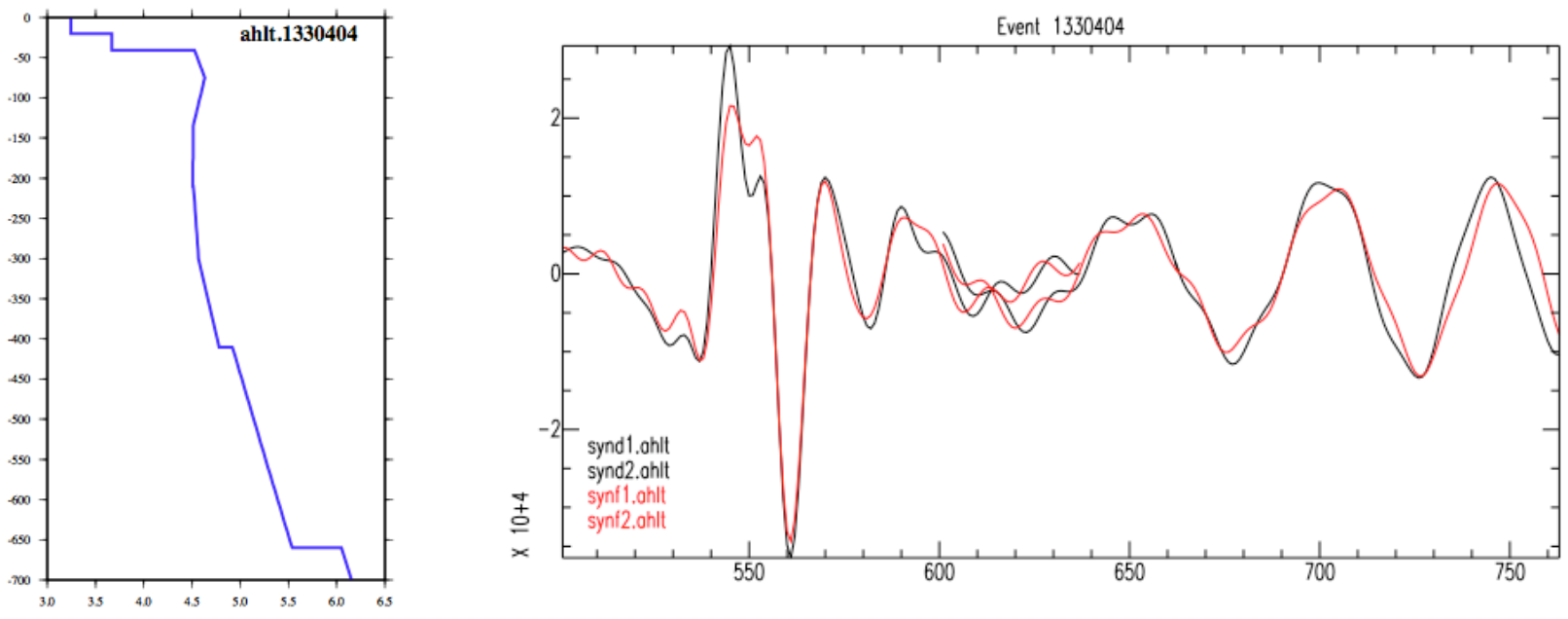

Figure 11j: Event 1330404 / Station AHLTET / Transverse component
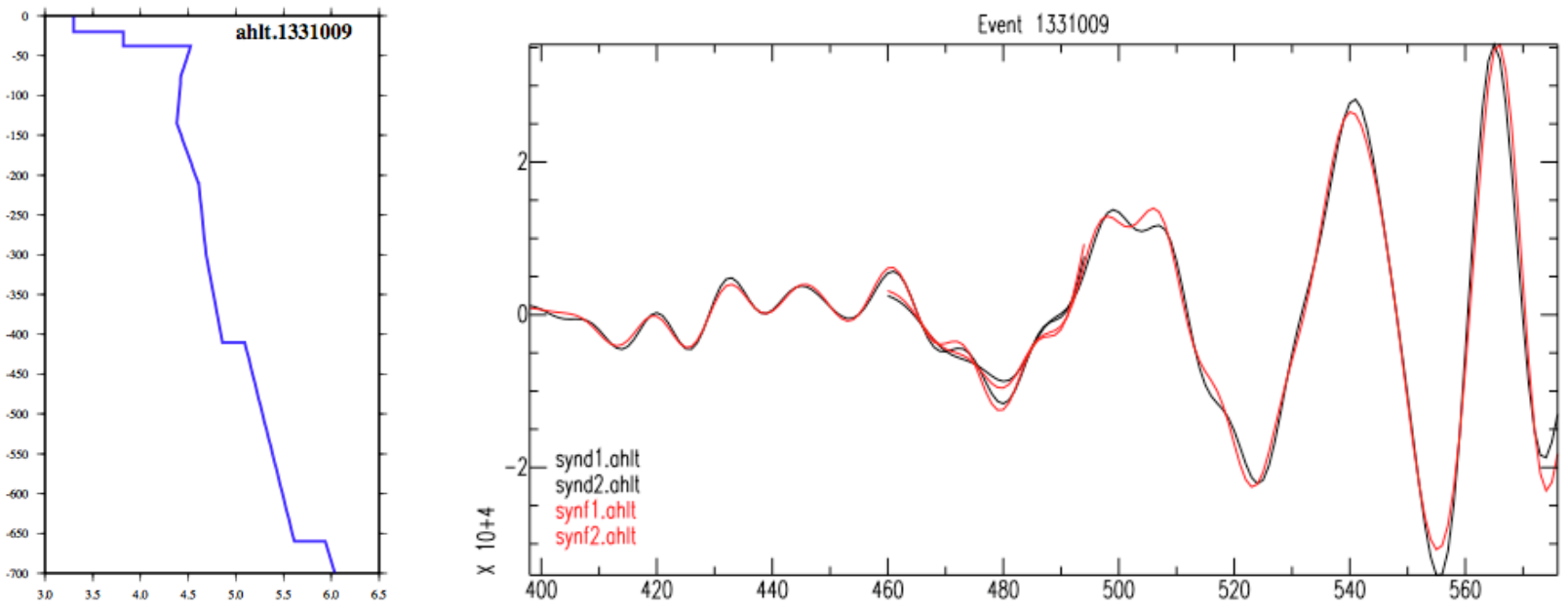

Figure 11k: Event 1331009* / Station AHLTET / Transverse component 


\section{III.) IOC Dataset}

The goal of this dataset was to calculate velocity constraints for data coverage to the south, allowing model to reach $20^{\circ} \mathrm{S}$ latitude, covering the East African Rift. This dataset originally consisted of $\sim 950$ waveforms. Seismic events in this dataset occurred primarily in the Indian Ocean (Carlsberg Ridge, Owen Fracture Zone), the Gulf of Aden, the Red Sea, with a few events occurring along the East African Rift. The tectonic features covered by this dataset are relatively young compared to the previous datasets, with the East African Rift, Gulf of Aden, and Red Sea Rift developing only in the Oligocene and Miocene. The region is not exclusively young, as a few raypaths also intersect both the Tanzania and Congo cratons.

Roughly 350 waveforms, or $37 \%$ of the data, was fit. Approximately 300 waveforms were discarded due to noisy waveforms. Those fit are shown in Figure 12; the double moment tensor problem did not arise in this dataset.

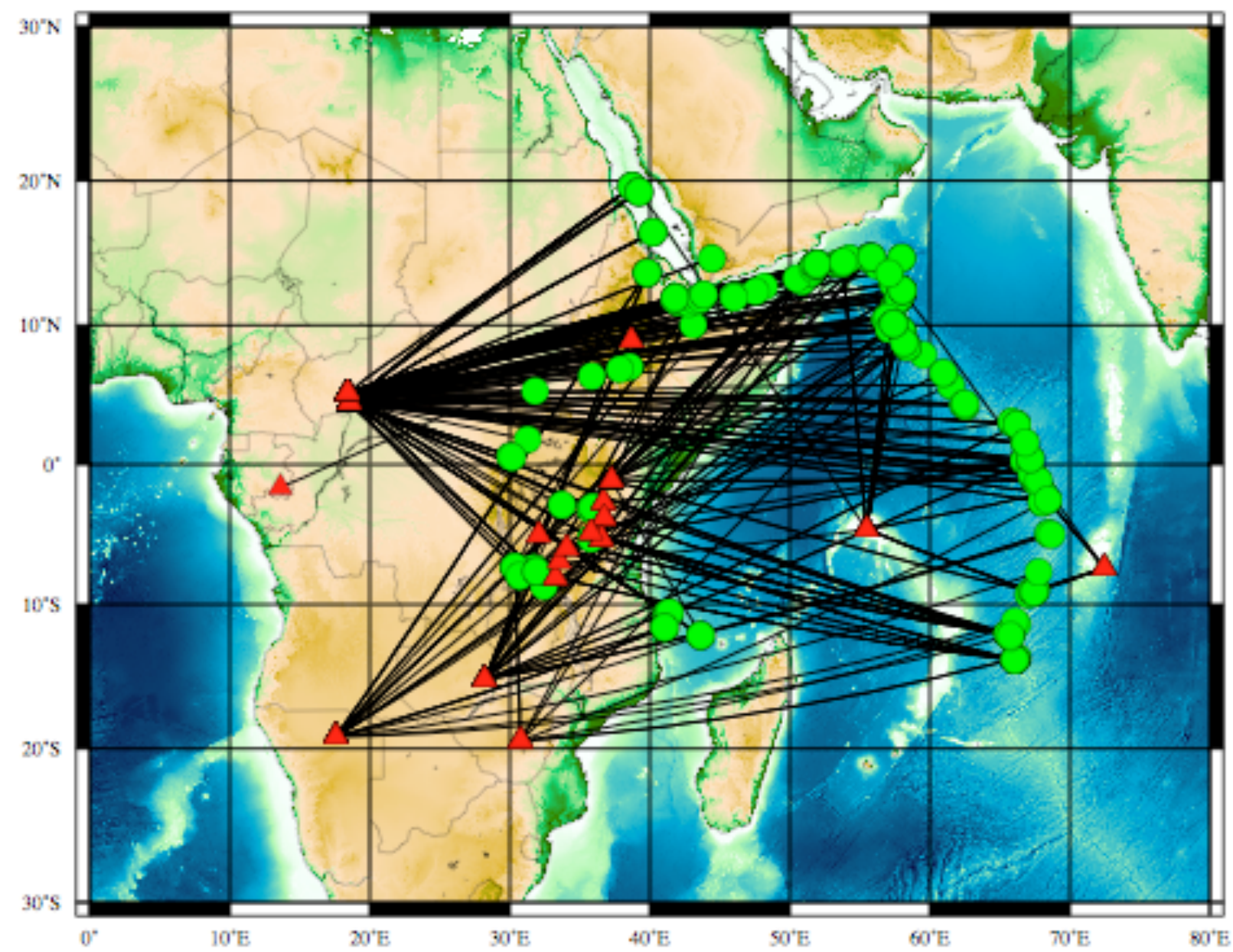

Figure 12: Map of waveform coverage from the IOC dataset

\section{Example Waveforms \\ Rejected Data}

Figures 13 through 15 show examples of waveforms that were rejected. Event 2980 (north-central Ethiopia) recorded at station BNG (Bangui, C.A.R.) displays an odd waveform. Meanwhile, Event 5711 (Red Sea), recorded at MSEY (Seychelles) shown in Figure 14 shows long period noise for the horizontal components. The vertical component in this case was successfully fit. Figure 15 shows an example of 
noisy data that was recorded at a long distance. Here the signal is not strong and because of the signal-tonoise ratio this set of waveforms was rejected.

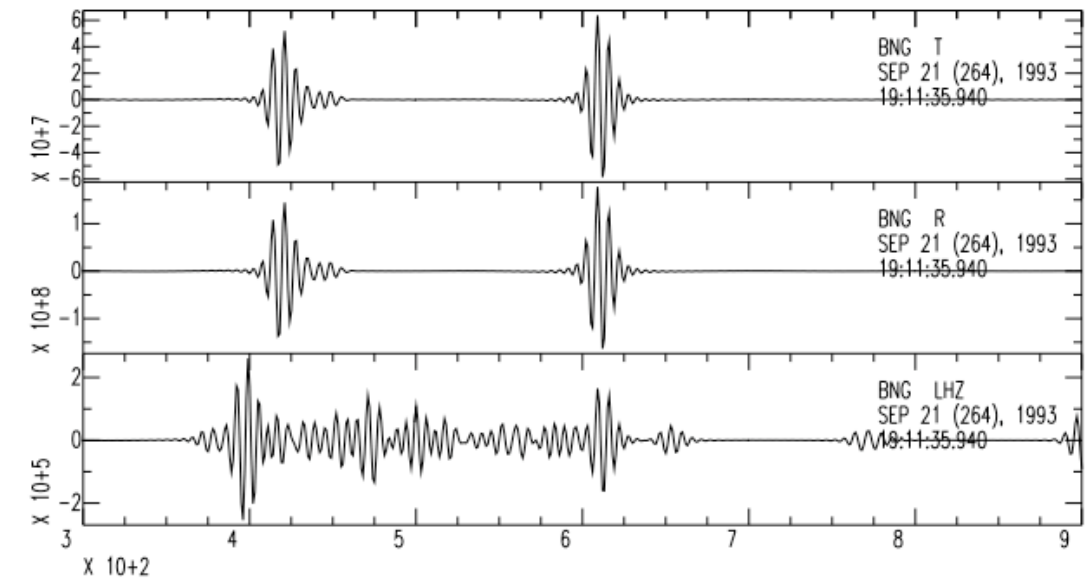

Figure 13: Event 2980: Example of bad waveform data

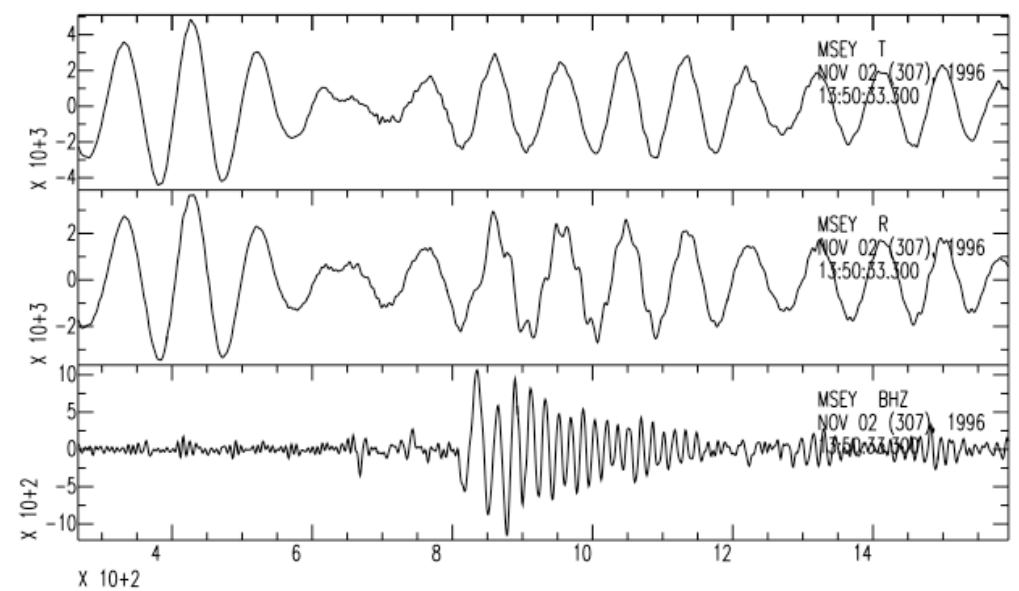

Figure 14: Event 5711: Example of bad waveform data for transverse and radial components.

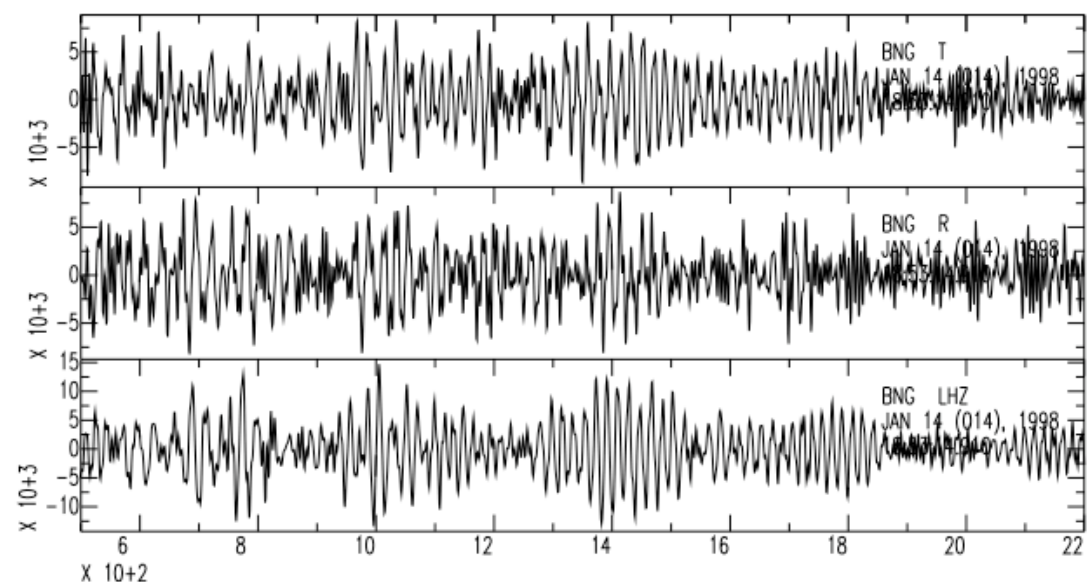

Figure 15: Event 8641: Example of noisy data at $\sim 50^{\circ}$ gcarc (event on Carlsberg Ridge) 


\section{Difficult Paths/ Events}

Figures 16 and 17 show waveforms from event-station pairs that had trouble converging.

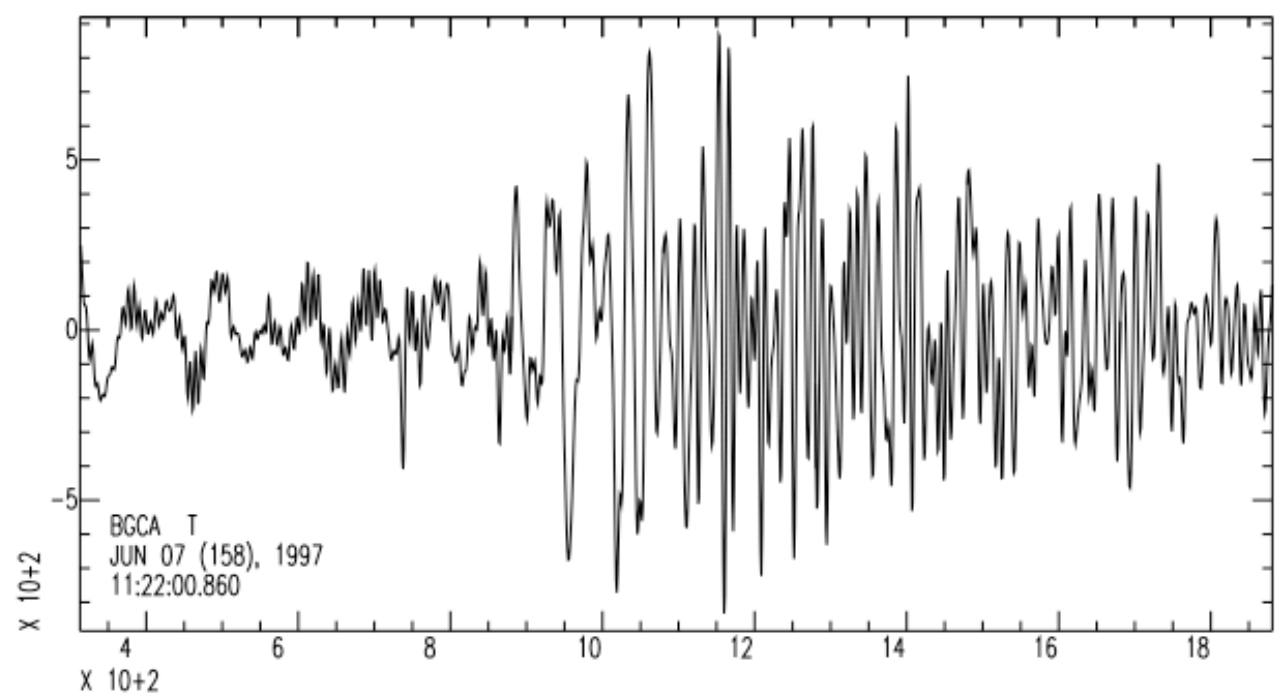

Figure 16: Event 6469, BGCA.T - low magnitude (4.9 Mb).

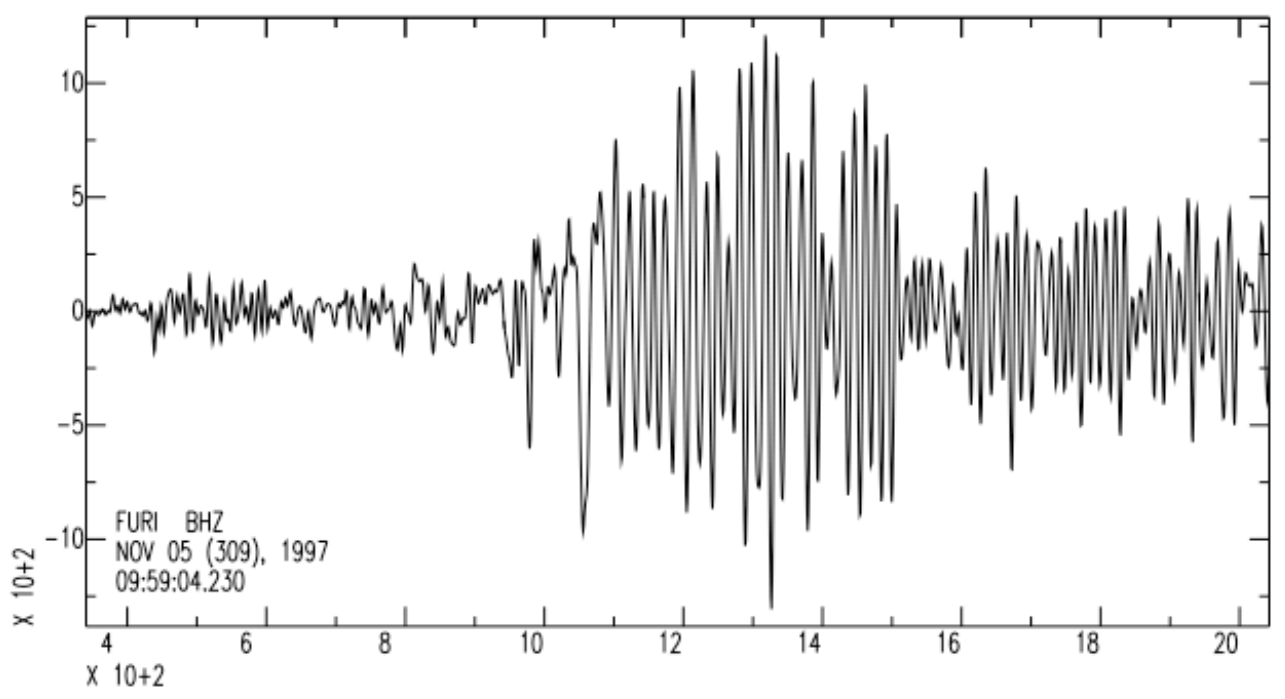

Figure 17: Event 6796 (Maldives) recorded by FURI.Z (Mt. Furi, Ethiopia). This may be due to the complexity of the raypath, which samples the upper mantle of both the ocean and of a continental rift.

\section{Good Waveform Fits}

In general, the data in this set was relatively easy to fit, as compared to the NEurope and ETSE dataset. Also, the radial and vertical components were more easily fit in this set. The examples chosen display a variety of geographically different events (and thus paths). A map of the paths for these waveforms are shown in Figure 18. Example waveform fits are show in Figures 18a-18h. In many of these examples the 1D solution converges to solution with a thin crust, which is expected in a rift or oceanic path setting. Many of these examples converge upon 1D models with slower than average uppermost mantle velocities and thin crustal thicknesses, as expected in regions of rifting (Figures $18 \mathrm{~g}$ and $18 \mathrm{~h}$ ). Figure 18d shows a more cratonic 1D velocity model, expected as this raypath samples both the Tanzania and Congo cratons. 


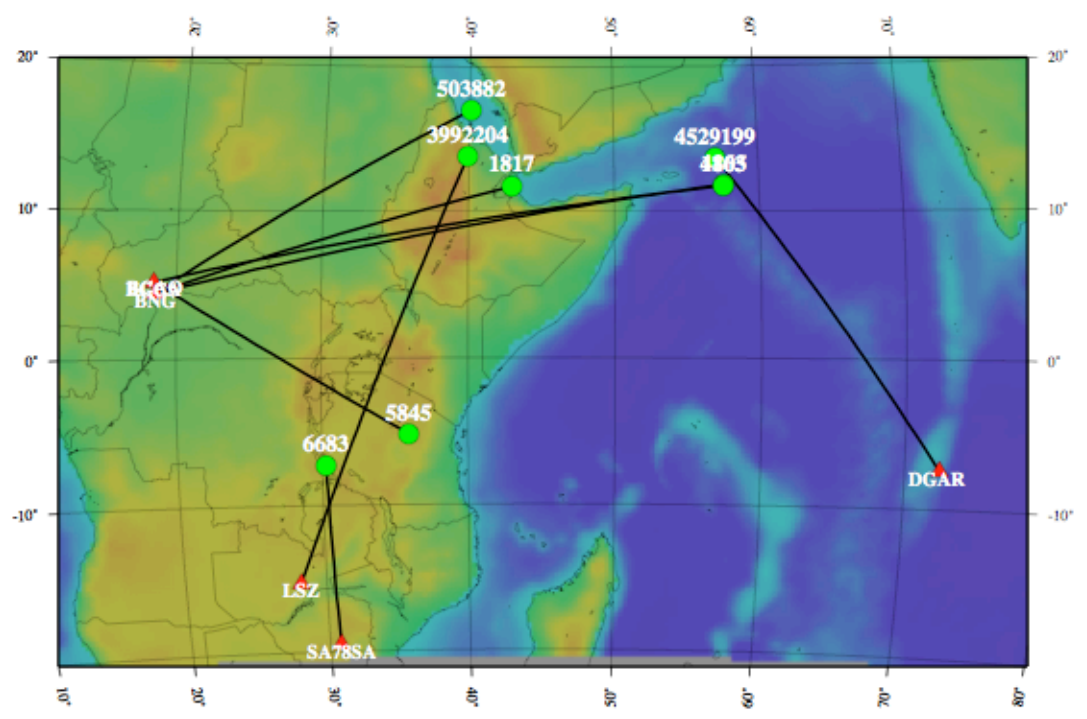

Figure 18: Raymap for the waveforms shown in Figures 18a-18h.
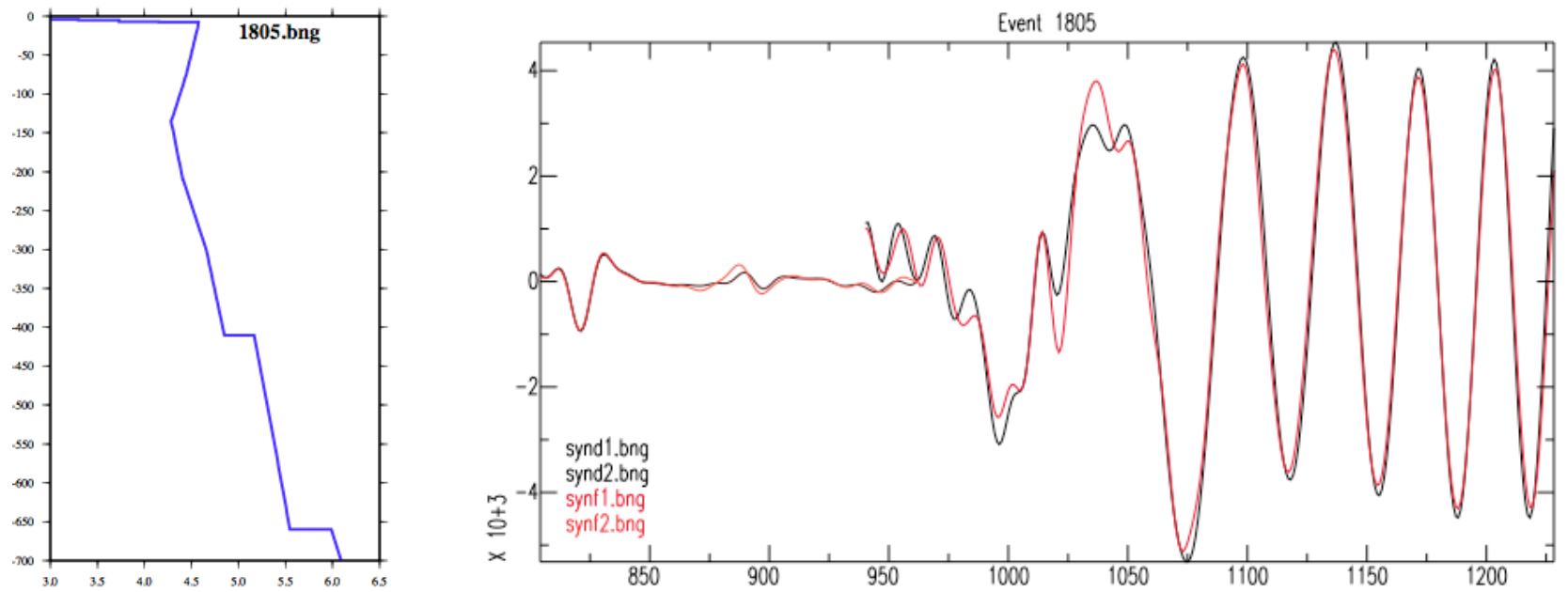

Figure 18a: Event 1805 / Station BNG / Transverse component
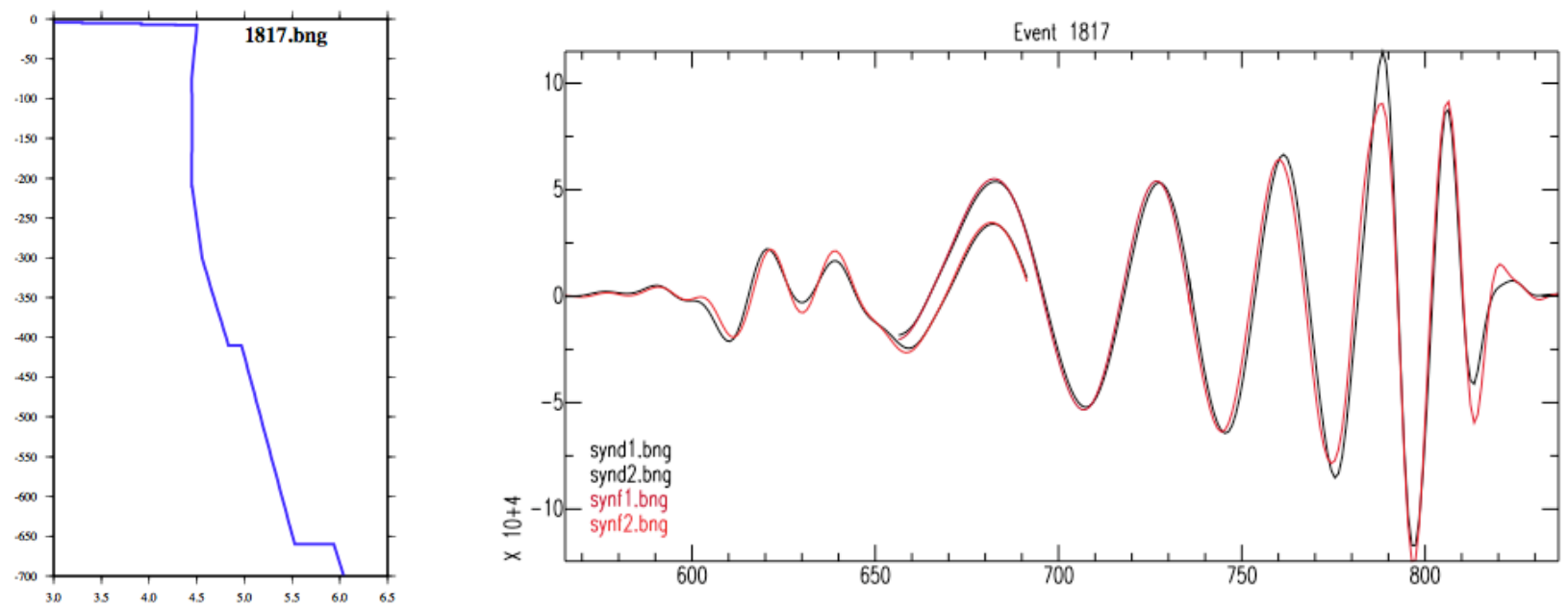

Figure 18b: Event 1817 / Station BNG / Transverse component 

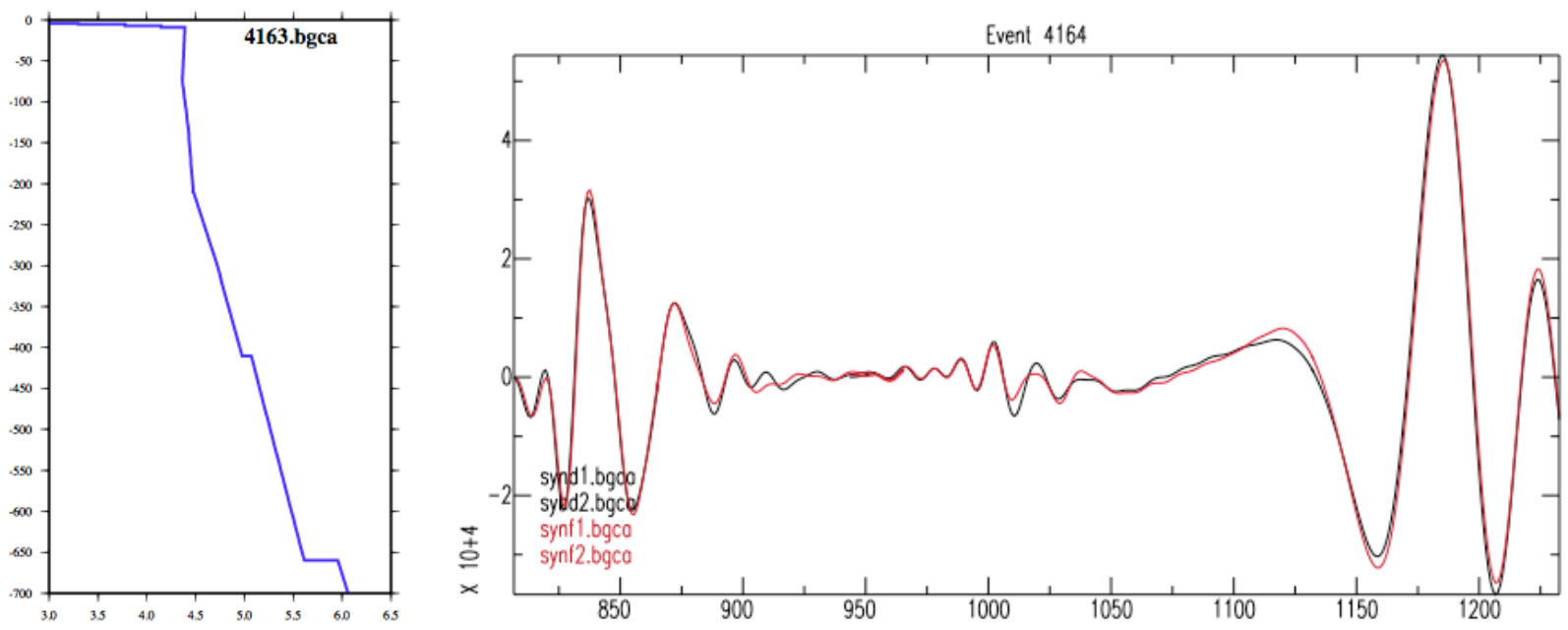

Figure 18c: Event 4163 / Station BGCA / Radial component
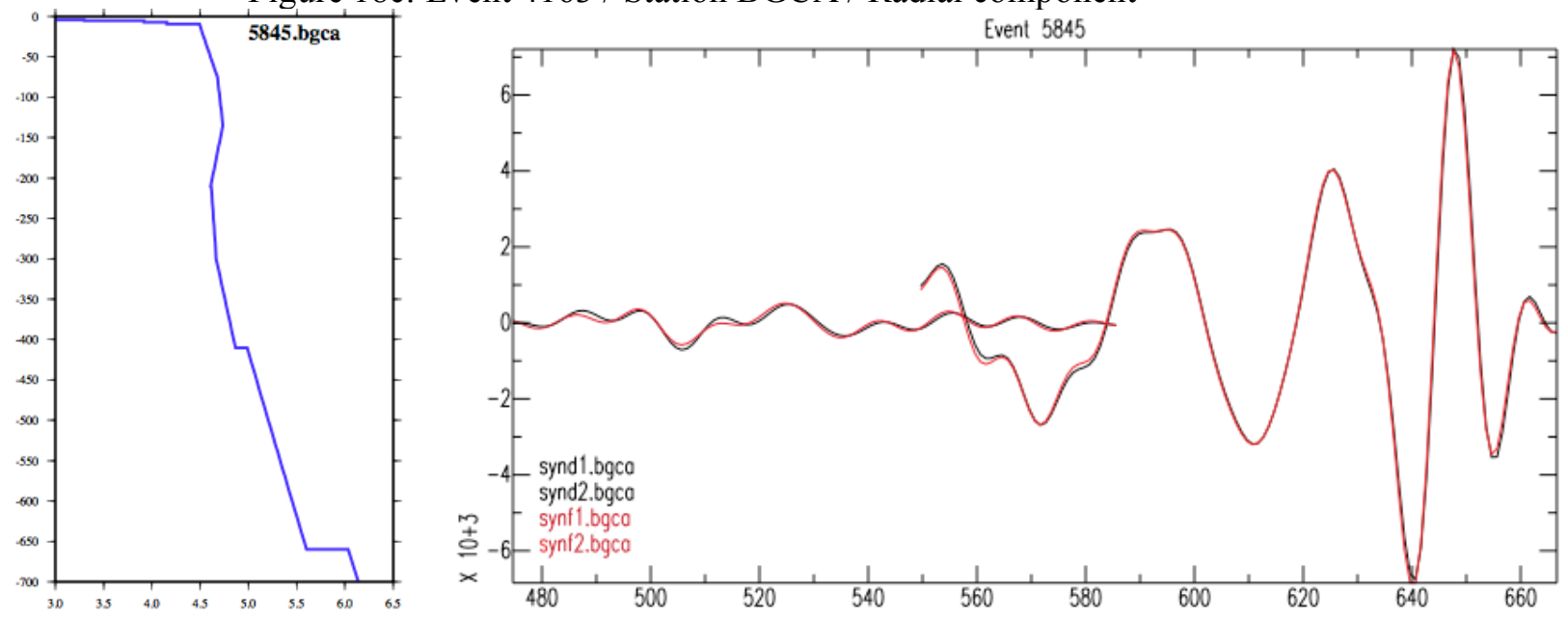

Figure 18d: Event 5845 / Station BGCA / Transverse component
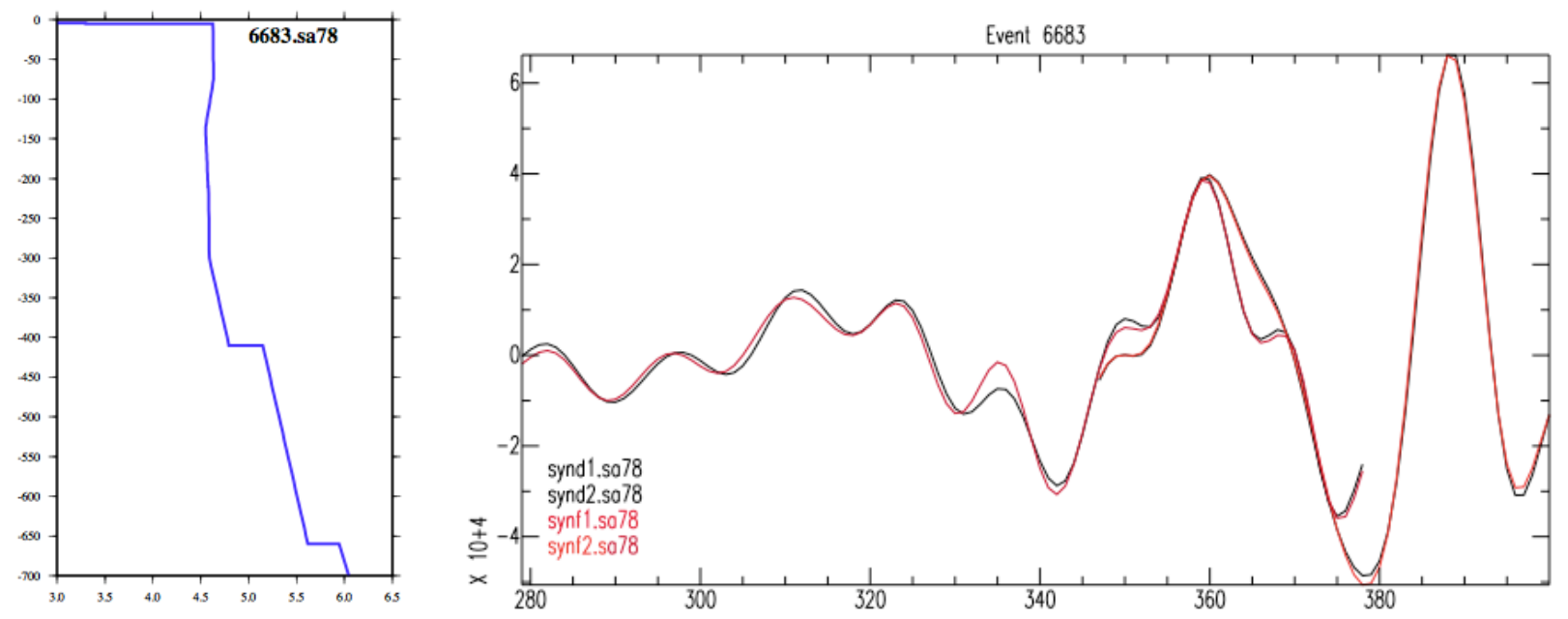

Figure 18e: Event 6683 / Station SA78SA / Transverse component 

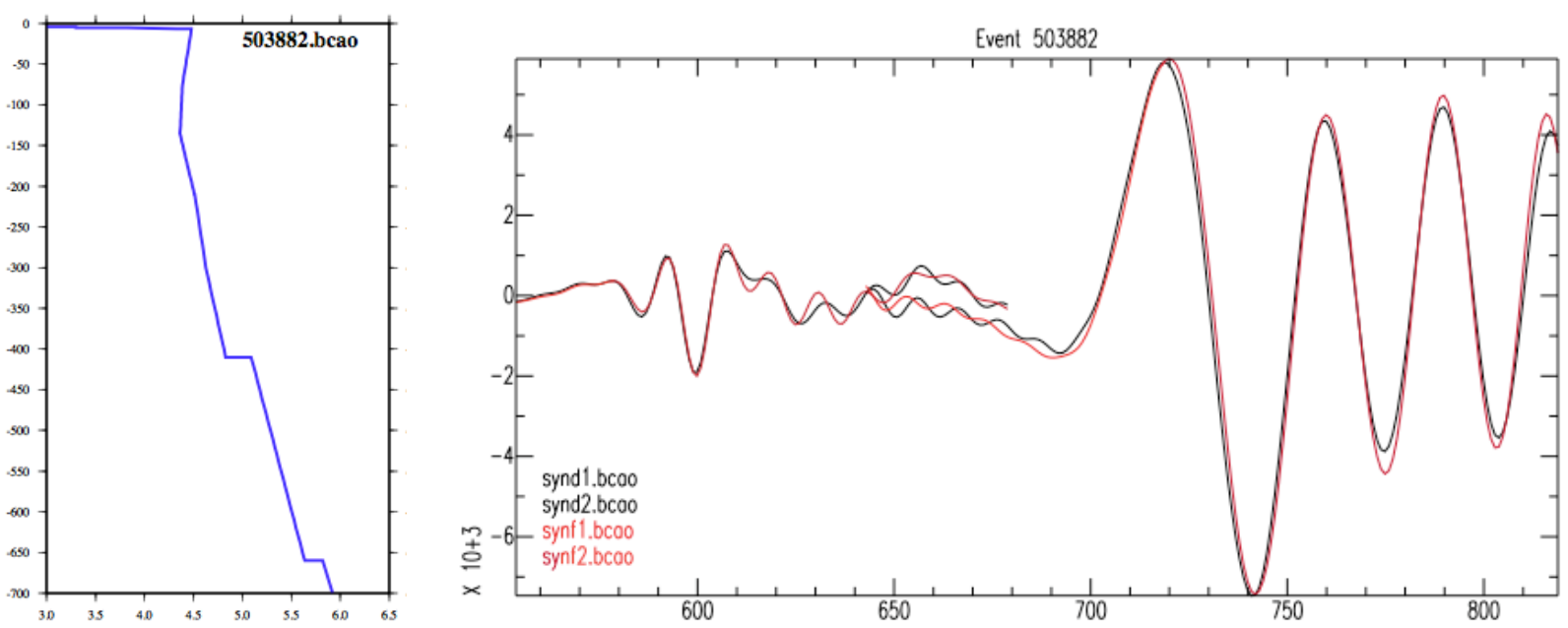

Figure 18f: Event 503882 / Station BCAO / Vertical component
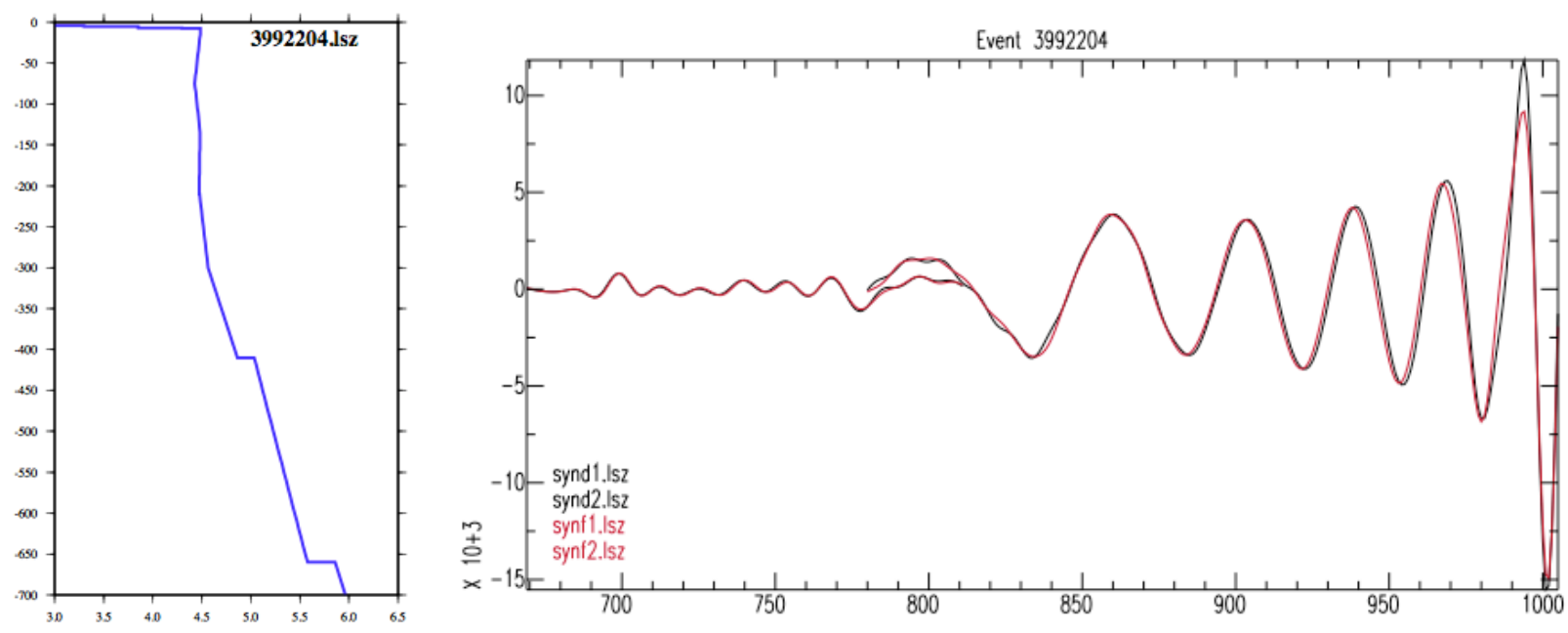

Figure 18g: Event 3992204 / Station LSZ / Transverse component
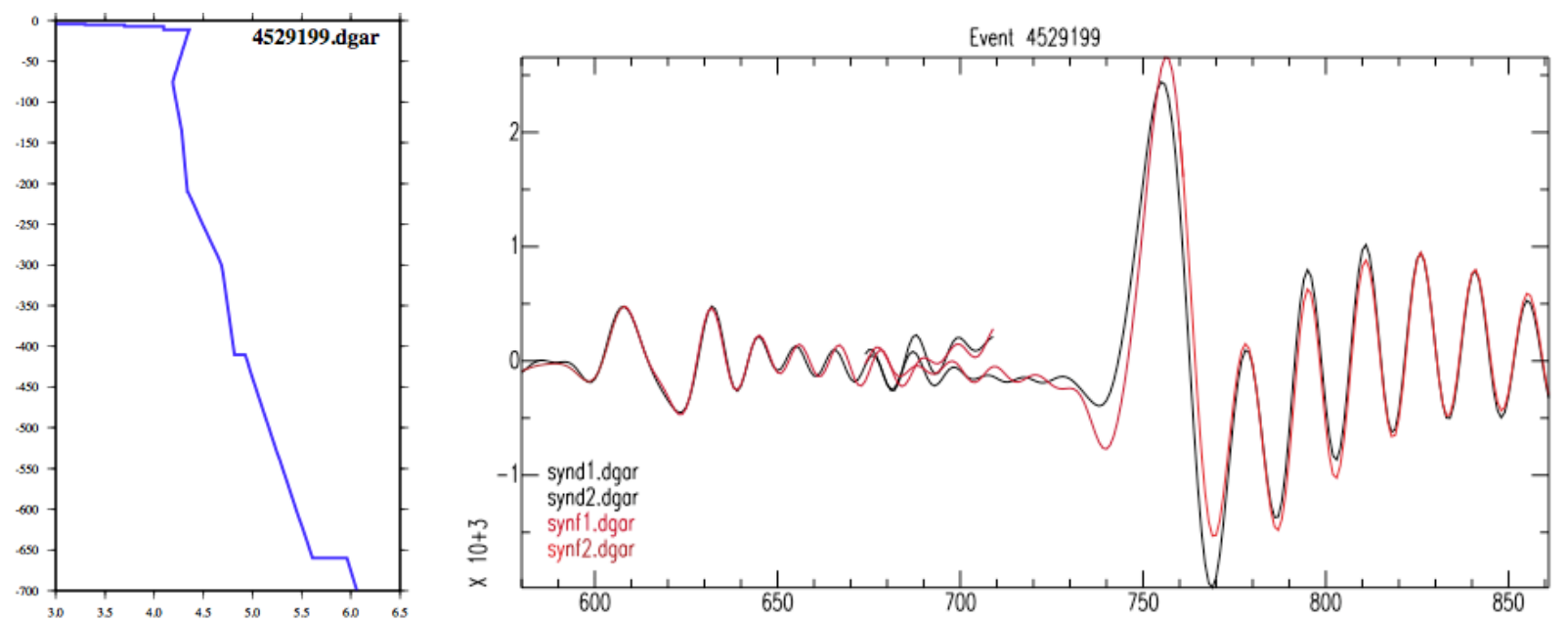

Figure 18h: Event 4529199 / Station DGAR / Vertical component 


\section{IV.) NEA Dataset}

The waveforms in this dataset were selected to improve coverage of the Northeastern quadrant of Africa, including the Arabian Peninsula. This waveforms in this dataset record primarily Middle Eastern and Mediterranean events at seismic stations BCAO and BNG in the Central African Republic, and at the PASSCAL Tanzania BB Experiment Array, which was deployed from 1994 to 1995 and sits on the Tanzanian craton (Nyblade et al., 1996). The raypath coverage of this dataset sparsely covers the West African Craton, the Red Sea and the rifting of the Arabian and Nubian Shields, as well as a portion of the East African Rift.

These paths were almost exclusively long, with great circle arcs over $40^{\circ}$. Of the $\sim 1000$ original waveforms, approximately $25 \%$ were discarded, and a little less than $20 \%$ were successfully fit. Those fit are shown in Figure 19.

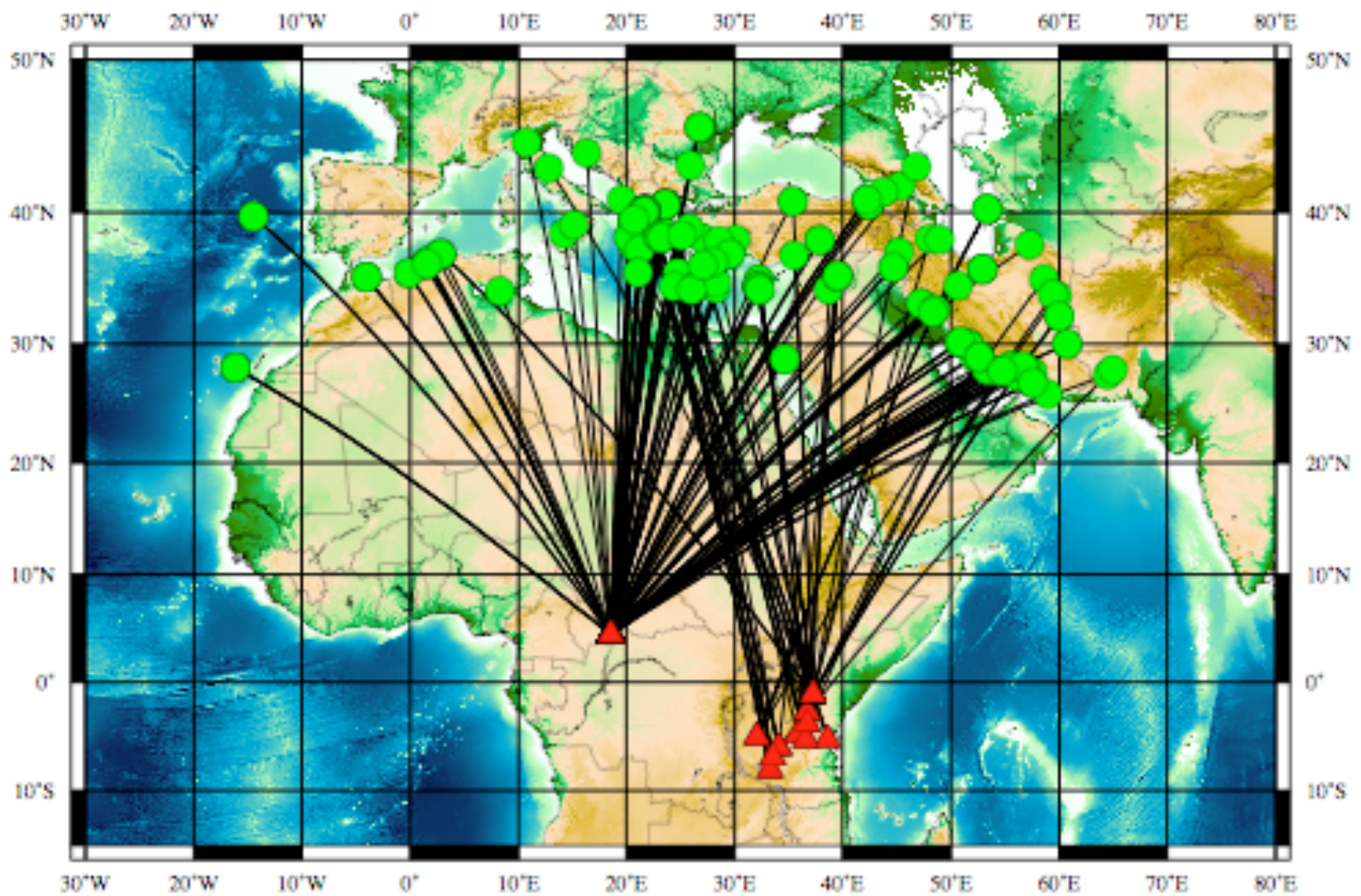

Figure 19: Raypaths fit for the NEA dataset.

\section{Example Waveforms \\ Rejected Data}

Similar problems were encountered as with other datasets, resulting in rejected waveforms - primarily, bad signal-to-noise ratios for weak and distant events, long and high period noise that interfered with the desired frequency band. And example is shown in Figure 20. 


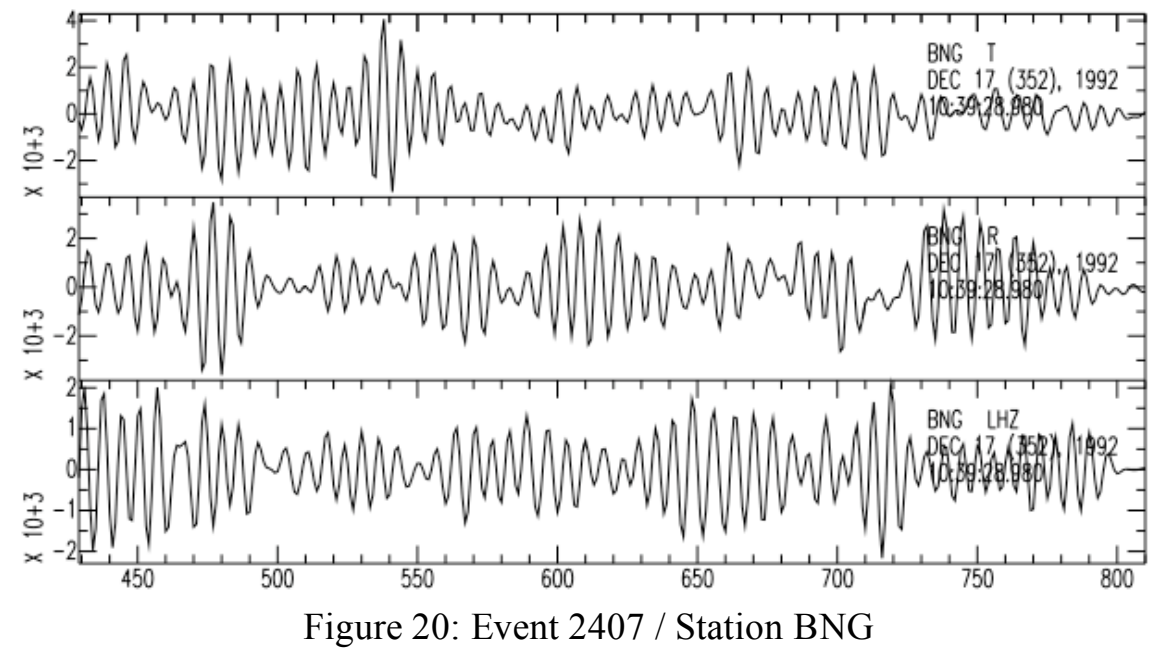

\section{Difficult Paths/ Events}

Figures 21 and 22 show waveforms for which the waveform fitting solution could not converge to an acceptable 1D velocity solution. In all three examples, the signal is strong, as are the body and surface waves. Both Figures 21 and 23 have long wavepaths and are recorded in the Central African Republic, with the event for the waveform shown in Figure 21 occurring on the Iran/ Persian Gulf border, and for Figure 23 occurring in the Caspian Sea region. Figure 22 is from a shallow event in Southern Greece that crosses the Mediterranean and is also recorded in the Central African Republic.

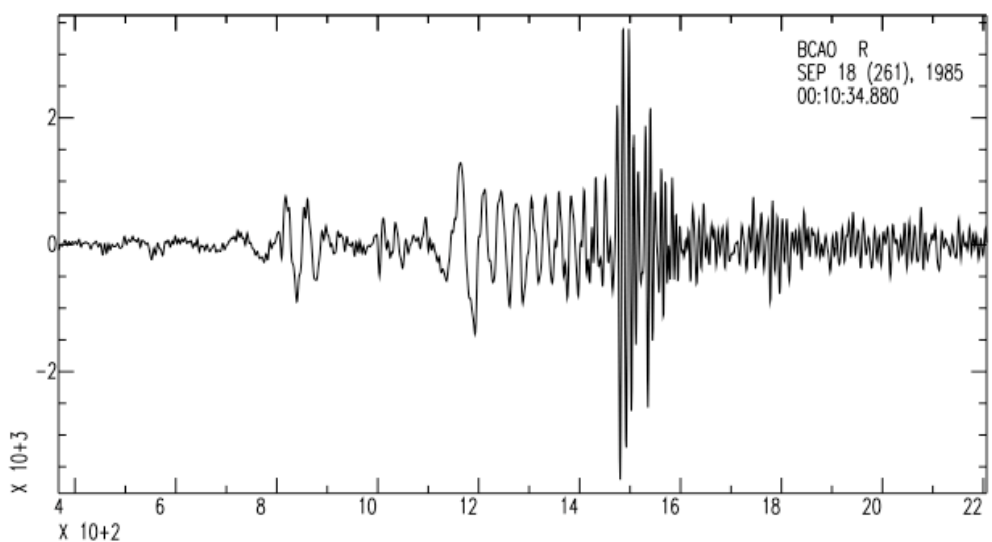

Figure 21: Event 554884 / Station BCAO / Radial Component

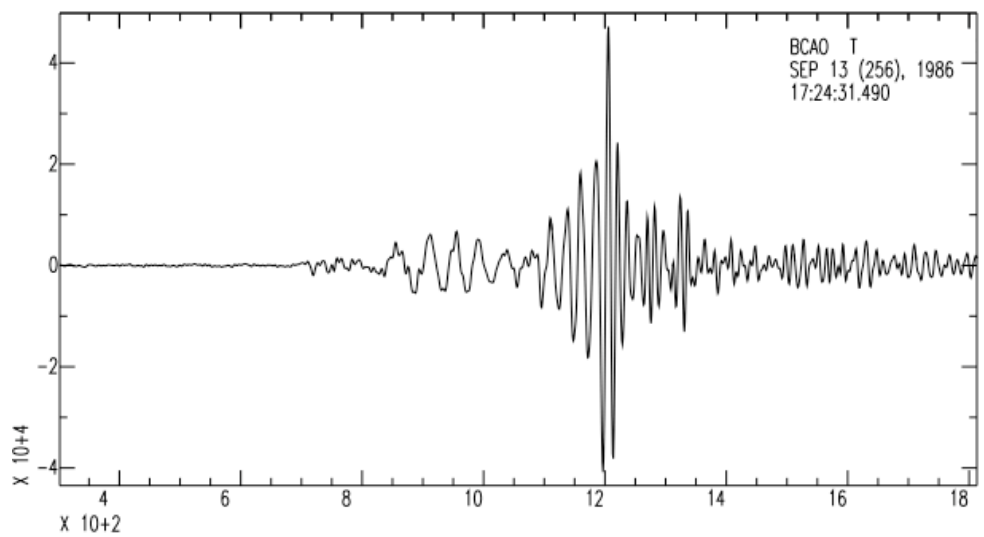

Figure 22: Event 568174 Station BCAO / Transverse Component 


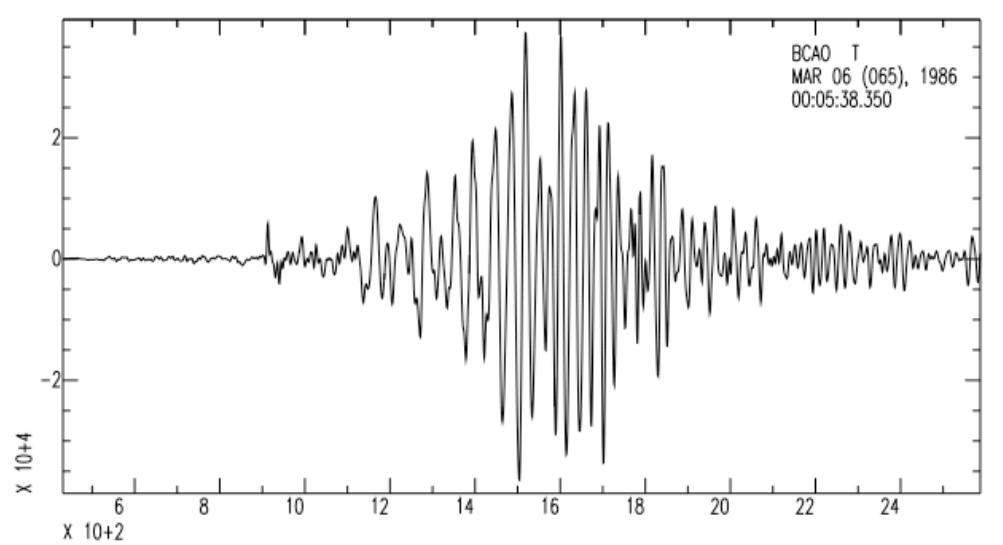

Figure 23: Event 561114 / Station BCAO / Transverse Component

\section{Good Waveform Fits}

This dataset was not too hard to fit waveforms to, although the long paths of the waveforms did cause more problems than is generally experienced. A map of the raypaths of some example waveforms is shown in Figure 24, and the waveforms, their synthetic fits, and resultant 1D $S$-velocity models are shown in Figures $24 \mathrm{a}-24 \mathrm{~h}$. The majority of the 1D models show some type of cratonic structure, as is expected in this region. The cratonic signature may be slightly damped as the 1D model must also account for the more active, slower velocity regions in the Mediterranean Sea, and areas of current rifting.

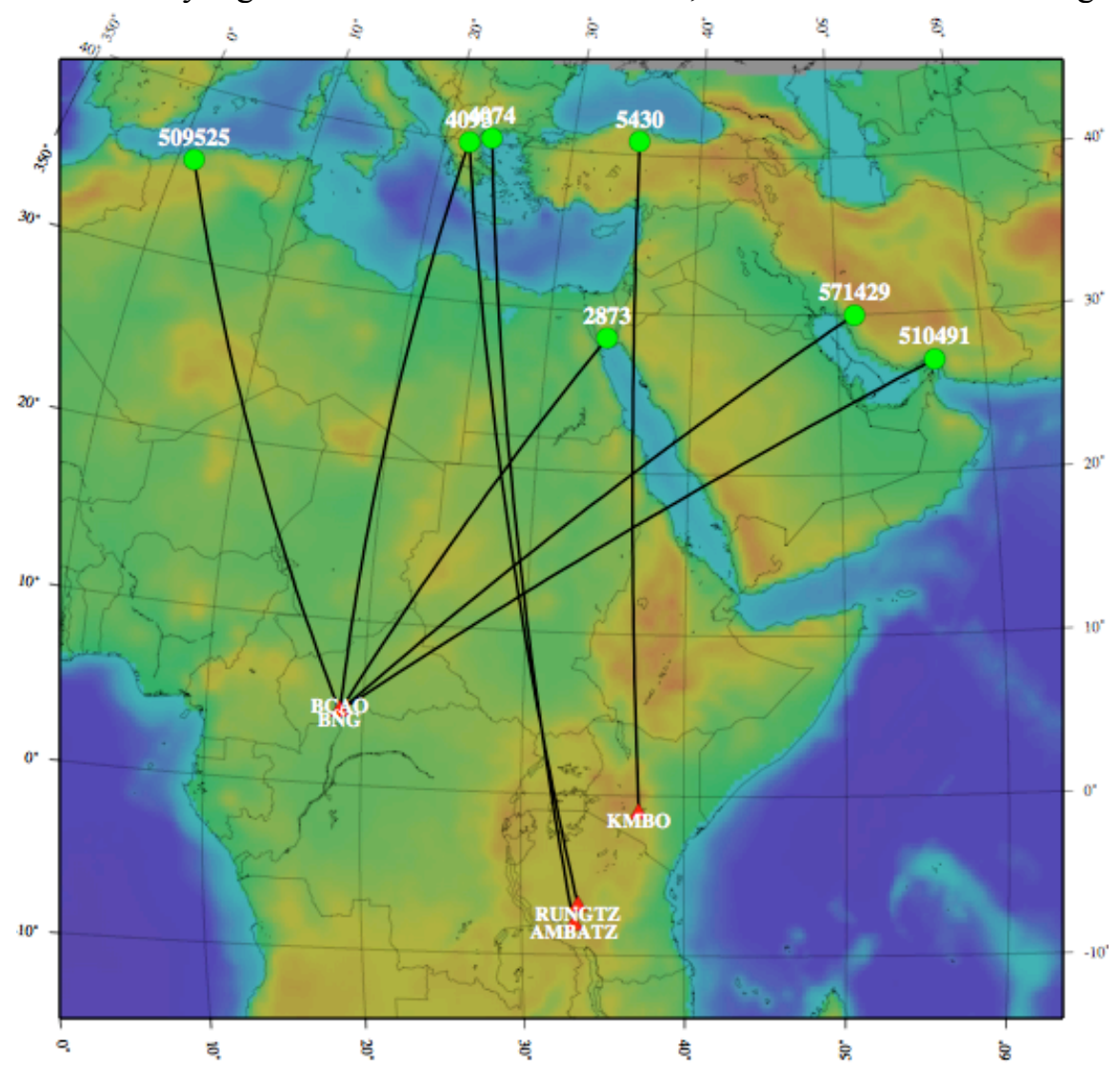

Figure 24: Raymap of good events shown 

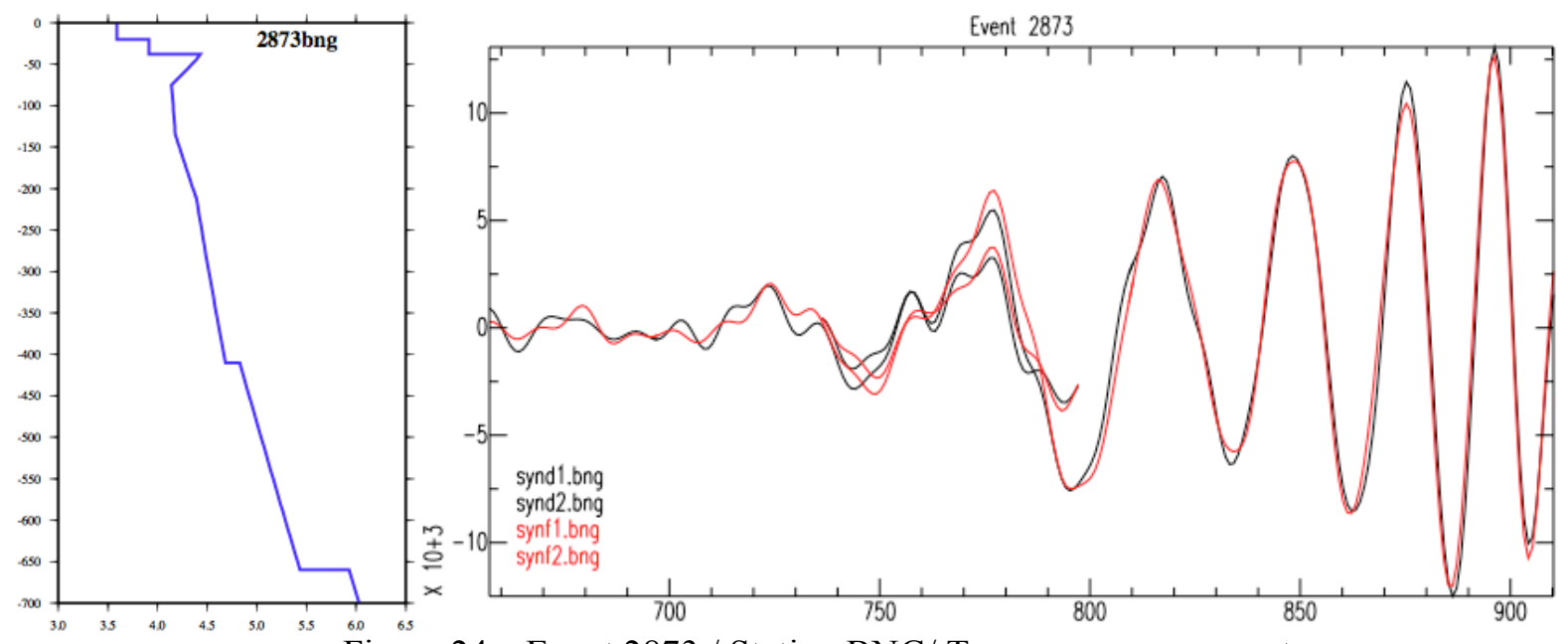

Figure 24a: Event 2873 / Station BNG/ Transverse component
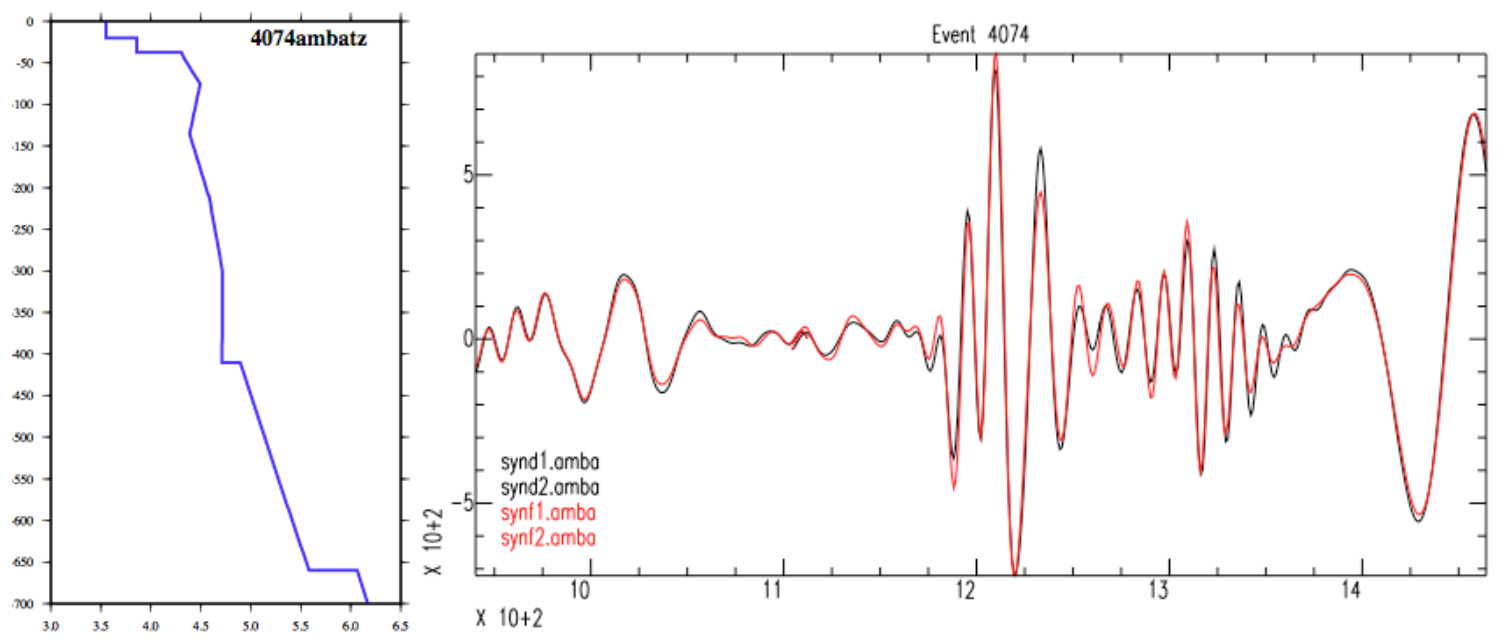

Figure 24b: Event 4074 / Station AMBATZ / Vertical component
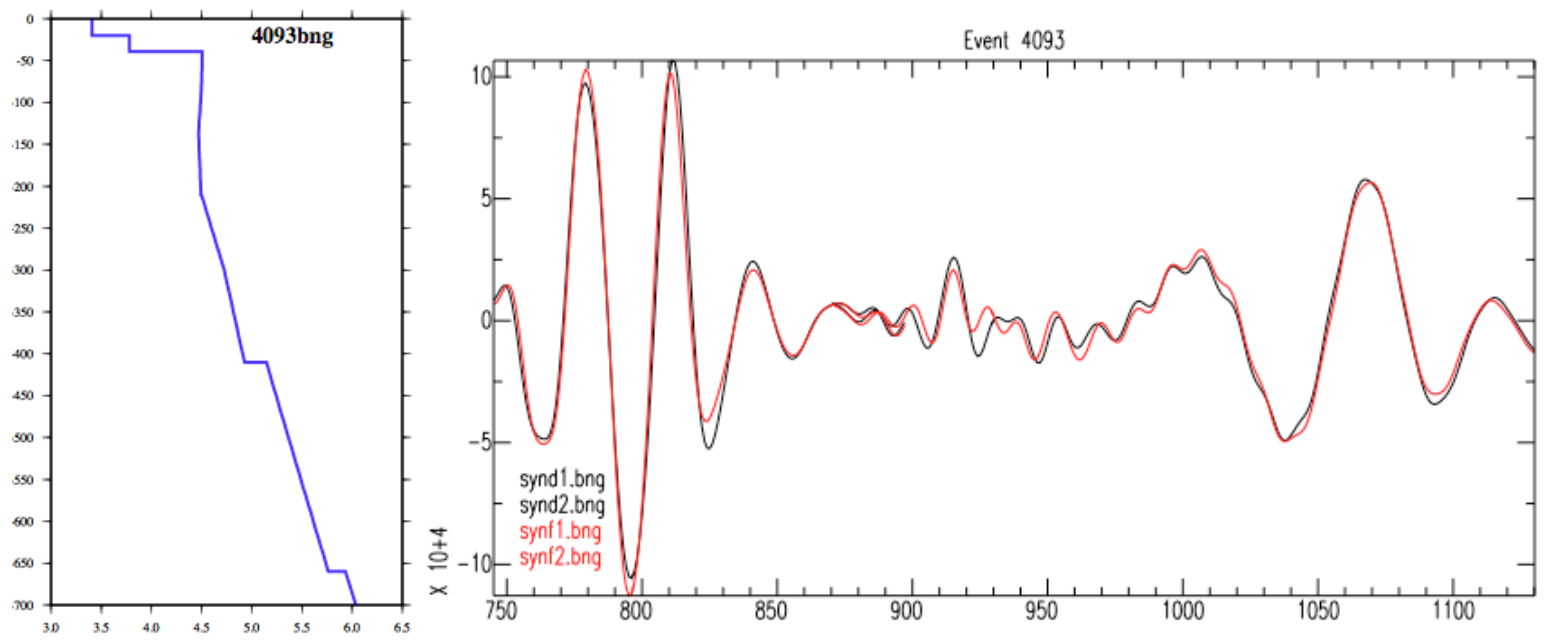

Figure 24c: Event 4093 / Station BNG / Radial component 

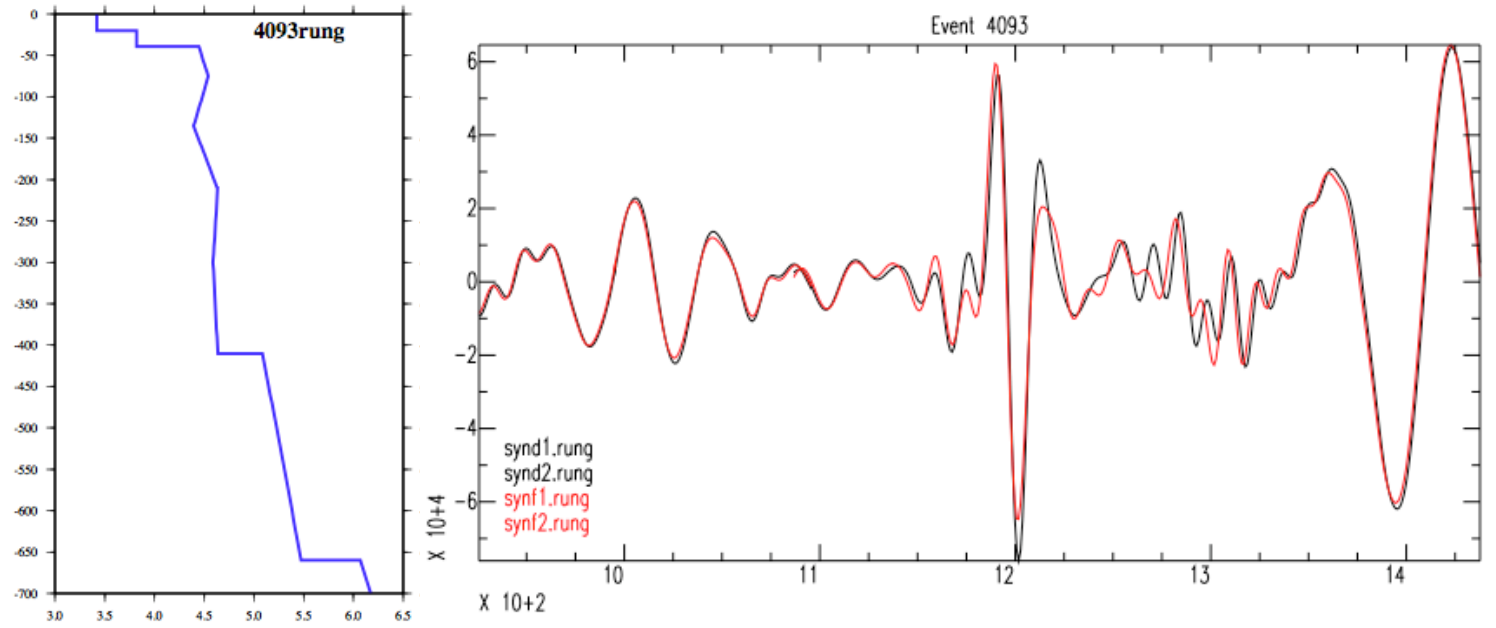

Figure 24d: Event 4093 / Station RUNGTZ / Vertical component
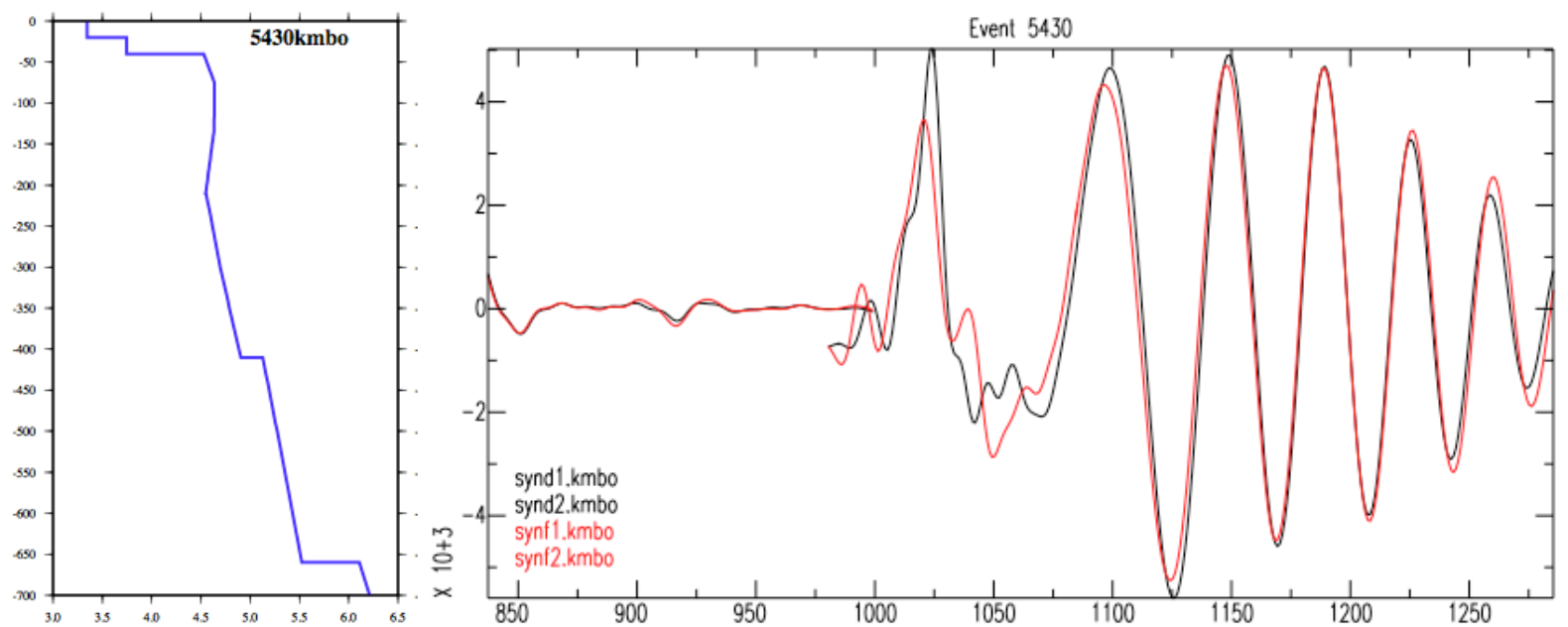

Figure 24e: Event 5430 / Station KMBO / Transverse component
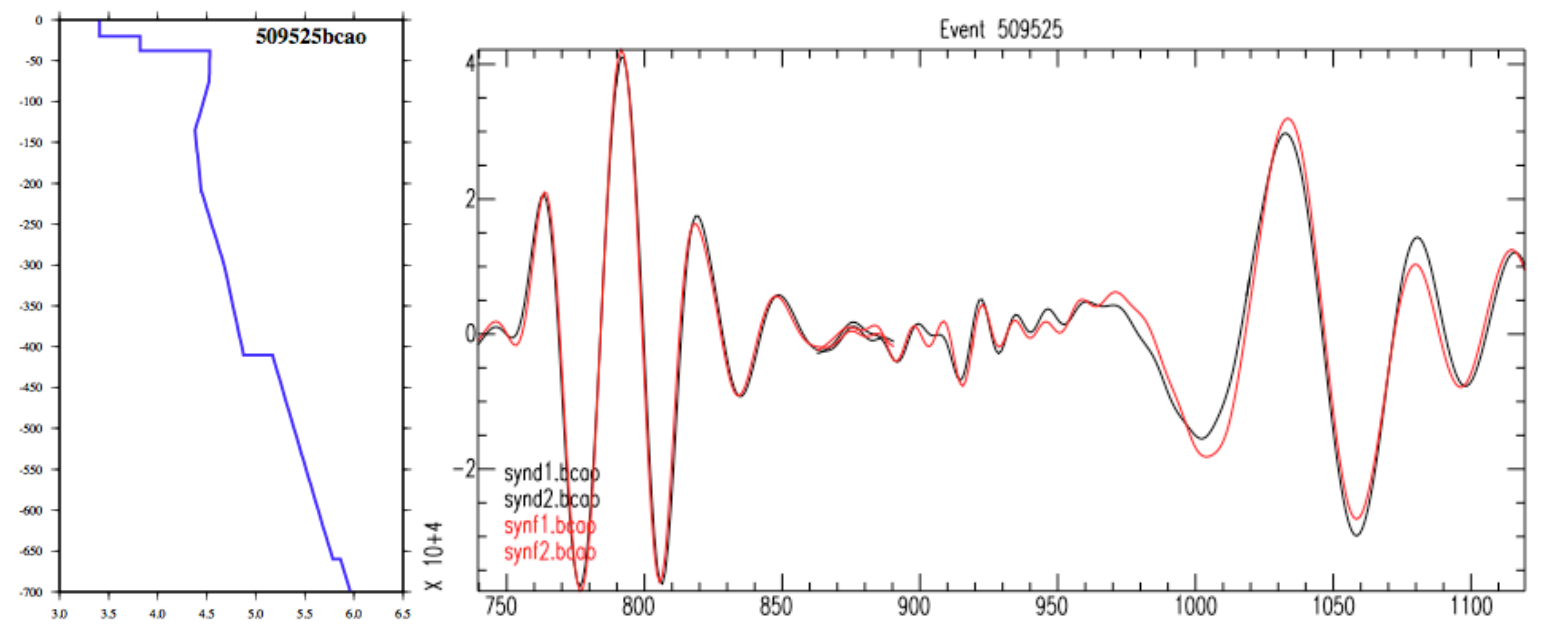

Figure 24f: Event 509525 / Station BCAO / Radial component 

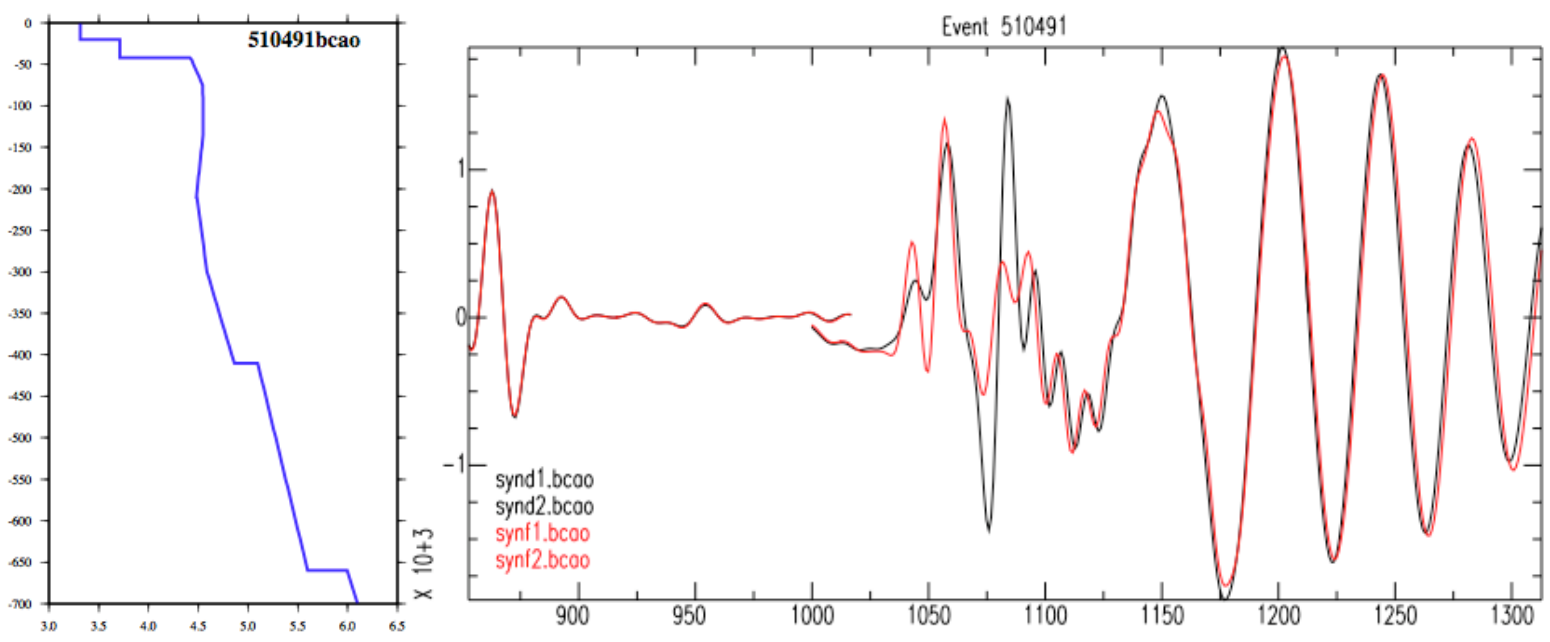

Figure 24g: Event 510491 / Station BCAO / Transverse component
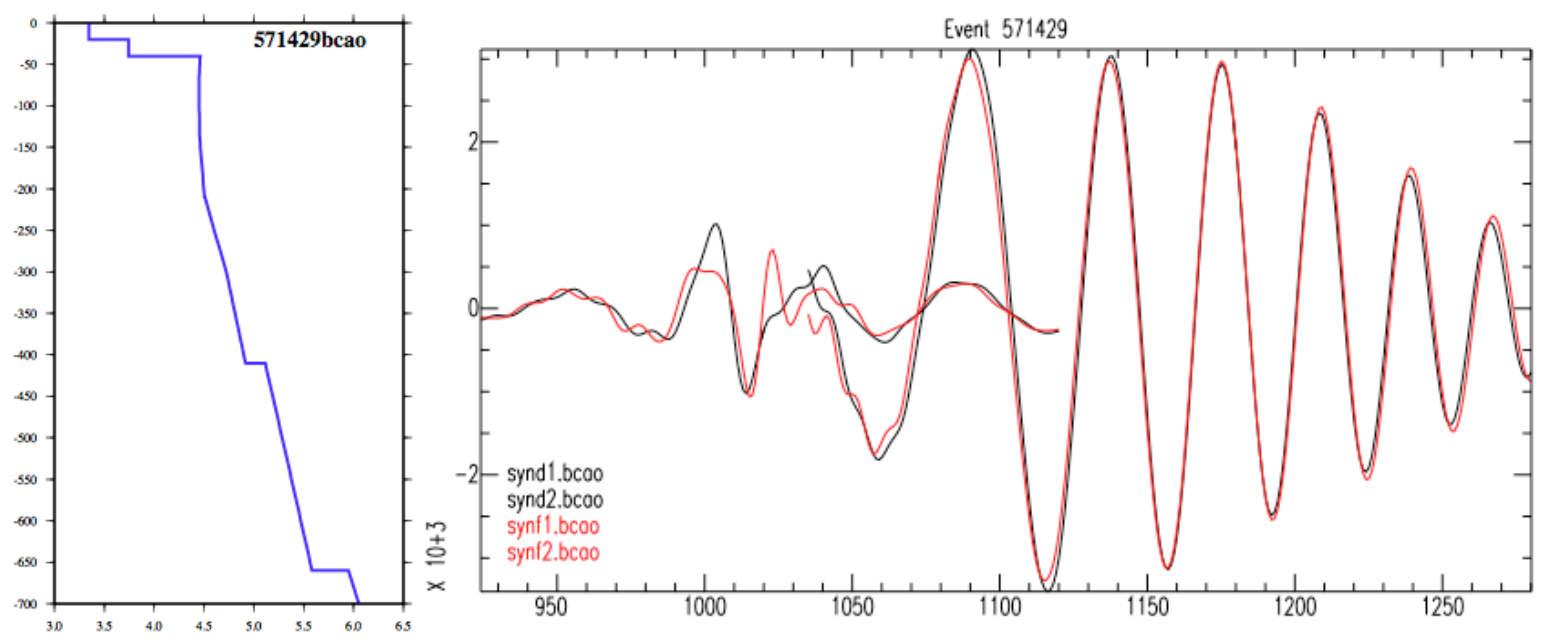

Figure 24h: Event 571429 / Station BCAO / Transverse component 


\section{RedSea Dataset}

The RedSea dataset only consists of 180 waveforms between the three components. This small dataset was used to address raypath coverage gaps that existed in the vicinity of the Red Sea using events that are $m_{\mathrm{b}} 4.4$ to 4.99 , with short paths of less than 20 degrees. The events used occurred in the Red Sea, as shown in Figure 25.

Out of this set, roughly $1 / 3$ of the waveforms were fit, and $1 / 3$ were discarded due to bad signal. As previously mentioned, the main tectonic feature of this region is the Red Sea Rift, which is splitting apart the Nubian and Arabian Shields. Some of the raypaths also cover the eastern Mediterranean Sea, and portions of the Middle East.

\section{Example Waveforms Rejected Data}

Figures 26 - 28 show examples of waveforms that were rejected. The waveforms shown in Figures 26 and 27 had a relatively high amount of noise, which could not be filtered out to retrieve a quality signal. Figure 28 shows waveforms that originated at the southern mouth of the Red Sea in Ethiopia and traveled straight up the Red Sea to be recorded at station EIL in Eilat, Israel.
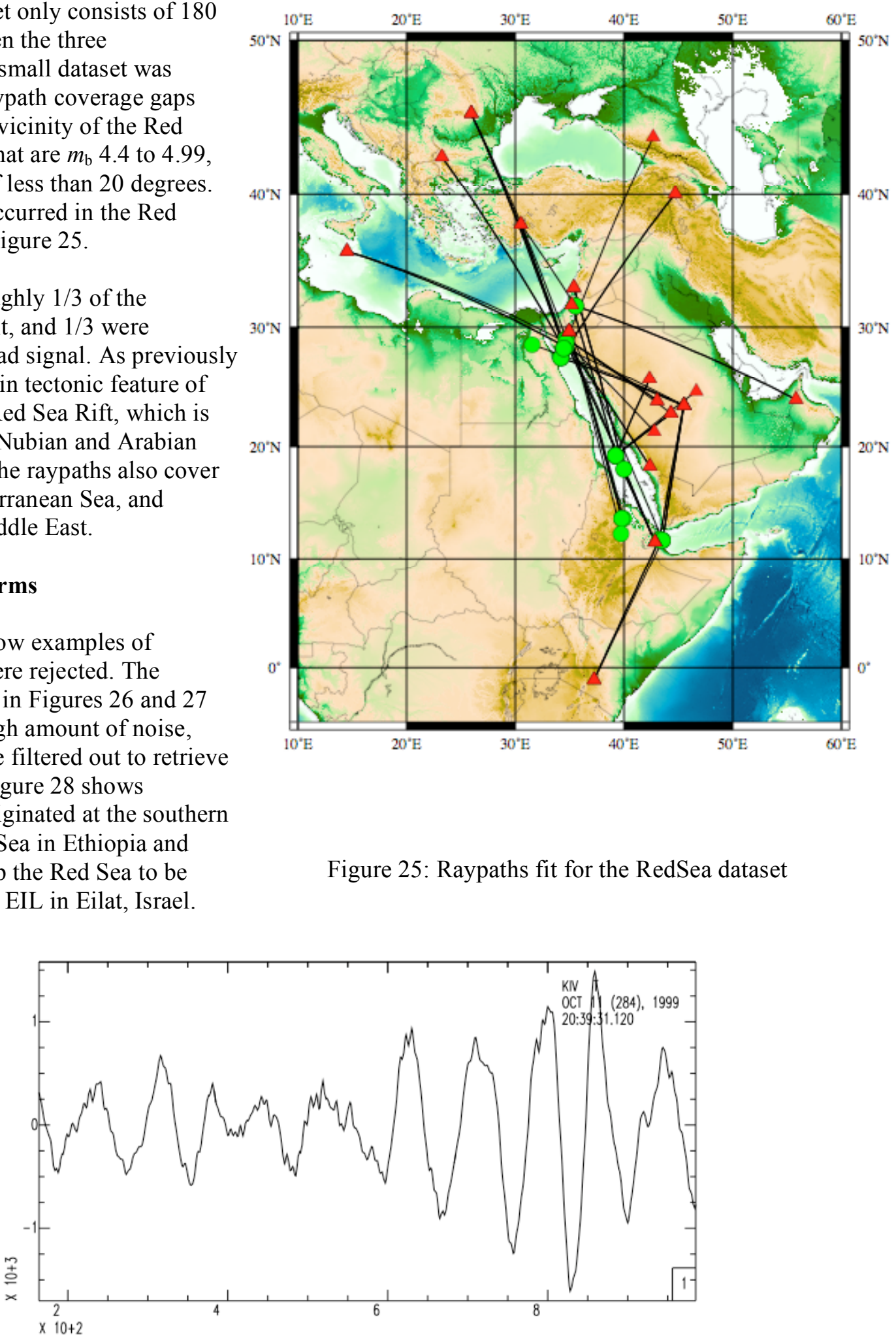

Figure 26: Event 1319354 / Station KIV/ Transverse component 


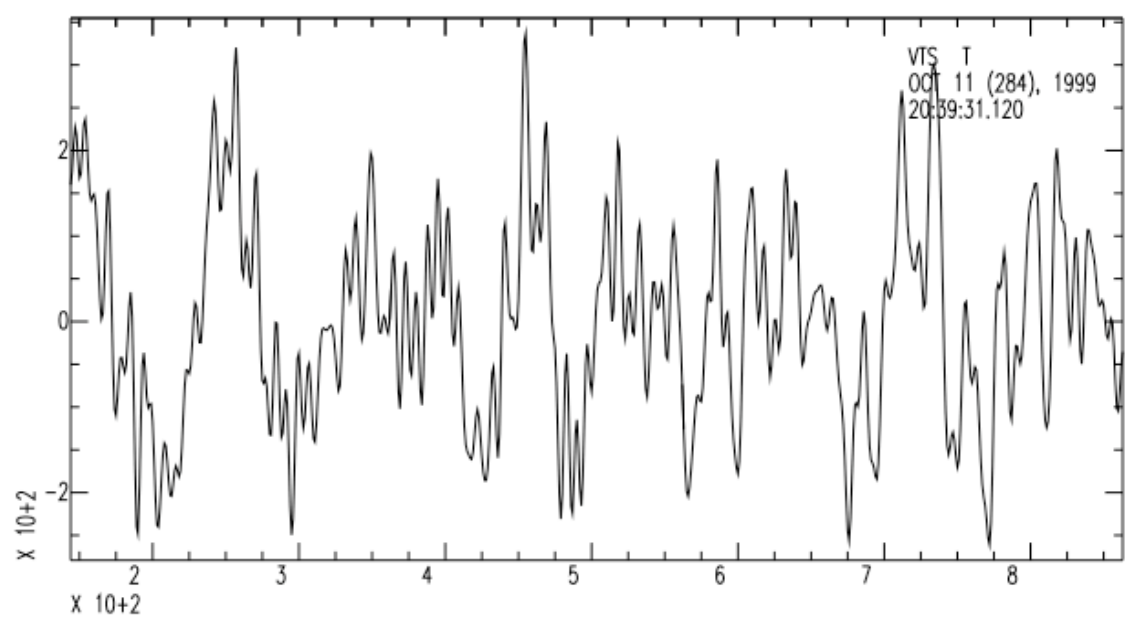

Figure 27: Event 1319354 / Station VTS/ Transverse component

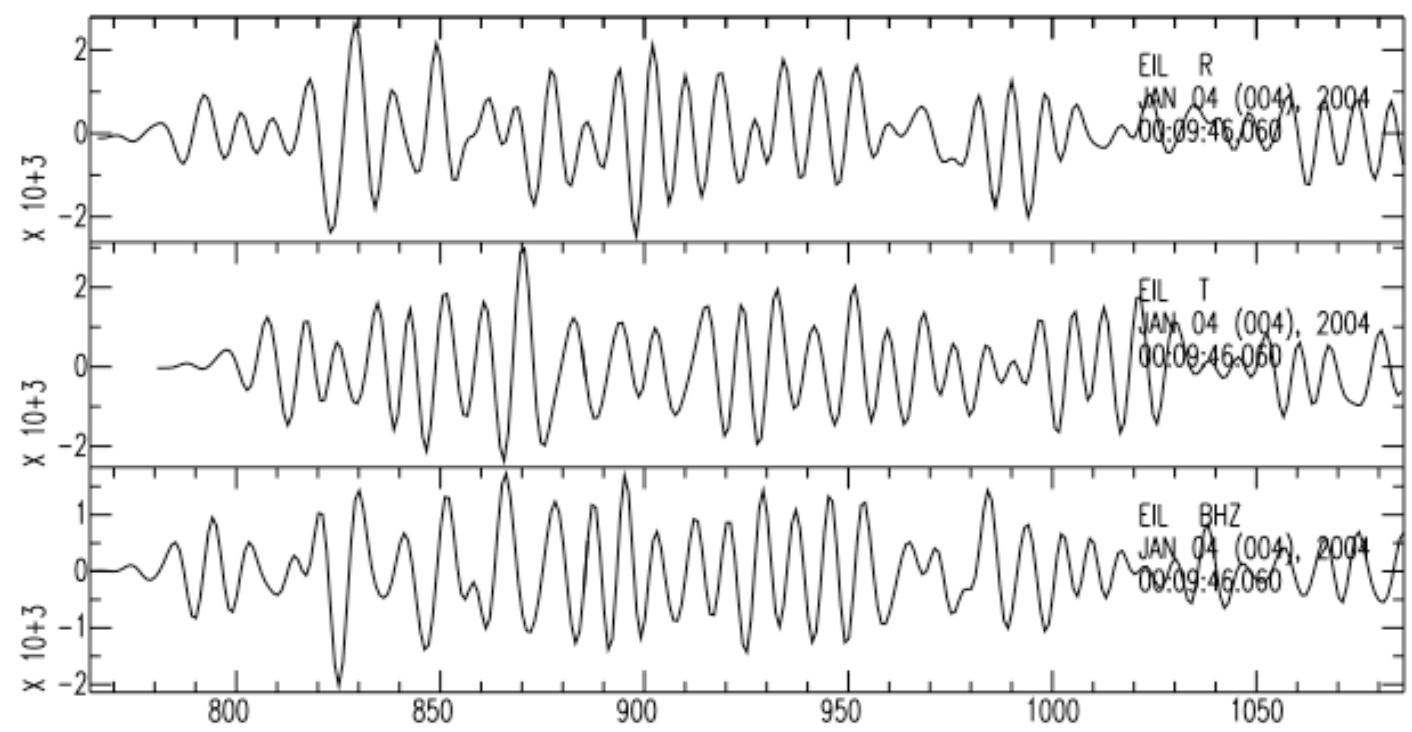

Figure 28: Event 4437000 / Station EIL / all components

\section{Difficult Paths/ Events}

Figures 29-31 show some of the waveforms that, while having a decent signal, to 1D solution could be converged upon. As shown below, a relatively high number of difficult waveforms occurred in the Red Sea and then were recorded is Israel. The event in Figure 29 occurred in the central portion of the Red Sea, and was recorded in Jerusalem, while those shown in Figures 30 and 31 occurred at the southern mouth of the Red Sea and were recorded in Eilat, Israel. In addition, these three events having differing focal mechanisms, and source radiation patterns, and the problem of convergence is not likely due to the stations lying in the radiation nulls. The problem with these fits may be that as the entire raypath lies within a rift, the $1 \mathrm{D}$ velocity solution may be too slow for convergence on a $1 \mathrm{D}$ model to occur. Some paths were fit with a similar raypath, as shown in Figure 25, but those that were able to be fit appear to be slightly askew of the traveling directly up the center of the rift. 


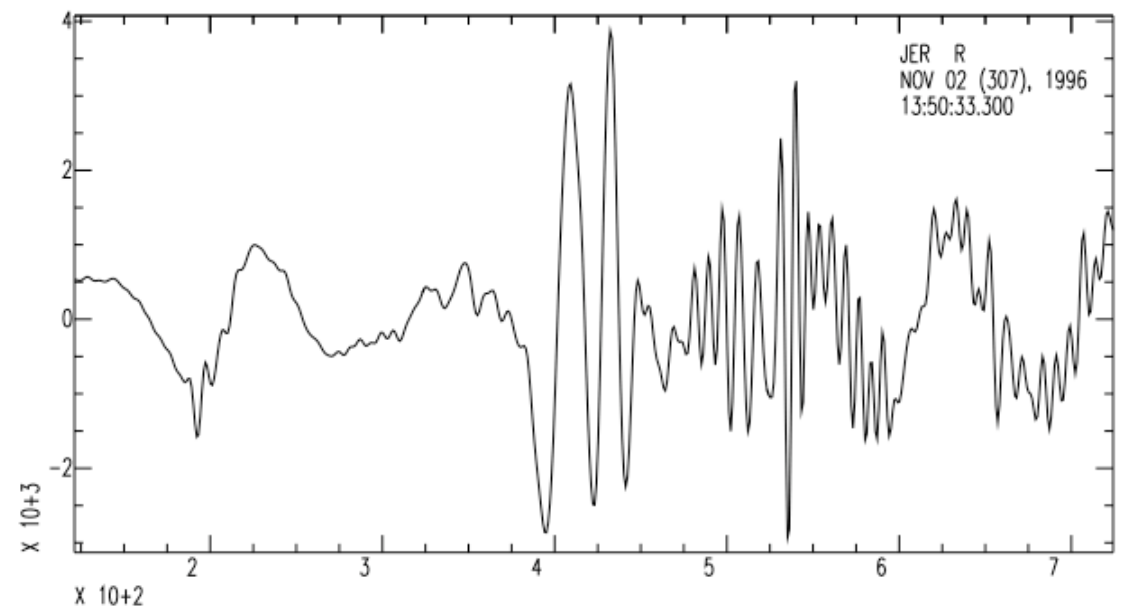

Figure 29: Event 5711 / Station JER / Radial component

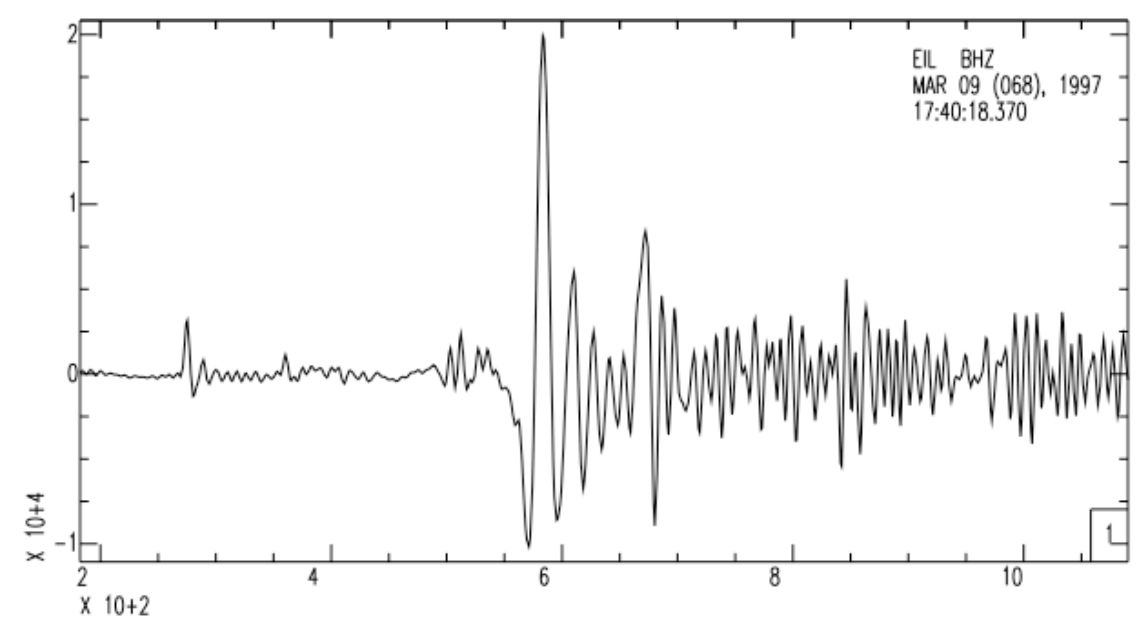

Figure 30: Event 6168 / Station EIL/ Vertical component

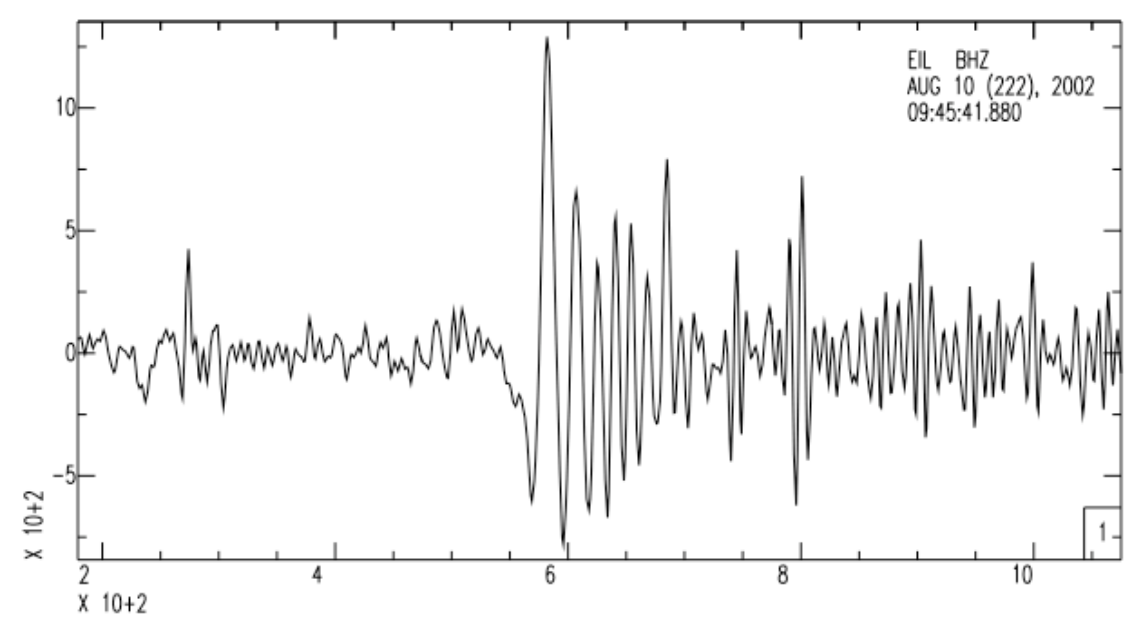

Figure 31: Event 3992189 / Station EIL / Vertical components 


\section{Good Waveform Fits}

Overall, a high percentage ( $\sim 33 \%$ ) was achieved within this dataset, demonstrating that in regions of sparse raypath coverage it may be beneficial to broaden the search parameter to include smaller magnitude events that are recorded at relatively close distances $\left(\right.$ gcarc $\left.<20^{\circ}\right)$. Within these examples, it becomes noticeable that the Arabian Shield has particularly low uppermost mantle velocities (Figures $32 \mathrm{c}-\mathrm{f}$ ). Also, Figure $32 \mathrm{~g}$, shows a waveform that traverses from the northern Red Sea to southernmost Russia - recorded in Kislovodsk, Russia - that shows a thin mantle lithosphere, as has previously been imaged beneath Turkey.

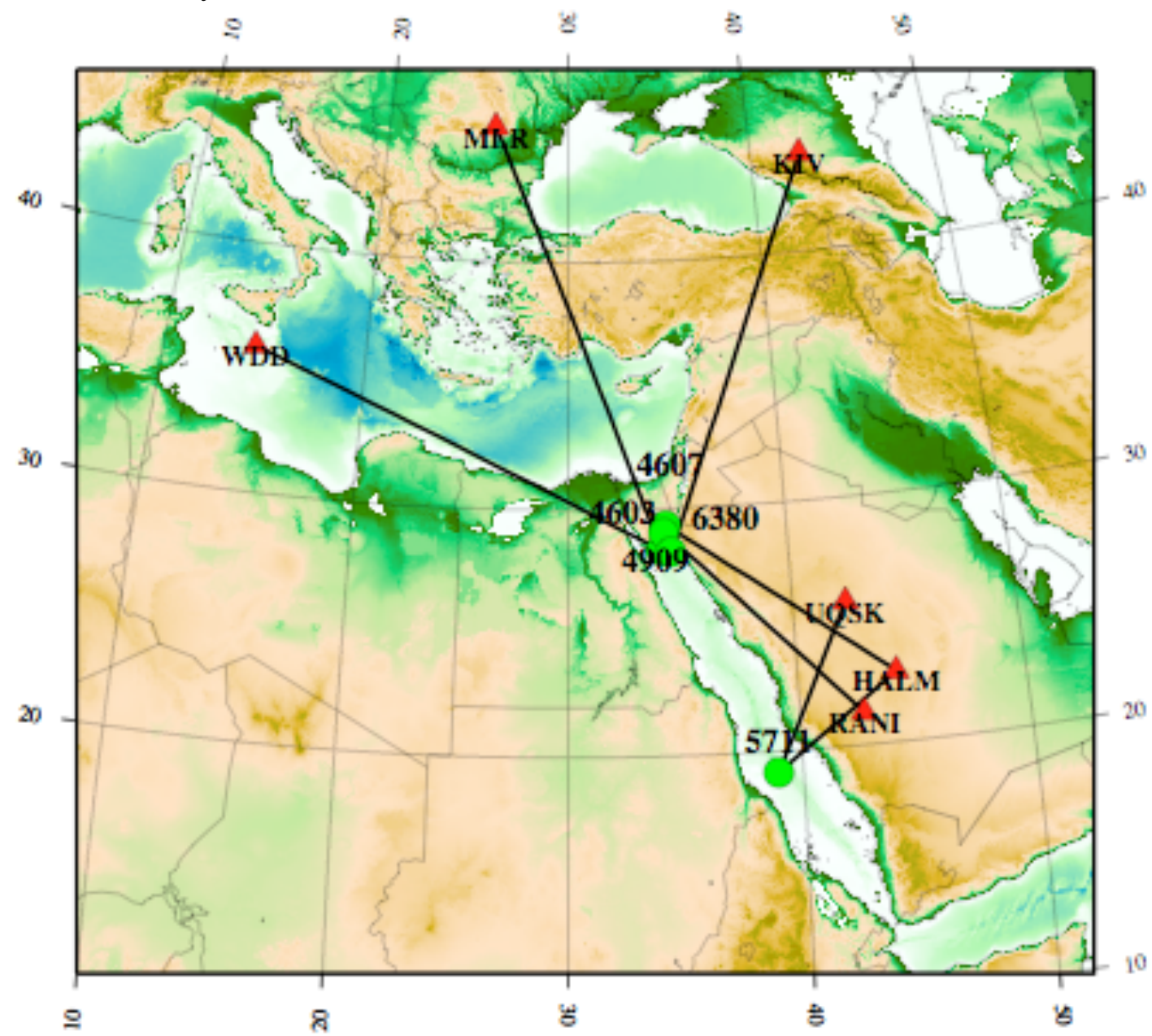

Figure 32: Raymap of example waveform fits shown in Figures $32 \mathrm{a}-32 \mathrm{~g}$. 

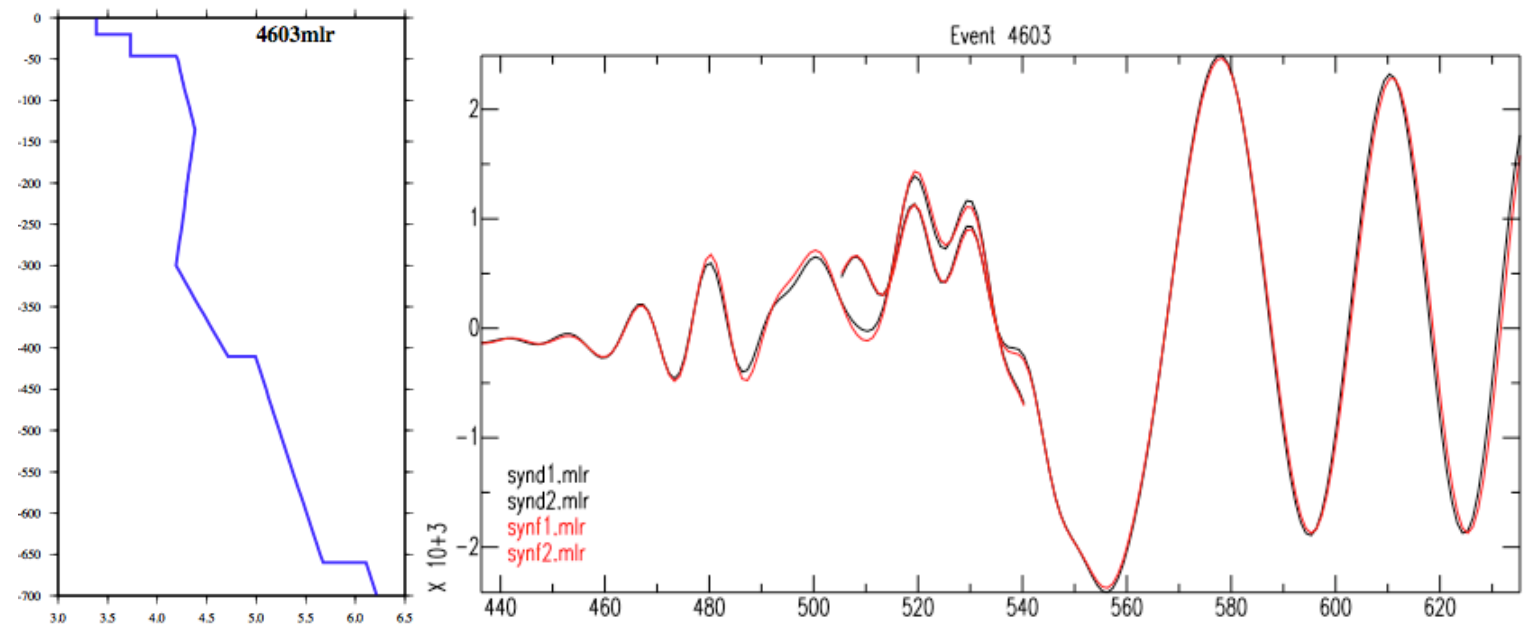

Figure 32a: Event 4603 / Station MLR / Vertical component
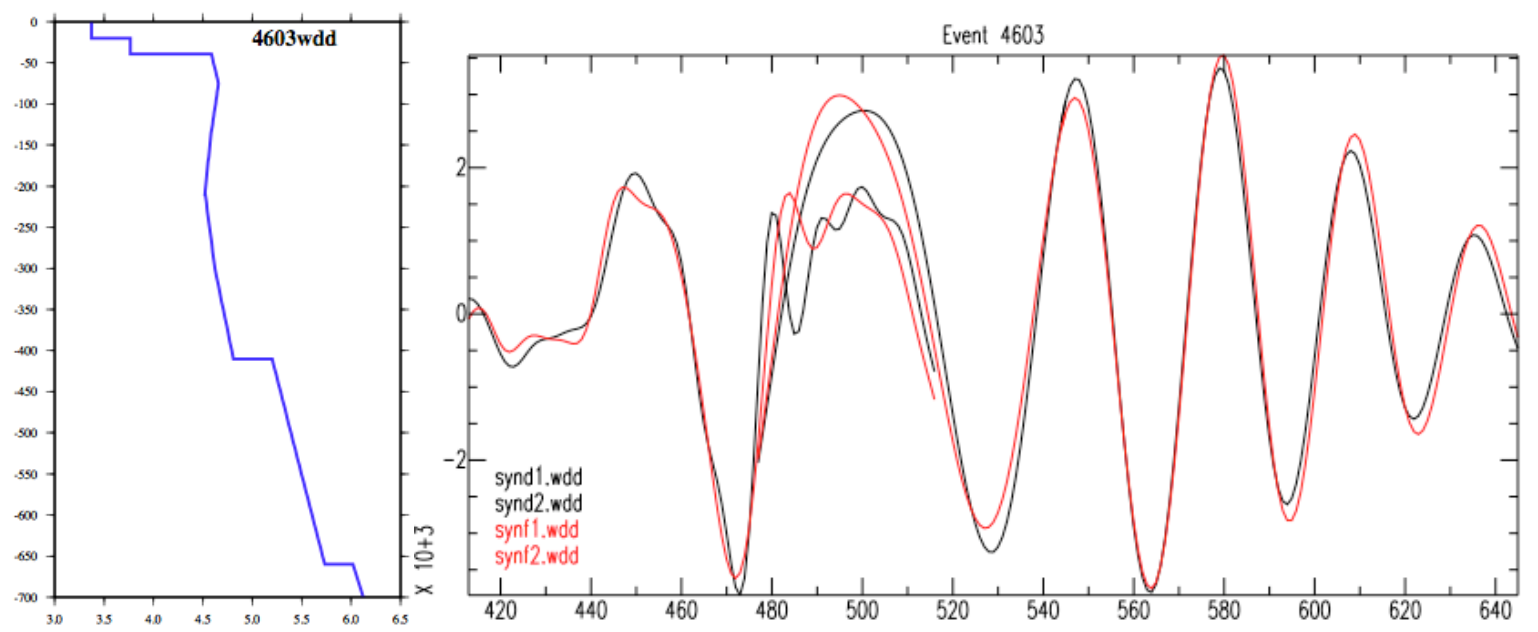

Figure 32b: Event 4603 / Station WDD / Transverse component
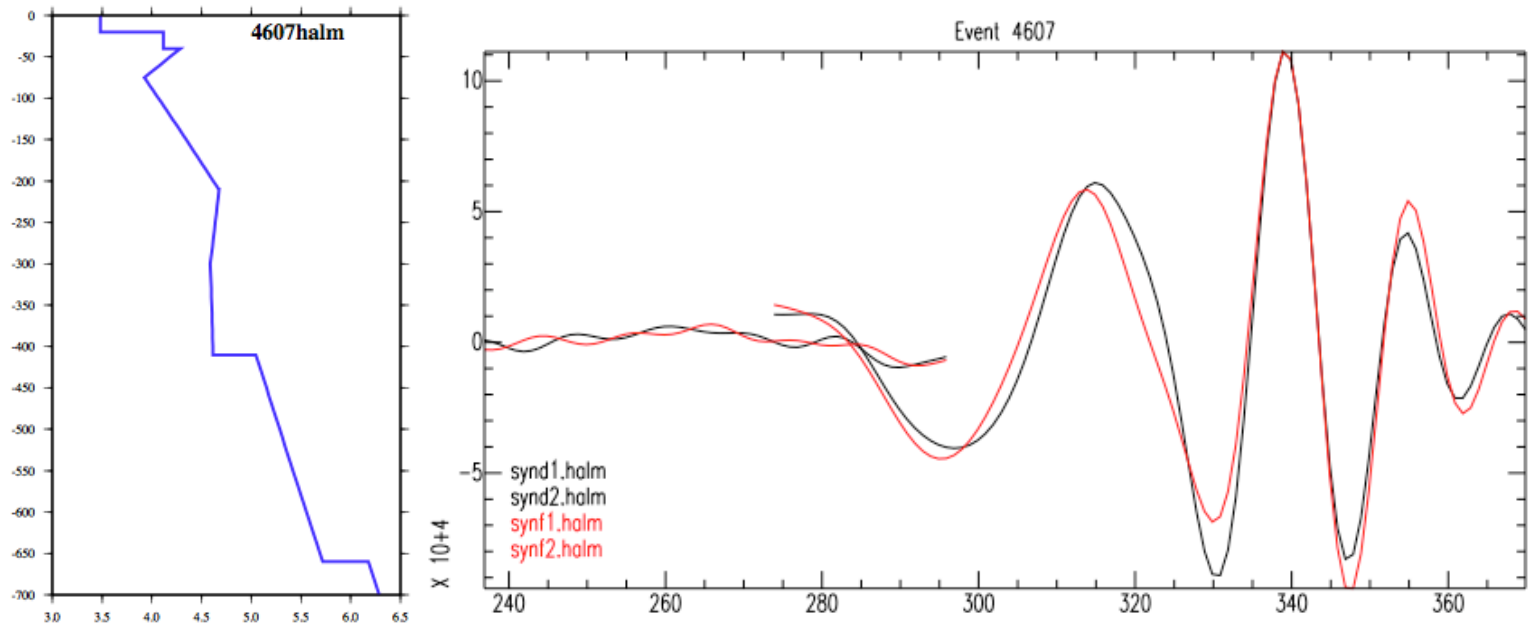

Figure 32c: Event 4607 / Station HALM / Transverse component 

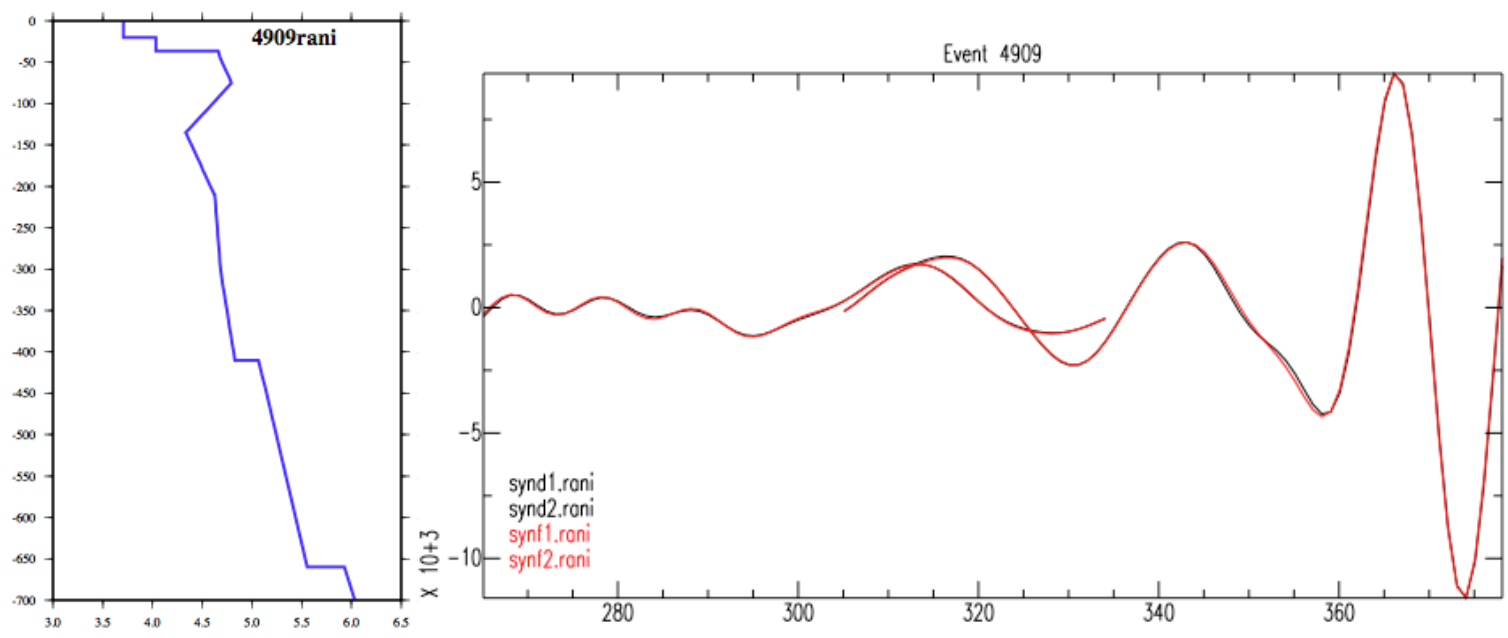

Figure 32d: Event 4909 / Station RANI / Vertical component
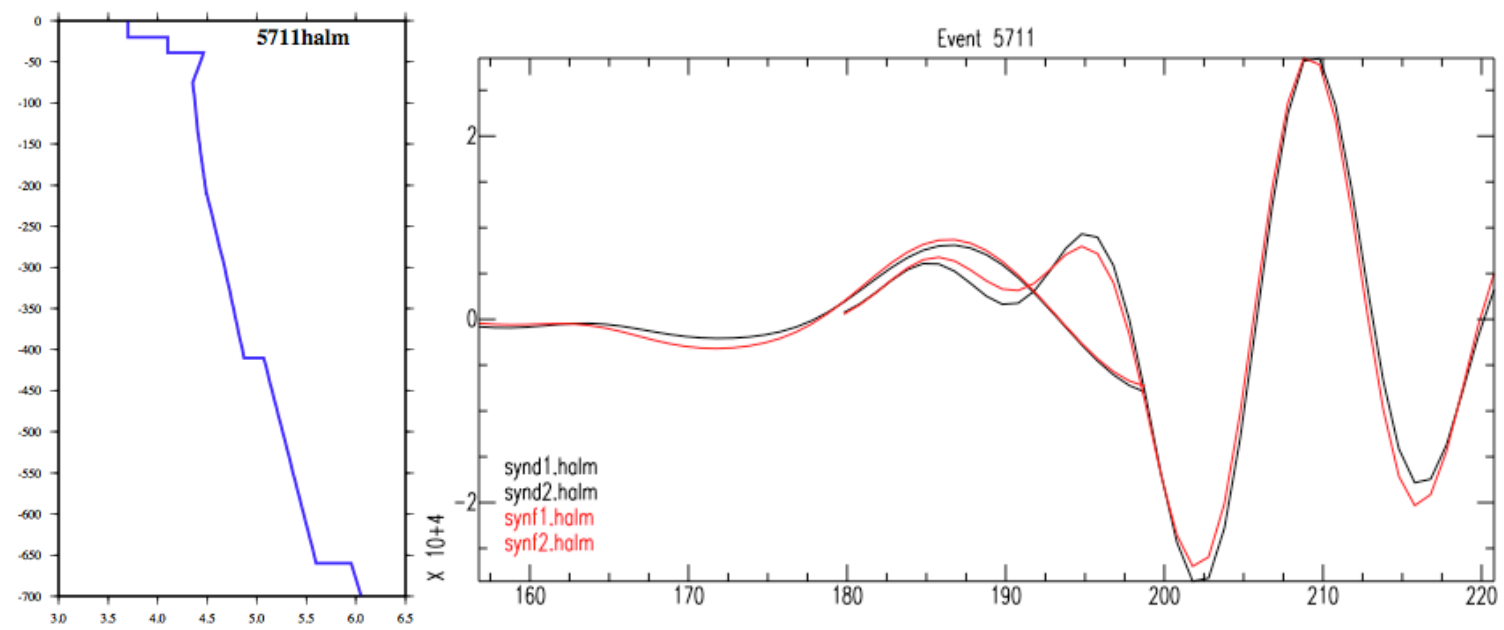

Figure 32e: Event 5711 / Station HALM / Radial component
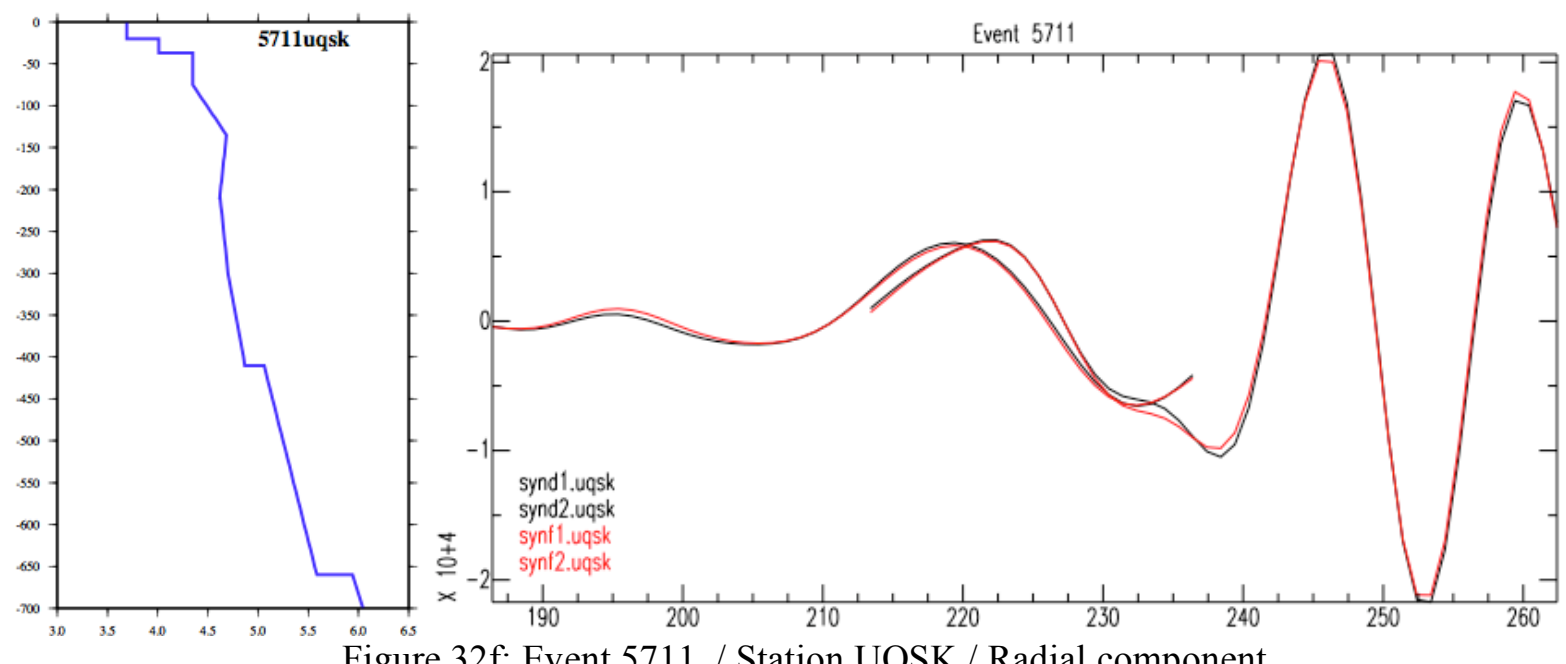

Figure 32f: Event 5711 / Station UQSK / Radial component 

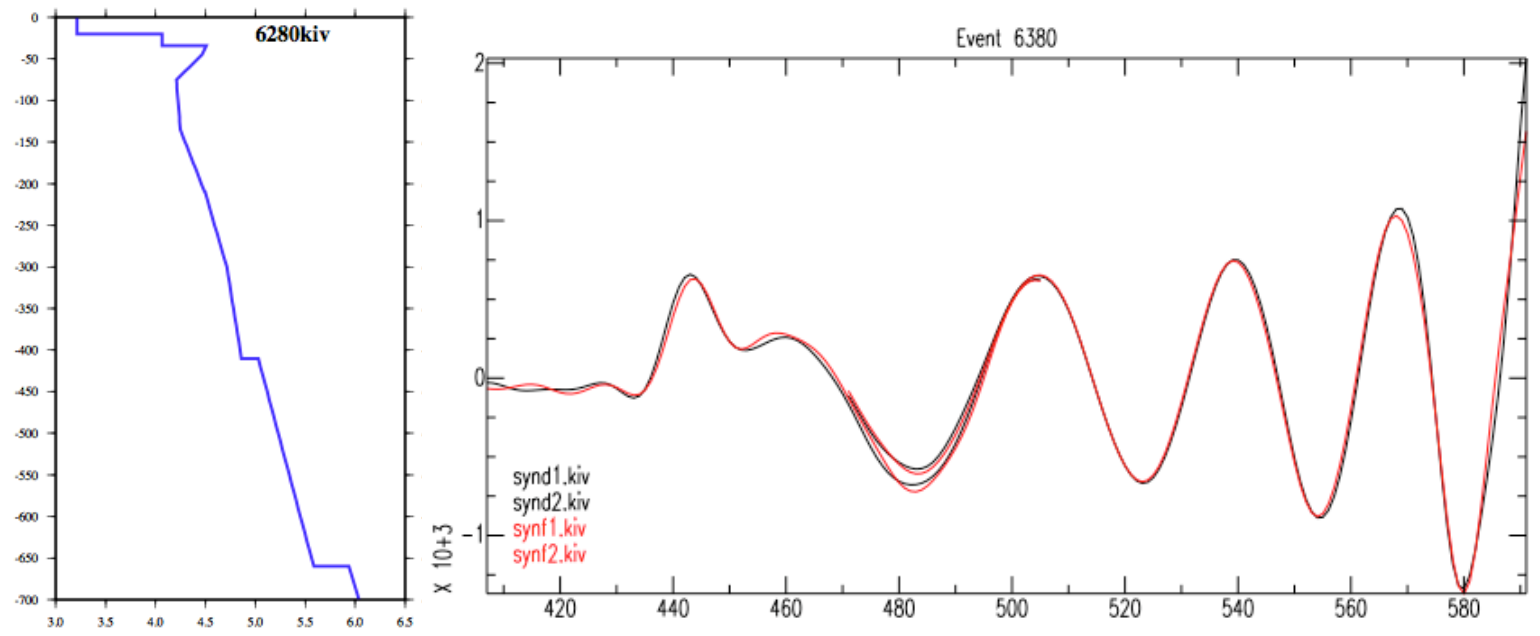

Figure 32g: Event 6380 / Station KIV / Transverse component 


\section{D INVERSION}

After fitting the waveforms of the five aforementioned datasets (Figure 33), the average velocity perturbations for each path are parameterized into a number of basis functions (for details see Nolet, 1990; Van der Lee and Nolet, 1997). These velocity constraints were then combined with point data constraints on crustal thickness determined from receiver functions, passive source studies, and gravity data. In this summary inversion, only radial and vertical components were used. The transverse components are set aside for a future inversion. After the constraints are combined a smoothing matrix is applied, as well as a damping coefficient. This system of equations is linear and is then solved by the least-squares algorithm of Paige and Saunders (1982).

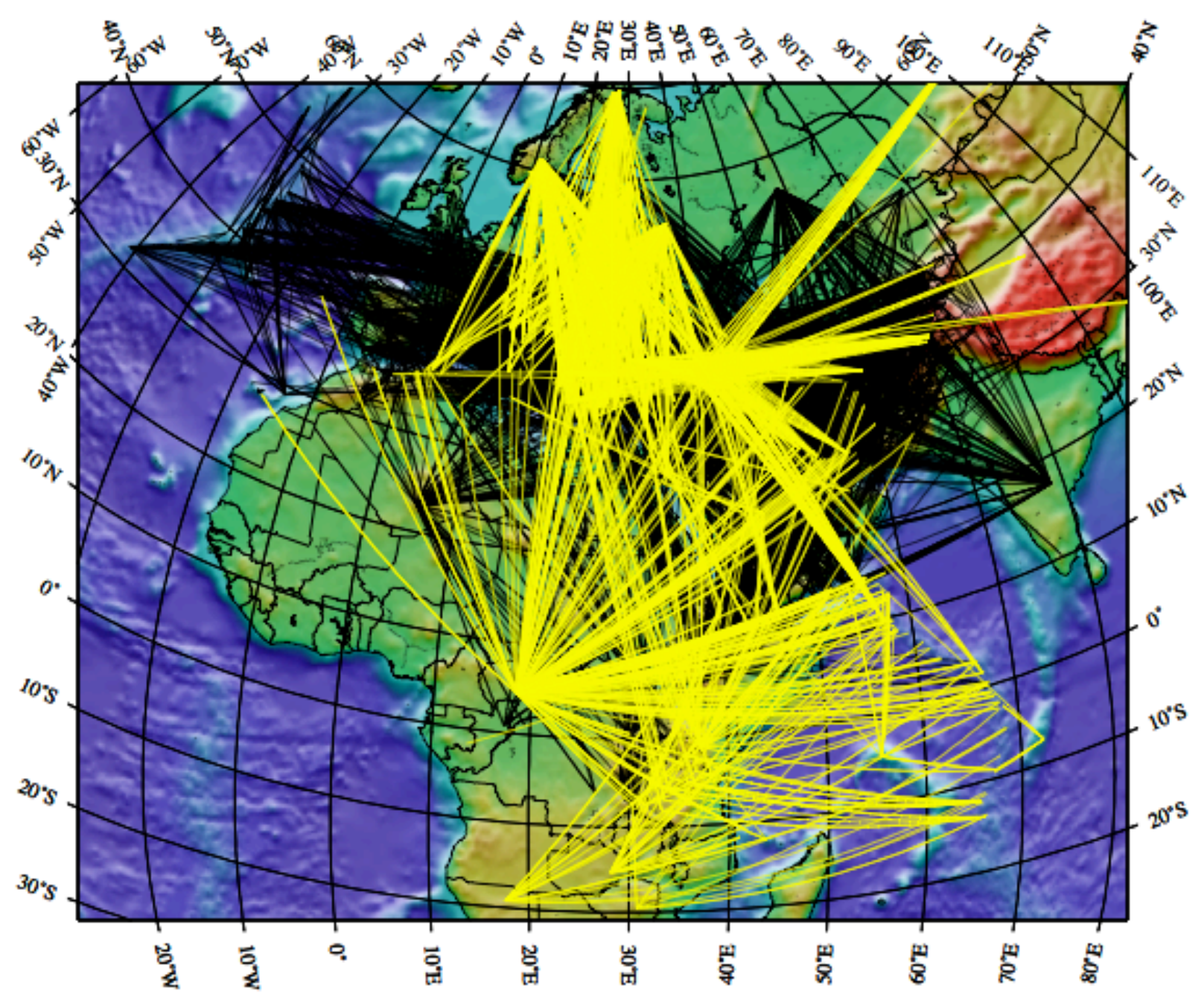

Figure 33: New raypaths have been added to the previous set of constraints. Those fit during the internship shown in yellow, those previously fit are shown as black lines.

\section{Grid Size and Smoothing Comparison}

Several inversions were performed, with varying grid size nodes for the $3 \mathrm{D}$ model, and varying smoothing parameters. A comparison is not shown here, but decreasing the distance between nodes in the vertical (depth) direction does not appear to improve the model, rather it makes the shallow and crustal and uppermost mantle structure more heterogeneous and jumbled, which does not improve with increased smoothing. The results shown and discussed below use a grid size of $60 \mathrm{~km}$ spacing in the $z$-direction, and $100 \mathrm{~km}$ spacing in the horizontal spacing, with the smoothing matrix set to $300 \mathrm{~km}$. 

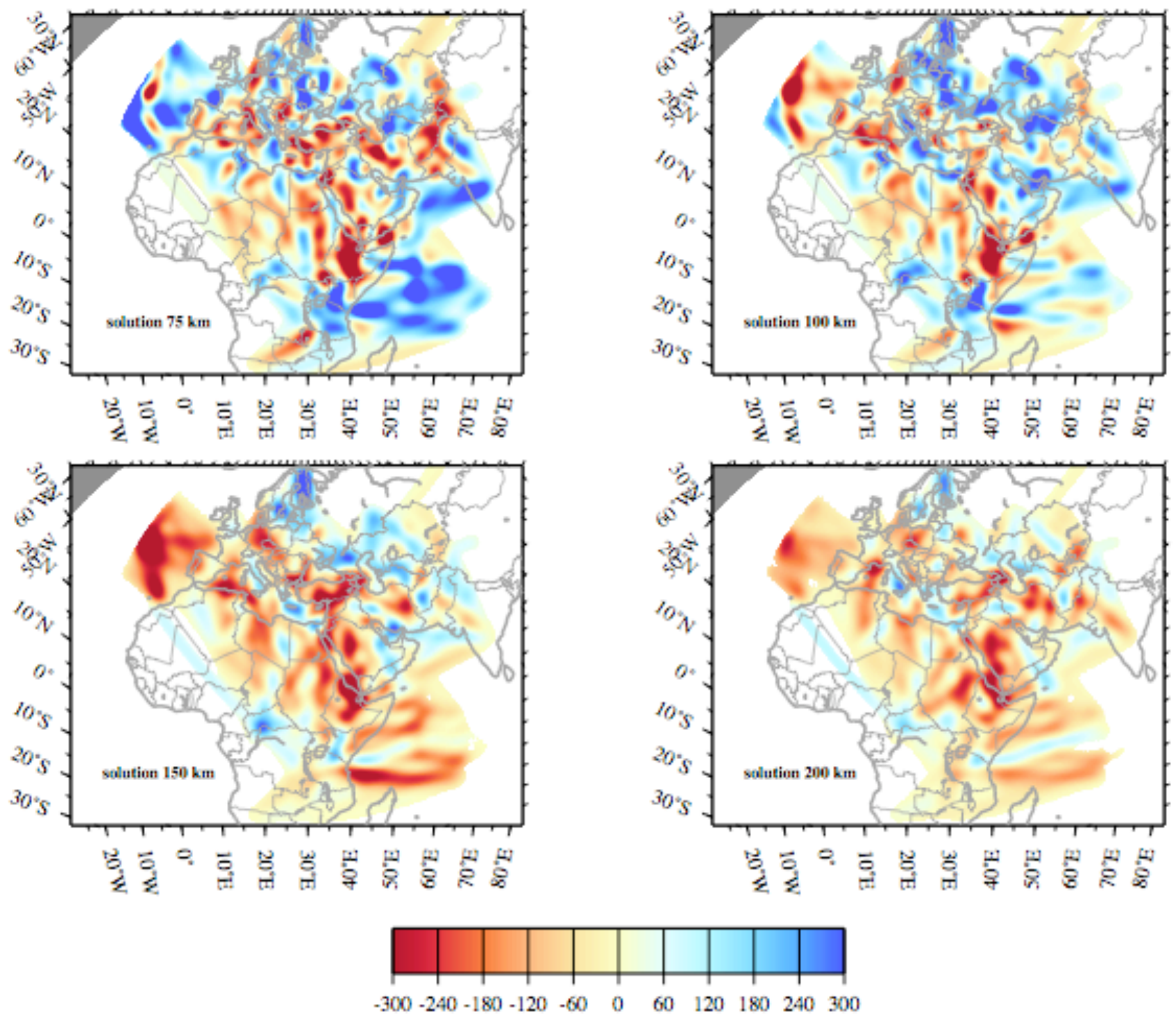

Figure 34a: Depth slices through the new 3D model, TMP, at 75, 100, 150 and $200 \mathrm{~km}$. The color scale shows plots the S-velocity difference between an averaged Earth 1D model and model TMP. 

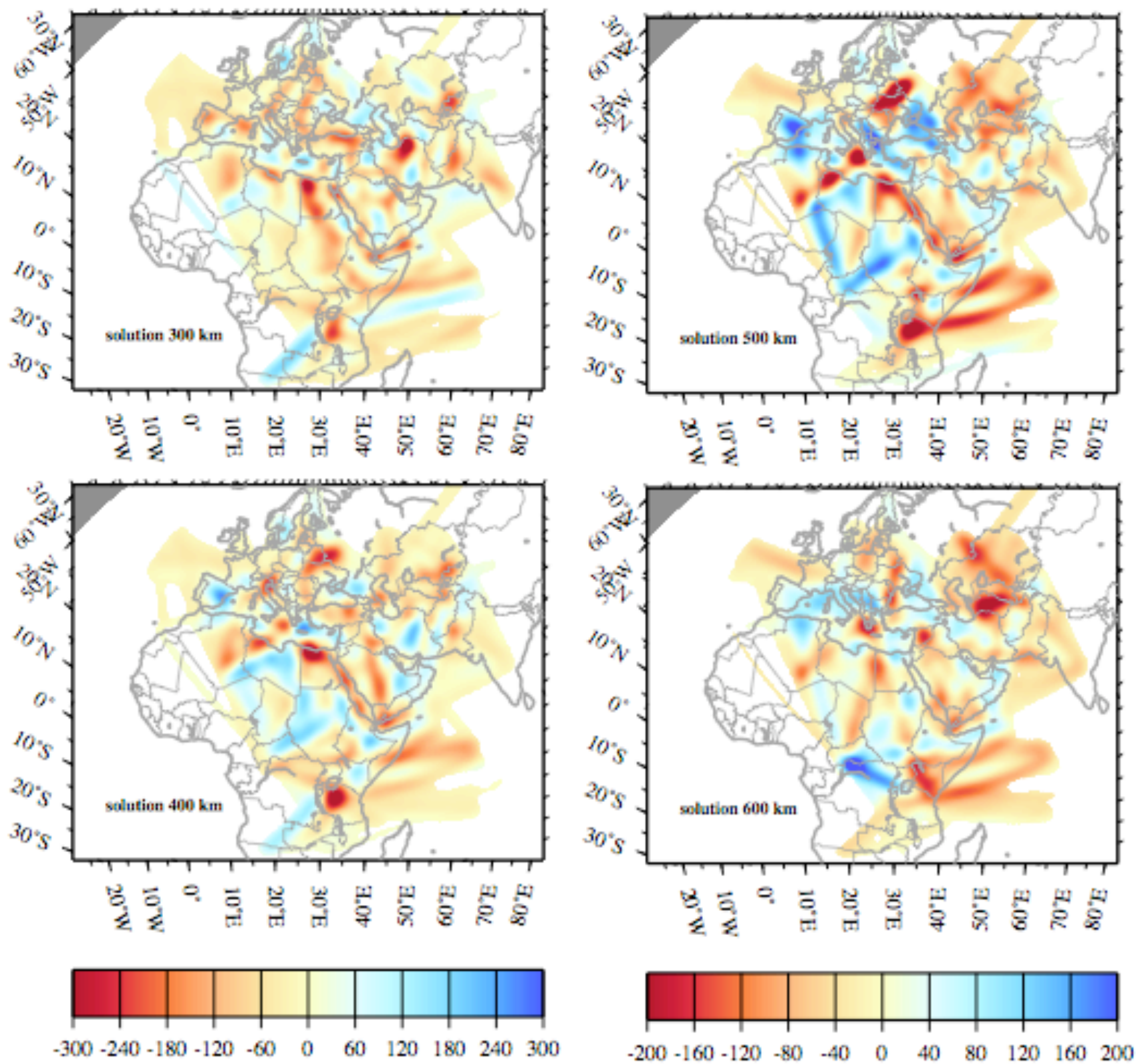

Figure 34b: Depth slices through the new 3D model, TMP, at 300, 400, 500 and $600 \mathrm{~km}$. The color scale shows plots the S-velocity difference between an averaged Earth 1D model and model TMP. Note that the color scale changes to $+/-200 \mathrm{~m} / \mathrm{s}$ for the depths 500 and $600 \mathrm{~km}$

\section{Resolution Tests}

The constraints added to the model this summer most likely helped improve resolution in some less sampled regions, such as northern and eastern Africa, northern Europe, including Scandinavia, and the Arabian Peninsula (Figure 33). Future work may include conducting resolution tests on this intermediate stage $3 \mathrm{D}$ model to see exactly where and how resolution was improved. 


\section{PRELIMINARY DISCUSSION}

We find that the 1D averaged constraints based on the fits to these waveforms represent a diverse set of velocity structures, as expected since the $S$-velocity structure has previously be shown to have large amounts of both horizontal and vertical variance (Marone et al., 2004, Maggi and Priestley, 2005). These 1D constraints result in a new, yet uncompleted 3D $S$-velocity model, referred to herein as TMP. One way that model TMP has been improved over the previous models is through the extension of the model further into northern Africa through the incorporation of more African waveforms. Below, we discuss some of the seismic features that are observable in model TMP, concentrating on those features which were not as strongly detected in a previous model, EAV (Marone et al., 2004). The signature of subducted plates (e.g., in the Mediterranean region) are modeled similarly as with model EAV, and are not discussed herein. These interpretations must be taken with caution, as resolution tests have not yet been performed to validate the resolving power of the model, especially in the newly covered regions, such as Africa.

\section{Cratons}

TMP now shows that the West African Craton can begin to be distinguished (Figure 34a). The signature of the craton may not be as strong as expected, since the raypaths that have been fit in this study run in similar paths and are not crisscrossing, smearing any anomalies out along the entire path. Also in Africa, a fast velocity signature is observed for the Tanzanian craton, down to depths of $\sim 200 \mathrm{~km}$. There is an incredibly sharp velocity transition in the upper lithosphere between the Tanzanian craton and the East African Rift to the north. The velocity difference between the craton and rift is approximately $1 \mathrm{~km} / \mathrm{s}$ within just a few hundred kilometers. Faster than average velocities are observed for the Congo craton, again to depths of $\sim 200 \mathrm{~km}$.

With the inclusion of data from Scandinavia, the Baltica composite craton can also be distinguished in northern Europe, in particular the Archean Karella and Sarmatia portions of the composite.

\section{Rifts}

With the additional raypath coverage, the triple junction of the East African Rift, Gulf of Aden, and Red Sea Rift has become fairly well resolved. As expected, low $S$-velocities are observed in the mantle beneath all three of these rifting arms. Interestingly, very low $S$-velocities are observed in the uppermost mantle beneath the East African Rift, down to $\sim 500 \mathrm{~km} / \mathrm{s}$ lower than an averaged Earth model. Low velocities are also observed beneath Gulf of Aden, and the Red Sea, although at depths of 100-200 km, the model does not show continuously slow upper mantle velocities between the northern and southern portions of the Red Sea.

\section{Hotspots}

Comparing the tomographic images to potential hotspots (Anderson and Schramm, 2004), there are six potential hotspots in this region (latitudes and longitudes are also given):

1) Eifel/ Central European volcanic center $(7,50) \mathrm{EIL}$

2) Hoggar Mountains in Algeria $(6,23) \mathrm{HOG}$

3) Tibesti, Chad $(17,21)$ TIB

4) Darfur $(24,13) \mathrm{DAF}$

5) East Africa $(34,6)$ EAR

6) Afar, Ethiopia $(42,12)$ AFR

Figure 35 shows tomographic images of TMP sliced at 100 and $300 \mathrm{~km}$ depth, with the location of these hotspots marked as green starts. While the resolution of TMP still remains to be tested since several of these locations lie on the edge of the model, it appears that there are seismically slow velocities at shallower depths for EIF, DAR, EAR and AFR, and possibly at deeper depths for AFR. Suggesting that of these hotspots, TMP shows evidence for only the Afar hotspot to be a deeper mantle plume. 

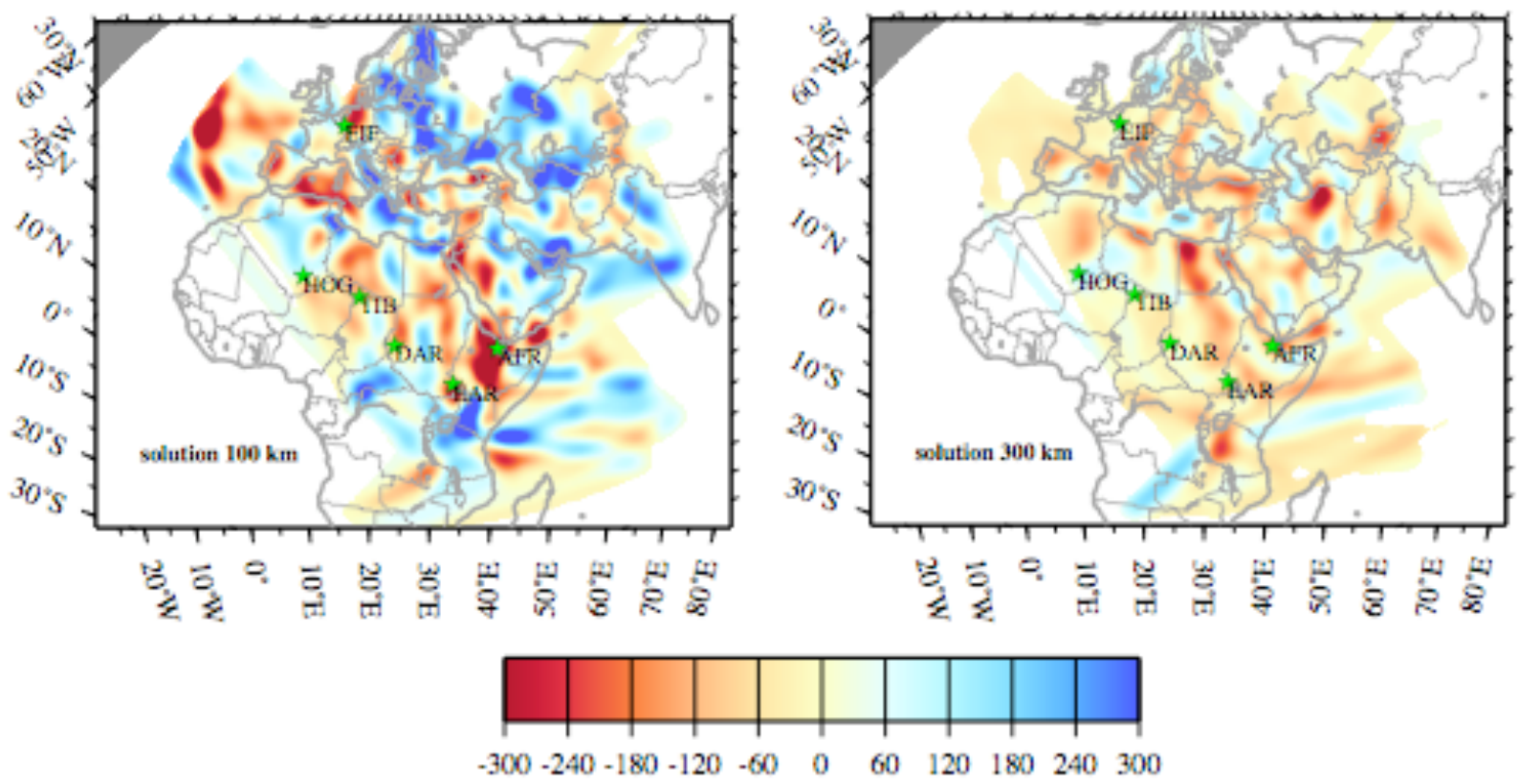

Figure35: Location of hotspots overlaying model TMP at 100 and $300 \mathrm{~km}$ depths.

\section{Turkey \& Iran}

As a portion of the data fit this summer included a seismic array from Eastern Turkey, I chose the region to look at in a little more depth. As seen in the 1D models (Figures 11), TMP shows slow velocities in the uppermost mantle, agreeing with the studies of Al-Lazki et al. (2003) and Gok et al. (2003), that the region beneath the Turkish plateau may not have lithospheric mantle lid. Figure 36 show a map of the crustal thicknesses calculated in the $3 \mathrm{D}$ inversion. Note that the thickness of the Turkish plateau ranges from $\sim 35 \mathrm{~km}$ in western Turkey to $\sim 45 \mathrm{~km}$ in eastern Turkey. This agrees with receiver function studies performed by Zor et al. (2003) using the ETSE data, who found the average crustal thickness beneath the plateau was $45 \mathrm{~km}$. Compared to EAV, the Turkish plateau has slower $S$-velocities in TMP particularly at 150 and $200 \mathrm{~km}$ depths in Eastern Turkey (Figure 34a). Thus, it appears that in the shallow structure of Turkey the updated model agrees with current literature.
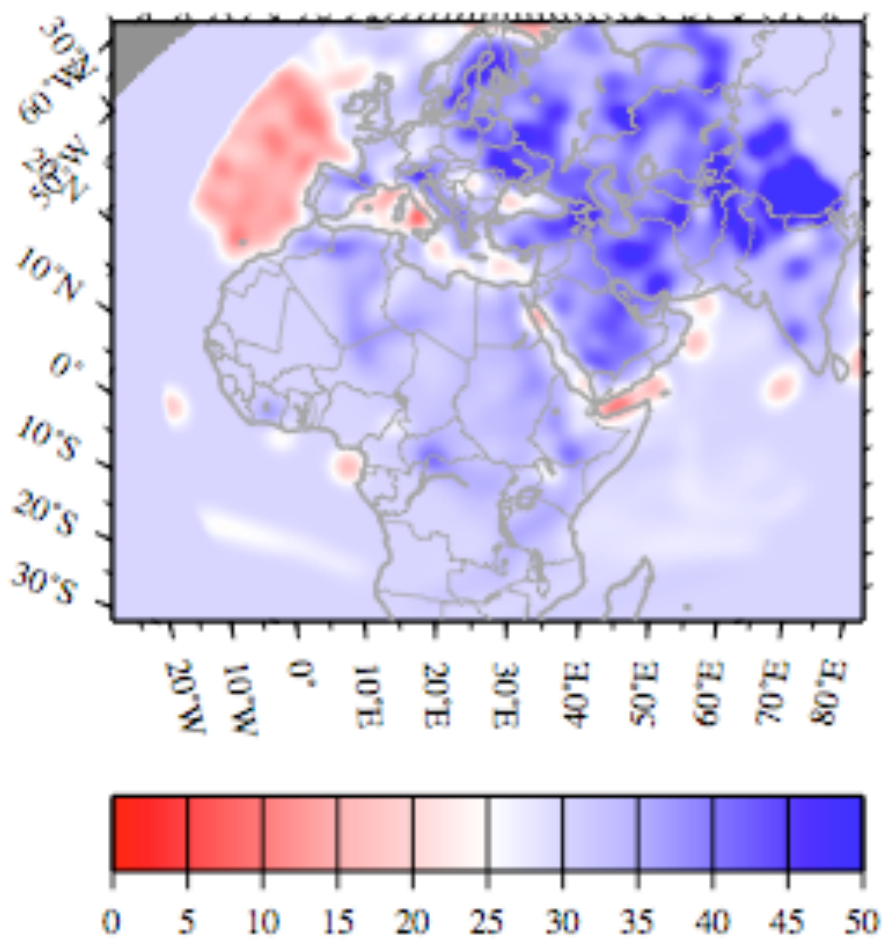

Figure 36: TMP Crustal thicknesses $(\mathrm{km})$

We do not interpret the tectonic relevance of the 3D $S$-velocity structure in these preliminary inversions any further as they are an intermediate step in our overall goal of performing a multi-dataset inversion. Before taking a closer look at these results, resolution tests must be performed, particularly to understand the resolution weaknesses of the 3D inversion at the edges of the model and in the less sparsely sampled regions. 


\section{REFERENCES}

Al-Lazki, A., Sandvol, E., Seber, D., Turkelli, N., Mohamad, R., and Barazangi, M., Tomographic Pnvelocity and anisotropy structure beneath the Anatolian plateau (eastern Turkey) and the surrounding regions, Geophys. Res. Lett., 30, 8040, doi:10.1029/2003GL018912, 2003.

Anderson, D. L. and Schramm, K. A., Global Hotspot Maps, in Plates, Plumes \& Paradigms, Foulger, G.R., Natland, J.H., Presnall, D.C, and Anderson, D.L., eds., Boulder, CO, Geological Society of America, Special Paper 388, 19-29, 2005.

Gok, R., Sandvol, E., Turkelli, N., Seber, D., and Barazangi, M., Sn Attenuation in the Anatolian and Iranian Plateaus and Surrounding Regions, Geophys. Res. Lett., 30, 8042, doi:10.1029/2003GL018912, 2003.

Maggi, A. and Priestley, K., Surface Waveform Tomography of the Turkish--Iranian Plateau, Geophys. J. Int., 160, 1068-1080, 2005.

Marone, F., Van der Lee., S., and Giardini, D., Three-dimensional upper-mantle $S$-velocity model for the Eurasia-Africa plate boundary region, Geophys. J. Int., 158, 109-130, 2004.

Marone, F., Van der Lee, S., Van der Meijde, M., and Giardini, D., Joint inversion of local, regional and teleseismic data for crustal thickness in the Eurasia-Africa plate boundary region, Geophys. J. Int, 154, 499-514, 2004.

Nolet, G., Partitioned waveform inversion and two-dimensional structure under the Network of Autonomously Recording Seismographs, J. Geophys. Res., 95, 8499-8512, 1990.

Nyblade A. A., Birt C., Langston C. A., Owens T. J., Last R. J. Seismic experiment reveals rifting of craton in Tanzania. Eos, Trans. Am. Geophys. Un., 51, 517-521, 1996.

Paige, C. C., and Saunders, M. A., LSQR: An algorithm for sparse linear equations and sparse least squares, ACM Trans. Math. Software, 8, 43-71, 1982.

Sandvol, E. et al., 2001. Crustal and upper mantle seismic velocity structure in eastern Anatolia: results from the eastern Turkey PASSCAL seismic experiment, Eos, Trans. Am. Geophys. Un., 82, 47.

Van der Lee, S. and Nolet, G., Upper mantle $S$-velocity structure of North America, J. Geophys. Res., 102, 22815-22838, 1997.

Zor, E., Sandvol, E., Gurbuz, C., Turkelli, N., Seber, D., and Barazangi, M., The Crustal Structure of the East Anatolian Plateau from Receiver Functions, Geophys. Res. Lett., 30, 8044, doi:10.1029/2003GL018912., 2003. 


\section{APPENDIX: The Partitioned Waveform Inversion Tool}

The partitioned waveform inversion process involves two major steps: first, each seismogram is inverted individually to obtain the best path averaged 1D model, then, the resulting models are combined to produce a tomogram of the region. Thousands of seismograms typically contribute to the final solution. Before the result for any single waveform is accepted, the researcher needs to visually assess both the data-synthetic match and the resulting model. This creates a problem of organization and efficiency. The researcher needs to be able to locate the results for each source-receiver pair, view the results, decide whether the model is realistic, and often needs to modify the inversion parameters and reinvert the data.

The partitioned waveform inversion tool (pwitool, figure 1) is a JAVA program created to serve as a driver for the inversion process; allowing researchers to invert large sets of data, accept or reject the results individually and reinvert the data as necessary. The tool calls the original fortran executable (Newton5) to perform the inversion. Newton5 reads SAC data, performs a conjugate-gradient inversion over a series of frequency bands then saves the results in a group of SAC and text files. The pwitool reads these files, plots the results, allows the user to modify the inversion parameters and accept, reject or reinvert the data as desired. The user can step through entire datasets with the push of a button, eliminating the need to remember the specific directory structure while the program keeps track of which traces have been evaluated.

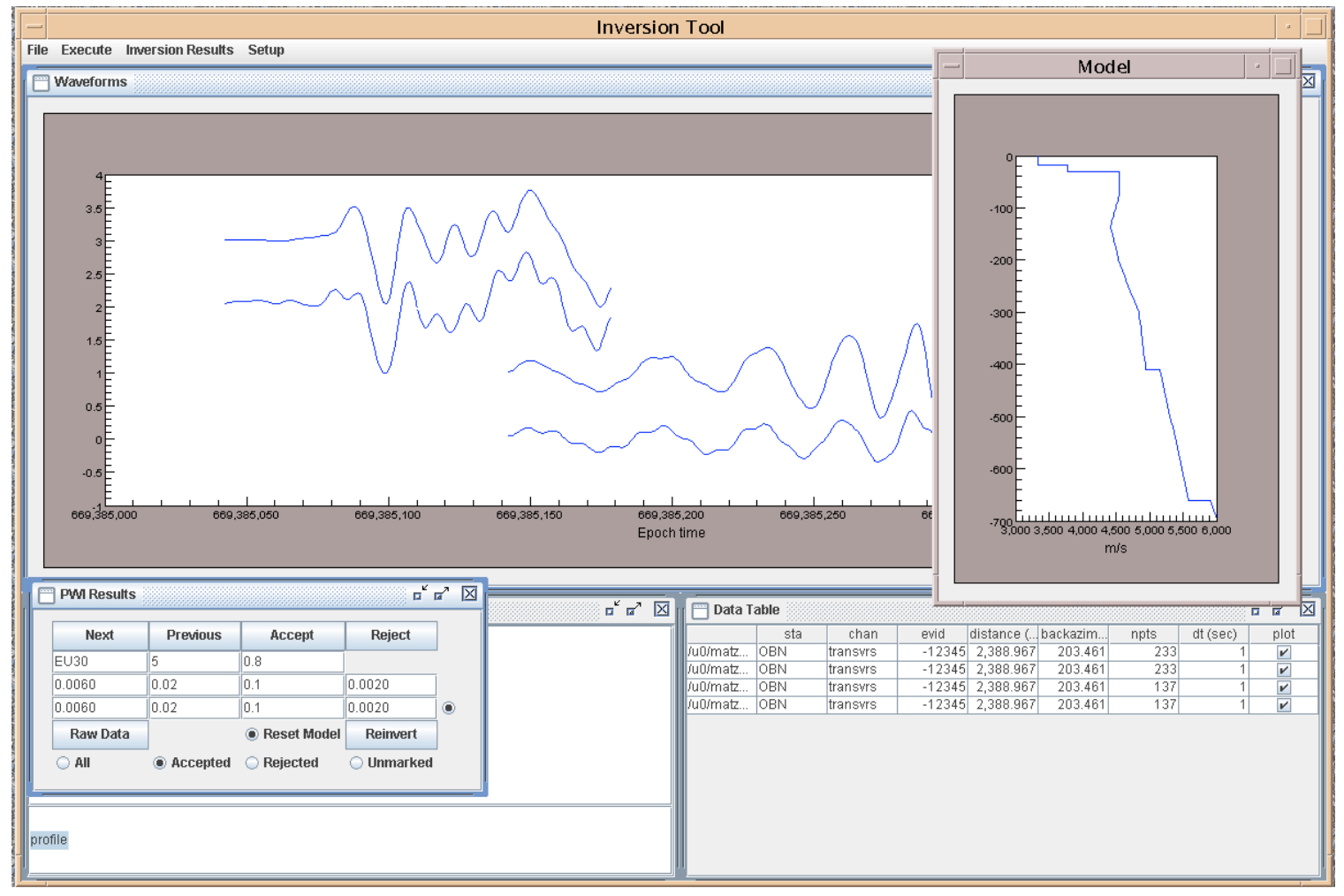

Figure A.1: A screenshot of the partitioned waveform inversion tool. Data and synthetics are plotted in the waveforms window and listed in the data table (lower right). The waveforms can be filtered using command-line options in a console window (lower left). The 1-D model result is plotted in a separate window (upper right). The PWI Results window allows the user to page through the dataset, accept or reject the model result, modify the inversion parameters, and reinvert the data as desired. 